\title{
Potential Role of Plant Growth Regulators in Administering Crucial Processes Against Abiotic Stresses
}

\section{OPEN ACCESS}

Edited by:

Mohammad Bagher

Hassanpouraghdam,

University of Maragheh, Iran

Reviewed by:

Andrzej Bajguz,

University of Białystok, Poland

Shah Saud,

Independent Researcher, Harbin,

China

Faheem Ahmed Khan, Huazhong Agricultural University,

China

*Correspondence:

Ayman EL Sabagh

ayman.elsabagh@agr.kfs.edu.eg

Specialty section:

This article was submitted to

Plant-Soil Interactions,

a section of the journal

Frontiers in Agronomy

Received: 01 January 2021 Accepted: 14 September 2021 Published: 08 December 2021

Citation:

Sabagh AE, Mbarki S, Hossain A Iqbal MA, Islam MS, Raza A, Llanes A,

Reginato $M$, Rahman MA

Mahboob W, Singhal RK, Kumari A,

Rajendran K, Wasaya A, Javed T,

Shabbir R, Rahim J, Barutçular C,

Habib Ur Rahman M, Raza MA,

Ratnasekera D, Konuskan Ö

Hossain MA, Meena VS, Ahmed S,

Ahmad Z, Mubeen M, Singh K,

Skalicky M, Brestic M, Sytar O,

Karademir E, Karademir C, Erman M and Farooq M (2021) Potential Role of

Plant Growth Regulators in

Administering Crucial Processes

Against Abiotic Stresses.

Front. Agron. 3:648694.

doi: 10.3389/fagro.2021.648694

\begin{abstract}
Ayman EL Sabagh ${ }^{1,2 *}$, Sonia Mbarki ${ }^{3}$, Akbar Hossain $^{4}$, Muhammad Aamir lqbal ${ }^{5}$, Mohammad Sohidul Islam ${ }^{6}$, Ali Raza ${ }^{7}$, Analía Llanes $^{8}$, Mariana Reginato ${ }^{8}$, Md Atikur Rahman ${ }^{9}$, Wajid Mahboob ${ }^{10}$, Rajesh Kumar Singhal ${ }^{11}$, Arpna Kumari ${ }^{12}$, Karthika Rajendran ${ }^{13}$, Allah Wasaya ${ }^{14}$, Talha Javed ${ }^{15}$, Rubab Shabbir ${ }^{15}$, Junaid Rahim ${ }^{16}$, Celaleddin Barutçular ${ }^{17}$, Muhammad Habib Ur Rahman ${ }^{18}$, Muhammad Ali Raza ${ }^{19}$, Disna Ratnasekera ${ }^{20}$, Ömer Konuskan I21, Mohammad Anwar Hossain ${ }^{22}$, Vijay Singh Meena ${ }^{23}$, Sharif Ahmed ${ }^{24}$, Zahoor Ahmad ${ }^{25}$, Muhammad Mubeen ${ }^{26}$, Kulvir Singh ${ }^{27}$, Milan Skalicky ${ }^{28}$, Marian Brestic ${ }^{28,29}$, Oksana Sytar ${ }^{29}$, Emine Karademir ${ }^{2}$, Cetin Karademir ${ }^{2}$, Murat Erman ${ }^{2}$ and Muhammad Farooq ${ }^{30}$
\end{abstract}

${ }^{1}$ Department of Agronomy, Faculty of Agriculture, Kafrelsheikh University, Kafr El-Shaikh, Egypt, ${ }^{2}$ Department of Field Crops, Faculty of Agriculture, Siirt University, Siirt, Turkey, ${ }^{3}$ Laboratory of Valorisation of Unconventional Waters, National Institute of Research in Rural Engineering, Water and Forests (INRGREF), Ariana, Tunisia, ${ }^{4}$ Department of Agronomy, Bangladesh Wheat and Maize Research Institute, Dinajpur, Bangladesh, ${ }^{5}$ Department of Agronomy, Faculty of Agriculture, University of Poonch Rawalakot, Rawalakot, Pakistan, ${ }^{6}$ Department of Agronomy, Hajee Mohammad Danesh and Technology University, Dinajpur, Bangladesh, ${ }^{7}$ Fujian Provincial Key Laboratory of Crop Molecular and Cell Biology, Oil Crops Research Institute, Center of Legume Crop Genetics and Systems Biology/College of Agriculture, Fujian Agriculture and Forestry University (FAFU), Fuzhou, China, ${ }^{8}$ Plant Physiology Laboratory. Universidad Nacional de Río Cuarto (UNRC)-Instituto Nacional de Investigaciones Agrobiotecnológicas (INIAB), Consejo Nacional de Investigaciones Científicas y Técnicas (CONICET), Río Cuarto, Argentina, ${ }^{9}$ Grassland and Forage Division National Institute of Animal Science Cheonan, Rural Development Administration, Cheonan, South Korea, ${ }^{10}$ Plant Physiology Division, Nuclear Institute of Agriculture, Tando Jam, Pakistan, ${ }^{11}$ Indian Council of Agricultural Research-Indian Grassland and Fodder Research Institute, Jhansi, India, ${ }^{12}$ Department of Botanical and Environmental Sciences, Guru Nanak Dev University, Amritsar, India, ${ }^{13}$ School of Agricultural Innovations and Advanced Learning, Vellore Institute of Technology (VIT), Vellore, India, ${ }^{14}$ College of Agriculture, Bahauddin Zakariya University, Bahadur Sub-campus, Layyah, Pakistan, ${ }^{15}$ College of Agriculture, Fujian Agriculture and Forestry University, Fuzhou, China, ${ }^{16}$ Department of Entomology, Faculty of Agriculture, University of Poonch Rawalakot (AJK), Rawalakot, Pakistan, ${ }^{17}$ Department of Field Crops, Faculty of Agriculture, University of Çukurova, Adana, Turkey, ${ }^{18}$ Institute of Crop Science and Resource Conservation (INRES), University Bonn, Bonn, Germany, ${ }^{19}$ College of Agronomy, Sichuan Agricultural University, Chengdu, China, ${ }^{20}$ Department of Agricultural Biology, Faculty of Agriculture, University of Ruhuna, Matara, Sri Lanka, ${ }^{21}$ Department of Field Crops, Faculty of Agriculture, Mustafa Kemal University, Antakya, Turkey, ${ }^{22}$ Department of Genetics and Plant Breeding, Bangladesh Agricultural University, Mymensingh, Bangladesh, ${ }^{23}$ Indian Council of Agricultural Research-Vivekananda Parvatiya Krishi Anusandhan Sansthan (VPKAS), Almora, India, ${ }^{24}$ International Rice Research Institute, Bangladesh Office, Dhaka, Bangladesh, ${ }^{25}$ University of Central Punjab, Bahawalpur, Pakistan, ${ }^{26}$ Department of Environmental Sciences, Commission on Science and Technology for Sustainable Development in the South (COMSATS) University Islamabad, Islamabad, Pakistan, ${ }^{27}$ Principal Scientist (Agronomy), Punjab Agricultural University, Regional Research Station, Faridkot, India, ${ }^{28}$ Department of Botany and Plant Physiology, Faculty of Agrobiology, Food, and Natural Resources, Czech University of Life Sciences Prague, Prague, Czechia, ${ }^{29}$ Department of Plant Physiology, Slovak University of Agriculture, Nitra, Slovakia, ${ }^{30}$ Department of Plant Sciences, College of Agricultural and Marine Sciences Sultan Qaboos University, Muscat, Oman

Plant growth regulators are naturally biosynthesized chemicals in plants that influence physiological processes. Their synthetic analogous trigger numerous biochemical and physiological processes involved in the growth and development of plants. Nowadays, due to changing climatic scenario, numerous biotic and abiotic stresses hamper seed germination, seedling growth, and plant development leading to a decline in biological and economic yields. However, plant growth regulators (PGRs) can potentially play a fundamental role in regulating plant responses to various abiotic stresses and hence, 
contribute to plant adaptation under adverse environments. The major effects of abiotic stresses are growth and yield disturbance, and both these effects are directly overseen by the PGRs. Different types of PGRs such as abscisic acid (ABA), salicylic acid (SA), ethylene (ET), and jasmonates (JAs) are connected to boosting the response of plants to multiple stresses. In contrast, PGRs including cytokinins (CKs), gibberellins (GAs), auxin, and relatively novel PGRs such as strigolactones (SLs), and brassinosteroids (BRs) are involved in plant growth and development under normal and stressful environmental conditions. Besides, polyamines and nitric oxide (NO), although not considered as phytohormones, have been included in the current review due to their involvement in the regulation of several plant processes and stress responses. These PGRs are crucial for regulating stress adaptation through the modulates physiological, biochemical, and molecular processes and activation of the defense system, upregulating of transcript levels, transcription factors, metabolism genes, and stress proteins at cellular levels. The current review presents an acumen of the recent progress made on different PGRs to improve plant tolerance to abiotic stress such as heat, drought, salinity, and flood. Moreover, it highlights the research gaps on underlying mechanisms of PGRs biosynthesis under stressed conditions and their potential roles in imparting tolerance against adverse effects of suboptimal growth conditions.

Keywords: abiotic stress, climate change, crosstalk, nitric oxide, polyamines, stress tolerance

\section{INTRODUCTION}

Abiotic stresses (heat, drought, salinity, waterlogging, heavy metals toxicity, soil erosion, etc.) adversely affect the growth, development, and yield of plants resulting in higher economic losses at the expense of global food security (Siddiqui et al., 2019; EL Sabagh et al., 2020b; Hossain et al., 2020). The combined effects of different abiotic stresses on the biological and economic yield of numerous crops are greater than individual stress (EL Sabagh et al., 2019b; Hoque et al., 2020a; Raza et al., 2020; Javeed et al., 2021). Plant growth regulators (PGRs) are naturally biosynthesized by plants which modify growth (increase in branching and rebranching, shoot and root growth, alter or trigger fruit maturing, reproduction etc.) of crop plants and play a significant role in mitigating abiotic stresses (Verma et al., 2016; Takahashi et al., 2019). PGRs also have an important role during stress conditions such as being thermoprotectants, reactive oxygen scavengers, improving photosynthesis, accumulation of stress proteins, and many other regulatory functions related to metabolisms (Akram et al., 2017; Ma et al., 2017; Sharma et al., 2020). The PGRs interrelate with complex signaling systems to equilibrate the responses to evolve eco-friendly strains and thereby, overcome damages caused by stress environmental conditions (Davies, 2013; Suzuki, 2016; Ku et al., 2018; Iqbal et al., 2019). Plants have developed complex mechanisms to detect external signals and can trigger an optimal response against stress conditions under the support of PGRs that mainly control the defensive responses of plants by synergistic and antagonistic activities (called signaling crosstalk) (Adesemoye et al., 2008; Tuteja and Sopory, 2008; Berens et al., 2019; Raza et al., 2019a; EL Sabagh et al., 2021a,b). In this context, PGRs crosstalk with the various inorganic and organic compounds under stress conditions such as nitrates, $\mathrm{H}_{2} \mathrm{O}_{2}, \mathrm{H}_{2} \mathrm{~S}$, reactive oxygen species, and $\mathrm{NO}$ to balance plant growth and development under unfavorable situations (Kolbert et al., 2019; Vega et al., 2019; Nazir et al., 2020; Xuan et al., 2020). During the stress perception process, there are variations in perceiving various hormonal signals from the early phase to the ongoing phase of stresses, allowing plants to advance to a well-organized growth. There are various ligands and receptors, which help in the perception of hormones. For instance, salicylic acid perceived by NPR proteins, strigolactone perceived and activated by DWARF 14 hydrolase receptor, ubiquitin ligase, leucine-rich receptor repeat kinase, and many other help in the recognition, perception, and signaling of PGRs (LRR-RK) (Chakraborty et al., 2019; Seto et al., 2019; Tal et al., 2020; Wang W. et al., 2020). To consider the above facts, in this review study, the authors discuss PGR-induced physiological adaptations in response to stressful environments, including the interactive effects and cross-talks of different PGRs on plant physiological and biochemical mechanisms under combined abiotic stresses and the potential of exogenous applications as remedies to overcome environmental stresses (Figure 1).

Under changing climatic conditions, numerous biotic and abiotic stresses hamper seed germination, seedling growth, and plant development leading to a severe decline in the biological and economical yield of crops (Iqbal and Iqbal, 2015; Abadi and Sepehri, 2016; EL Sabagh et al., 2021a,b; Hong et al., 2021; Shabbir et al., 2021). The biosynthesis of PGRs including gibberellins (GAs), auxin, cytokinin (CT) abscisic acid (ABA), ethylene (ET), jasmonic acid (JA), brassinosteroid (BR), nitric oxide (NO), salicylic acid (SA), and strigolactone (SL) constitutes a potent strategy for plants to respond to stress conditions (Kreps et al., 


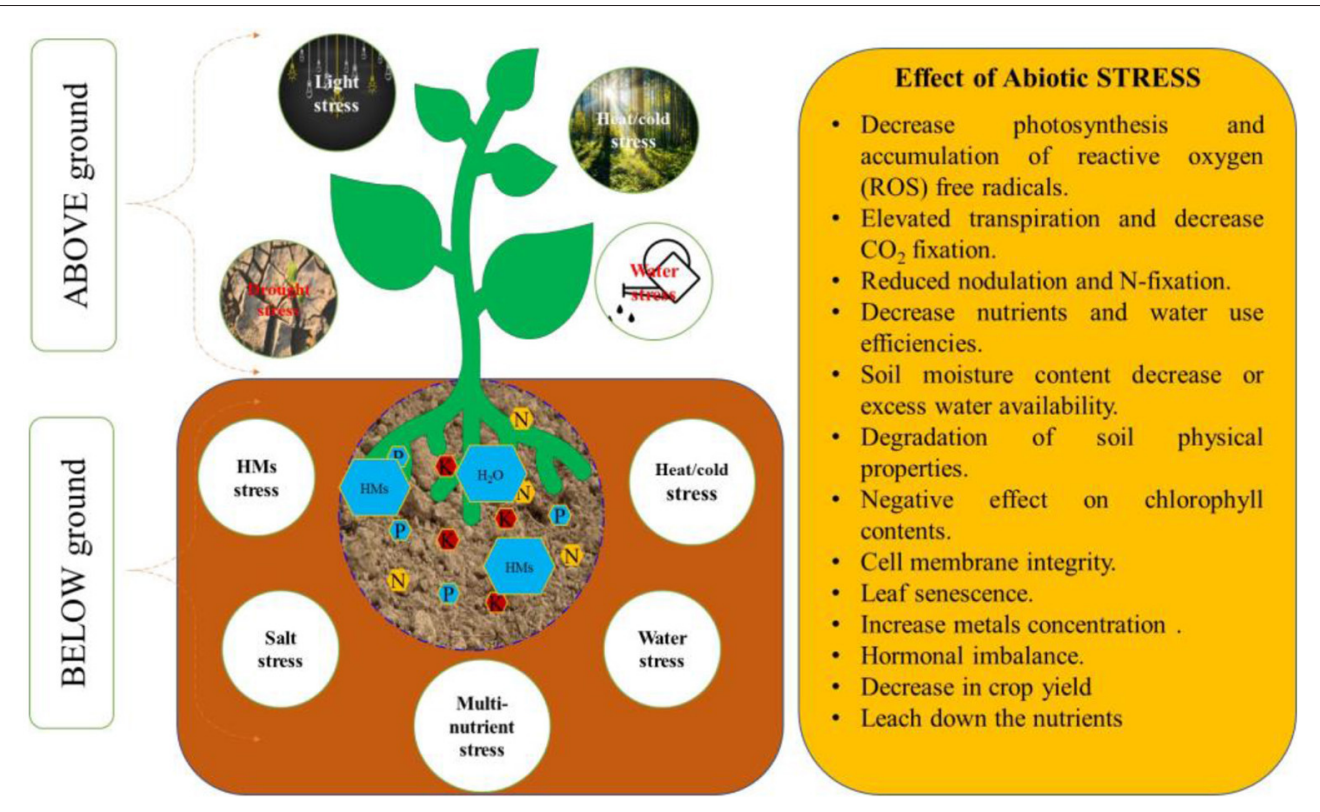

FIGURE 1 | Abiotics tree conditions and their effect on the growth and development of plants.

2002; Seki et al., 2002; Raza et al., 2019b; Ahmad et al., 2021). Typically, hormones are interdependent in action by synergistic or antagonistic cross-talk, thereby modulating each of their biosynthesis or responses in a complex way (Aerts et al., 2021). The current review aims to synthesize recent advancements about the roles of PGRs in boosting the defense systems of plants against abiotic stresses (Basu et al., 2021). Also, gaps in knowledge of studied PGR topics have been identified to propose future research perspectives. Furthermore, some perspective compounds especially polyamines have also been objectively discussed due to their similarity of actions with PGRs against different stresses (Chen D. et al., 2019). The article also provides an overview of the recent advances in PGRs in boosting plants' tolerance to various abiotic stresses (Figure 2).

\section{PHYTOHORMONES MEDIATED ABIOTIC STRESS TOLERANCE IN PLANTS}

\section{Auxin Induced Physiological and Biochemical Mechanisms for Stress Tolerance}

Auxins are vital due to having multiple roles in plant growth and development by influencing various physiological processes including cell elongation, involved in phototropisms and gravitropism, phyllotactic patterning, apical dominance maintenance, and control of root development (Benkova et al., 2003; Blancaflor and Masson, 2003; Blilou et al., 2005; Teale et al., 2006; Holland et al., 2009; Enders and Strader, 2015; Casanova-Sáez and Voß, 2019). Auxins can interact with other hormones on various parameters of the growth and development of cells (Mao et al., 2020; Xu et al., 2020). One example of it is the regulation and transcription of several genes. Many studies have been reported on the association of metabolism, transport, and signaling of auxins in the growth responses of plants under stressful conditions (Shen et al., 2010; Zhang et al., 2012; Kazan, 2013; Remy et al., 2013; Cao et al., 2019; Casanova-Sáez et al., 2021). Thus, more knowledge about the auxin-mediated signaling in the plant stress adaptation responses will help to design strategies for enlightening stress resistance in several crop plants. Furthermore, auxin interacts with stress-responsive signaling components, like calcium $\left(\mathrm{Ca}^{2+}\right)$ and reactive oxygen species (ROS), which are accumulated in plants during exposure to biotic and abiotic stress conditions (Tognetti et al., 2017). Different stressed conditions could affect the development of stress-induced morphogenic response (SIMR) during different stress tolerance mechanisms of plants (Potters et al., 2007). Auxin biosynthesis in different concentrations under varying abiotic stresses need further investigations in order to explore different factors which tend to trigger auxin production (Figure 3).

\section{Auxin Mediated Physiological Changes Under Nutrient Deficiency}

Auxin signaling and transport are involved in the stimulation of growth and developmental responses of roots to improve accessibility to nutrients in the soil solution. Primary nutrients like nitrogen, phosphorus, and potassium supplement the crucial role of auxins in boosting the development of lateral roots. Nitrate accumulation and sensing procedures are reported to be associated with alterations in the auxin transport causing rapid changes in the architecture of roots (Krouk et al., 2010; Gojon et al., 2011; Bouguyon et al., 2012; Zhang et al., 2020). Nitrate Transporter1-1 (NRT1-1) protein has a high-activity nitrate influx carrier, which allows the absorption of nitrogen in the form of nitrate $\left(\mathrm{NO}_{3}^{-}\right)$from the soil along with acting as a nitrate 


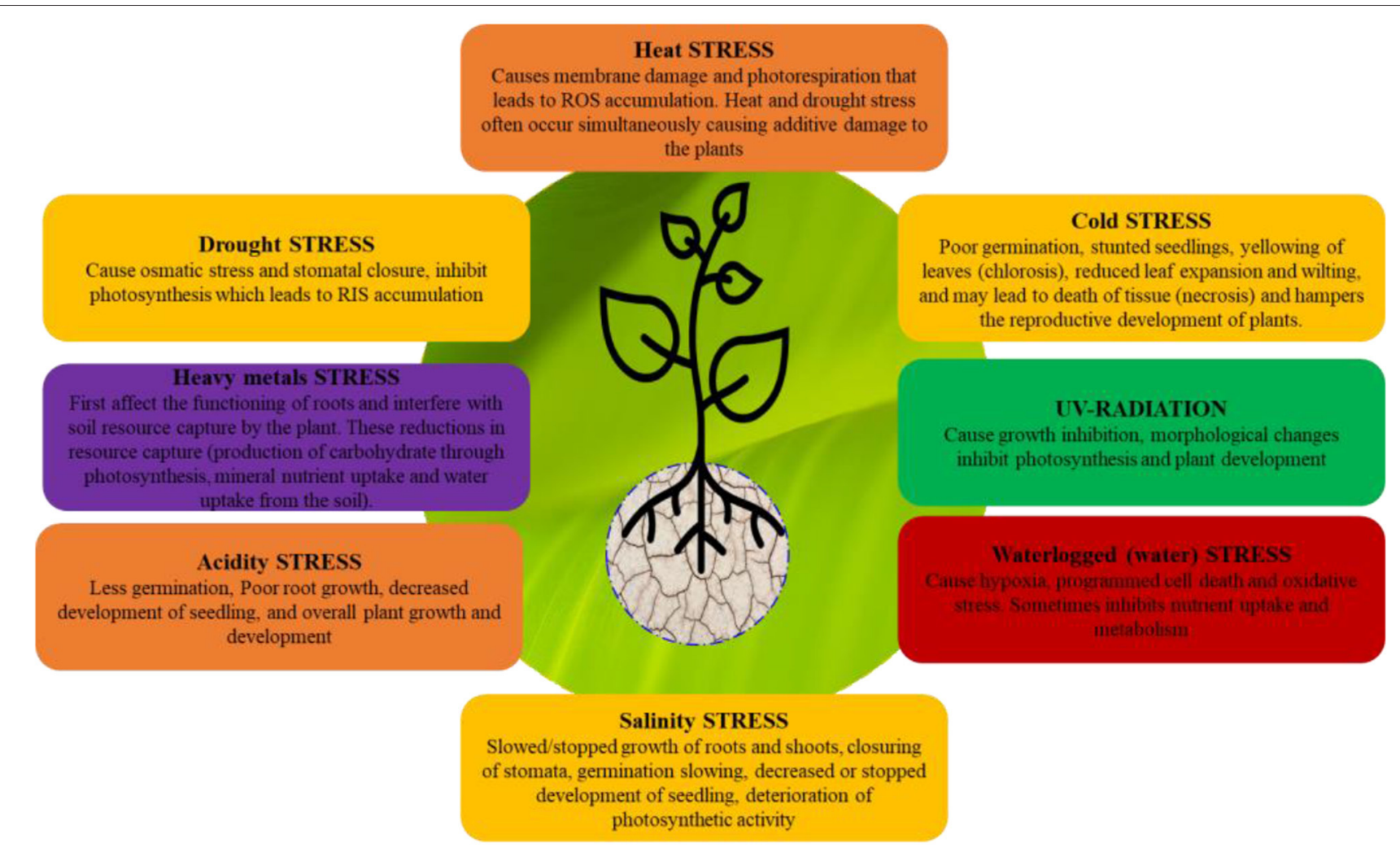

FIGURE 2 | Overview of abiotic stress and effects on plant growth and development.

feeler and integrate $\mathrm{N}$ signal toward root growth (Lay-Pruitt and Takahashi, 2020). NRT1-1 is associated with alterations in lateral root development because NRT1-1 induces the basipetal auxin transport, thereby, inhibiting the auxin accumulation in lateral root and their growth under low $\mathrm{NO}_{3}^{-}$concentrations in the soil solutions. On the other hand, at elevated $\mathrm{NO}_{3}^{-}$stages, NRT1-1 regulates the transport of auxins inducing their accumulation in lateral root and promoting the growth of this organ (Krouk et al., 2010; Gojon et al., 2011; Bouguyon et al., 2012, 2016).

Similarly, TINY ROOT HAIR 1 (TRH1) gene isolated in roots of Arabidopsis plants encoding a KT/KUP/HAK family protein was associated with controlling potassium $\left(\mathrm{K}^{+}\right)$and auxin passage (Vicente-Agullo et al., 2004; Sustr et al., 2019). Impairment of trh1 in Arabidopsis plants caused harmful effects on root hair development, alterations in the gravitropism responses, and a lower capacity to convey $\mathrm{K}^{+}$(Rigas et al., 2001; Sun et al., 2020). Auxin-linked low phosphate mediated lateral root development was controlled by auxin receptor genes/proteins such as SIZ1, AFB2, AFB3, and AXR3/IAA7 (Pérez-Torres et al., 2008; Kazan, 2013). Further in-depth studies need to be conducted to explore the gene receptors which modulate its synthesis under specific nutrients deficiency.

Other metal ions like sulfur (S), copper $\left(\mathrm{Cu}^{2+}\right)$, cadmium $(\mathrm{Cd})$, aluminum $\left(\mathrm{Al}^{3+}\right)$, boron $(\mathrm{B})$, and iron $(\mathrm{Fe})$ tend to alter the expansion and growth of lateral roots by modifying the root architecture of plants by hampering auxin biosynthesis, signaling, and/or passage pathways (Dan et al., 2007; Lequeux et al., 2010; Mattiello et al., 2010; Martín-Rejano et al., 2011; Peto et al., 2011; Aquea et al., 2012; Giehl et al., 2012; Hu et al., 2013; Yuan et al., 2013). Thus, it has been widely inferred that auxins tend to modify and alter root architecture especially when plants are exposed to nutrient deficiency.

\section{Auxin Mediated Physiological Changes Under Drought Stress}

Modifications in root architecture are vital in coping with water scarcity and soil salinity. Auxins regulate hydrotropism responses through which plants roots sense and subsequently, respond to soil moisture (Kaneyasu et al., 2007). The transition from cell division to cell differentiation in roots of Arabidopsis thaliana plants was auxin minima dependent (Di Mambro et al., 2017). Auxins, in conjunction with ABA, promote root hair growth due to the two antagonistic phenomena called gravitropism and hydrotropism which occur concurrently in the soil. The contribution of auxin in hydrotropism is less than gravitropism (Cassab et al., 2013). However, the ultimate direction of root extension in the direction of moist areas of the soil is primarily controlled by ABA signaling, which can be overwhelmed by the auxins mediated gravitropism (Taniguchi et al., 2010). Xu Q. T. et al. (2013) inferred that the ABA regulates primary root and root hair growth by mediating the auxin passage in both Arabidopsis thaliana and Oryza sativa plants. Furthermore, 


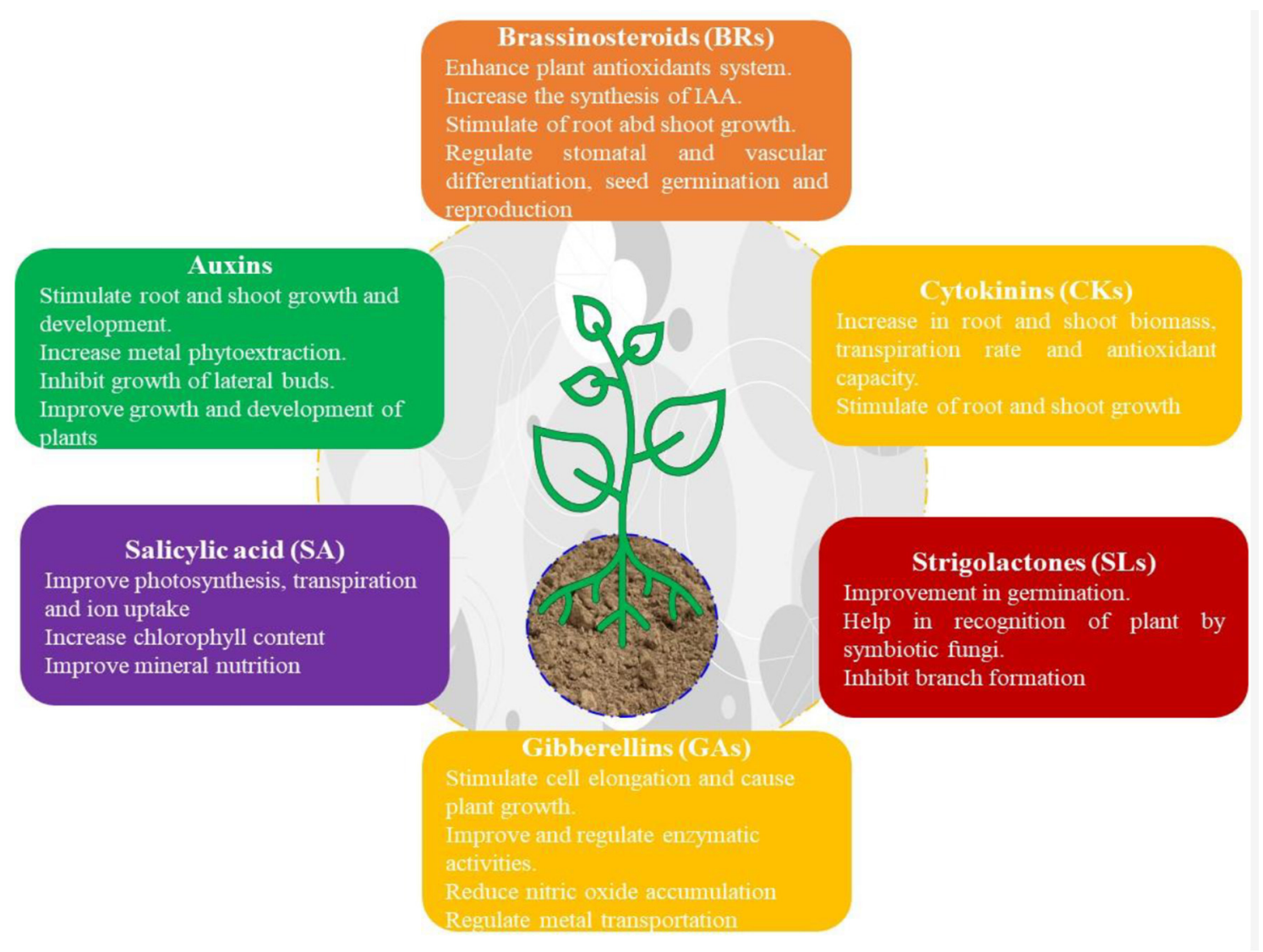

FIGURE 3 | Role of selected PGRs on plant growth and development.

it causes an increase in the proton secretion process by the accomplishment of plasma membrane-bounded H-ATPases and maintains root elongation.

More studies are required to separate the complex connections among auxin and other PGRs on modifications in root architecture, which can be modified in plants under stress conditions (Indu Lal et al., 2021). A hydrolase called IAA-Ala Resistant-3 (IAR3) in Arabidopsis plants modulated root architecture throughout osmotic conditions (Kinoshita et al., 2012) and has a capability of producing free auxin by hydrolyzing auxin indole acetic acid (IAA) forms in roots under drought (Rampey et al., 2004). Thus, IAR3 is proposed to be a bioactivator of auxin generation and thereby stimulating lateral root development under water deficit soils to survive in such extreme environments (Kinoshita et al., 2012).

Genome-wide expression analyses of plants confronting water deficit conditions often indicate distinguishingly expressed auxin-connected genes. For example, MIZU-KUSSEI (MIZ1) protein in Arabidopsis regulates auxin levels and increases primary and lateral root growth under water stress conditions (Miyazawa et al., 2012). The auxin-responsive genes encoding several associates of the ARF transcription factor (TF) family were also differentially expressed in Glycine max roots of plants under water deficit environments. These genes could act as potential candidates for the breeding of water deficit tolerant soybean cultivars (Ha et al., 2013).

In a study, Arabidopsis activation-tagged yuc7-1D mutant showed enhanced expression of the stress-correlated genes RD29A and COR15A, which augmented the drought resistance of plants (Lee et al., 2012). Similarly, the Arabidopsis YUCCA gene in the drought tolerance responses regulate the auxin invention when it was articulated in potato plants (Kim et al., 2013). The increased expression of YUCCA protein, CONSTITUTIVELY WILTED1 (Woo et al., 2007), and supposed auxin efflux transporter OsPIN3t are complicated in the maintenance of water homeostasis in rice plants (Zhang et al., 2012). Recently, the Arabidopsis SMALL AUXIN UP RNA 32 (SAURs) protein regulates the drought adaptation through modulating ABA transduction (He et al., 2021). Likewise, INDITTO2 transposons convey auxin mediated DEEPER ROOTING 1 (DRO1) transcription factor for drought avoidance in rice (Zhao et al., 2021). However, auxin synthesis with respect to crop growth stage under varying extent and duration of drought stress must be studied to increase our understanding regarding the ameliorative effect of auxin in drought-stressed plants. 


\section{Auxin Mediated Physiological Changes Under Salt Stress}

Salinity drastically affects plants by exerting physiological drought resulting from high osmosis in soil solution and causing ion imbalance due to high solubility of certain minerals hampering root development (Islam et al., 2011; EL Sabagh et al., 2019a, 2020a; Liu et al., 2020). Mild saline conditions caused a decrease in the elongation of lateral roots and increased lateral root sizes, while high salt conditions inhibited the root development (Zolla et al., 2010). The salt stress could be regulated by the synergism of many signaling molecules such as phytohormones with auxin as a key mediator (Ribba et al., 2020). The salt responsive auxin signaling genes, AXR1, AXR4, IAR4, and TIR1 enhanced lateral root development in plants under salt environments. In contrast, the lateral root development was reduced in the mutants axr1, axr4, and tir1, iar4 and it was impaired in the auxin invasion mutant auxl (Wang Y. et al., 2009; Zolla et al., 2010; Fu et al., 2019). The circulation of auxin efflux transporters (PIN2) regulates the gravitropism responses through the changes in basipetal auxin transport, which could be involved in growth responses associated with decreasing the consequences of salinity in plants (Vanneste and Friml, 2009; Galvan-Ampudia and Testerink, 2011). The salt overly sensitive (SOS) genes, such as SOS1-3, are obligatory for salt resistance responses in $A$. thaliana (Ji et al., 2013). These genes are associated with the auxin-mediated lateral root formation in plants under salinity (Yang et al., 2008). Plant roots grown in highly acidic soils exhibit vast transcriptional modifications in the expression of some auxin-related genes, implying auxin-mediated alterations on root architecture (Lager et al., 2010). The PIN2 maintained buffering of extreme soils was observed in roots of plants growing in alkaline conditions where auxin transport activity is mediated by PIN2 followed by auxin-mediated activation of plasma membrane $\mathrm{H}^{+}$-ATPase and photon emission in the root tips (Xu Q. T. et al., 2013). Auxin biosynthesis and transportation in response to specific salt stress should be further studied to understand the underlying mechanism of auxin modulation.

\section{Auxin Mediated Physiological Changes Under Flooding or Waterlogging}

Different abiotic stresses such as flooding, submergence, or waterlogging cause either hypoxia or anoxia depending on plant species. These responses include an increase in aerenchyma development, adventitious root development, and shoot development along with epinastic or hyponastic growth phenomena, among others (Jackson, 2002; Visser and Voesenek, 2004; Voesenek et al., 2006; Bailey-Serres and Voesenek, 2010; Lin et al., 2017). Ethylene trap by water would break new ground alarming signals to the plant, indicating waterlogging. Flooding or waterlogging-dependent adventitious root production requires both increased auxin accumulation and altered auxin transport, together with an enhanced ethylene invention (Vidoz et al., 2010). Further, it was found that ethylene induces the auxin transport through auxin flux to the flooded portions of the tomato plants resulting in a novel root organization, which can substitute the root system injured during their submergence. The auxin transport is necessary for adventitious root development in tobacco and rice plants (McDonald and Visser, 2003; Xu et al., 2005; Yamauchi et al., 2019). Overall, there is complex cross-talk between stress hormones ET and auxin the modulation of growth or development of lateral and adventitious roots under waterlogged plants (Muday et al., 2012; Hu et al., 2018).

\section{Auxin Mediated Physiological Changes Under Oxidative Stress}

The oxidative stress under abiotic stress alters redox status in cells which gives rise to the biosynthesis of ROS (Fahad et al., 2019). The controlling mechanisms of ROS biosynthesis redox homeostasis involve key regulators like thioredoxin (TRX) and glutathione (GSH) (Hasanuzzaman et al., 2020). These regulators participate in the growth and developmental processes through the modulation of auxin signaling (Bashandy et al., 2010). Thus, lack of thioredoxin and glutaredoxin in triple mutants of Arabidopsis (two genes encoding NTRA and NTRB) cad2 showed perturbed auxin passage (Bashandy et al., 2010). Terrile et al. (2012) demonstrated that nitric oxide (NO) also played a part in the optimum process of auxin signaling by inducing the breakdown of AUX/IAAs during lateral root formation. Root growth of rice in Cd-stressed soils has been reported to be regulated by the interaction of $\mathrm{H}_{2} \mathrm{O}_{2}$ and auxin signaling where enhanced $\mathrm{H}_{2} \mathrm{O}_{2}$ regulates the gene expression of auxin signaling, showing strong links between auxin signaling pathways and ROS synthesis under stressful conditions (Zhao et al., 2012; Zwiewka et al., 2019).

The rapid auxin-reliant hindrance of root formation and early stage of root gravitropism responses are regulated by the TIR1/AFBauxin co-receptors. One of which, called AFB1, has an essential role in these responses (Prigge et al., 2020). The loss of function mutations of TIR1/AFB2 seedlings showed reduced salt sensitivity. In contrast, in seedlings experiencing oxidative stress, double receptor mutants of tir1 afb2 and tir 1 afb3 showed an augmented percentage of primary root formation and cell death induced by $\mathrm{H}_{2} \mathrm{O}_{2}$. Together, the antioxidant defense enzymes like catalase (CAT), ascorbate peroxidase (APX), and ROSdegrading enzymes such as glutathione $S$-transferase 1 (GST1), cytosolicAPX1, and a zinc finger TF (ZAT12) were in tir1 abf2 plants under saline conditions. These results suggest that the decrease of auxin signaling pathways may be utilized by plants to improve tolerance against oxidative stress (Iglesias et al., 2010; Pasternak et al., 2020).

Auxin signaling interacts with shade avoidance mechanisms and communicates with different plants in the rhizosphere (Faget et al., 2013; Falik et al., 2013) as a sensor for detecting other roots in close plants (Fang et al., 2013), regulating the communication between the roots of the plant itself, or with neighboring plants and also in the root-shoot communication (Kabouw et al., 2012). The complex connections among auxin and other PGRs play essential roles in stress-associated developmental modifications in auxin biosynthesis, signaling, or carriage mutant plants (Bielach et al., 2012; Muday et al., 2012; Rahman, 2013; Shani et al., 2013; Sereflioglu et al., 2017). However, a comprehensive understanding of these interactions has not yet been reported. 


\section{Gibberellin Induced Physiological and Biochemical Mechanisms of Stress Tolerance}

Gibberellins play key roles in plant growth and development (Figure 3) along with their physiological (cell division, seed dormancy, germinations, etc.) and biochemical processes (Olszewski et al., 2002; Hedden and Thomas, 2012; Tanimoto, 2012; Vishal and Kumar, 2018; Islam et al., 2021). The inhibition of the biosynthesis of GAs is the primary mode of action (Rademacher, 2000), followed by retarded growth and dwarf growth habit in plants under stress environments. Suppression of GA signaling through alternative splicing is the common response to abiotic stresses, which is accompanied with upregulation and fine tuning of GA2ox, CsGA2ox8 (encoding GA-inactivating enzymes), and DELLA (negative controller of GA signaling) (Achard et al., 2006, 2008a,b; Lo et al., 2008; Rieu et al., 2008; Liu et al., 2021). Likewise, genome wide expression analysis of GA2ox, GA3ox, and GA20ox are related to oxidase gene under multiple stresses. However, the mechanism of GA signaling in stress tolerance is less explored compared to the role of GA as a growth-promoting controller (Colebrook et al., 2014).

The GA2-oxidases (GA2ox), DELLA domain proteins, GAI (GA insensitive), and RGL1 (repressor of ga1-3 like), are vital in GA regulation and signaling in stress environments. GA2oxs inhibit bioactive GAs leading to dwarfism (Lo et al., 2008; Rieu et al., 2008). Activation of DELLA domain proteins is essential for surviving in stress environments (Achard et al., 2006, 2008a,b; Zhou and Underhill, 2017) as it causes inhibition of cell proliferation and expansion (Olszewski et al., 2002; Claeys et al., 2012). The role of GA in various physiological processes governing growth under various abiotic stresses has been documented. However, a detailed underlying mechanism of GA signaling in each response is still needed to be further explored (Colebrook et al., 2014).

\section{Gibberellin Mediated Physiological Changes Under Flooding or Waterlogging}

The GA-mediated signaling under submergence could be best explained using rice genotypes modified to tolerate flooding stress (Bailey-Serres and Voesenek, 2010). The most common strategy to escape long-term flooding is rapid inter node elongation, allowing the shoots to out-grow the flood waters. The internode development is mediated by ethylene due to activation of the ERF domain proteins named SNORKEL1 and SNORKEL2 (Hattori et al., 2009), which leads to the accumulation of GA in submerged rice plants. The expression of gene submergence tolerance-1 (Sub1A) (Xu et al., 2006) provides an escape to short-term deep flooding through inhibiting shoot elongation and relates to improved levels of DELLA protein SLR1 and the negative controller of GA signaling SLRL1 in rice (BaileySerres and Voesenek, 2010; Claeys et al., 2014). The Sub1A gene enhances leaf viability and promotes leaf growth under submergence (Fukao et al., 2006) and similar related escape responses such as hyponasty. Particularly, due to variance growth of the petiole, leaf blade formation was observed in
Rumex palustris at submergence (Polko et al., 2011). Flooding escape is controlled by two ERFs, namely, SNORKEL1 (SK1) and SNORKEL2 (SK2) which activate internode development through GA during flooding stress (Hattori et al., 2009).

\section{Gibberellin Mediated Physiological Changes Under Osmotic and Salt Stress}

Gibberellin mediates osmotic adjustments in response to salt stress (Skirycz et al., 2011; Claeys et al., 2012). GA, together with ET and ABA, regulates cell proliferation and expansion in Arabidopsis leaves during abiotic stresses (Skirycz et al., 2010). In addition, ET and GA coordinately regulate the cell cycle and cell proliferation of A. thaliana exposed to salt stress (Skirycz et al., 2011; Claeys et al., 2012). The ethylene and GAarbitrated responses are related to ERF as a dominant activator of both inhibition of leaf growth and initiation of stress tolerance genes (Claeys et al., 2012) where DELLA acts as a conjunction of numerous hormone signaling pathways in stress situations (Achard et al., 2006; Fukao and Bailey-Serres, 2008).

\section{Gibberellin Mediated Physiological Changes Under Drought Stress}

Drought stress lowers water availability and nutrients accessibility to the roots which affects crop growth and yield. Drought reduces GA accumulation and impaired membrane stability resulting in cell damage in maize leaves (Wang et al., 2008). Drought stress also reduces GA signaling, leaf area, and transpiration rate, which enhances water use efficiency in plants. The decreased GA2ox expression in the roots (Krugman et al., 2011) and lateral roots elongation is linked with a cross-talk among GA and IAA (Gou et al., 2010; Chen Z. et al., 2019) in the roots in response to drought. Root-derived signals maintain root growth and reallocate photo-assimilates to adjust the growth of shoot and root. ABA-mediated root signals that cause stomatal closure seem to be the result of crosstalk of ethylene and GA (Coelho Filho et al., 2013). However, root-derived signals do not regulate leaf growth and leaf metabolism. As such, regulation is mediated by leaf/shoot GA (Kaneko et al., 2003). In Arabidopsis, drought stress increased the expression of DELLA and XERICO genes, which cause growth inhibition but increase the survival of plants (Achard et al., 2006; Zentella et al., 2007). The impaired GA activity and suppressive signaling facilitate shoot growth under drought stress. Water deficit conditions and short-day photoperiod prompted modulation of a group of GA2ox and DELLA protein-encoding genes which are downstream of diverse signal transduction ways (Zawaski and Busov, 2014).

\section{Cytokine-Induced Physiological and Biochemical Mechanisms of Stress Tolerance}

Cytokinins play key roles in regulating plant cell discrepancy, delaying leaf senescence (Sakakibara et al., 2006), and other main developmental progressions such as governing integrate compounds apportioning (Ronzhina and Mokronosov, 1994), sink asset (Kuiper, 1993), and source/sink associations. The ISOPENTENYL TRANSFERASE (IPT) encoding enzyme 
catalyzes cytokinin (CK) synthesis, increased the sink capacity, and militarizes nutrients to the cells or tissues where they are utilized. Altered sink/source associations were detected in CK-lacking tobacco shoots and roots (Werner et al., 2008). The stress-induced CK synthesis improved $\mathrm{N}$ and $\mathrm{C}$ assimilation associated with enhanced sink in the transgenic plants during water stress, which characterized physiological responses and metabolic pathways connected with the CK persuaded stress resistance in $P_{S A R K}:: I P T$ transgenic rice plants (Reguera et al., 2013). The CK-regulated $\mathrm{N}$ uptake controls the $\mathrm{N}$ levels in the plant (Kiba et al., 2011) where C-N interaction regulates $\mathrm{CK}$ biosynthesis in response to soil $\mathrm{N}$ availability (Sakakibara et al., 2006). Transgenic $P_{S A R K}: I P T$ rice plants showed CK mediated higher $\mathrm{N}$ assimilation in a $\mathrm{C}-\mathrm{N}$-dependent manner (Reguera et al., 2013). It was assumed that a decrease in root tip turgor can disturb the synthesis and passage of CKs in the root tip and simultaneously abridged their passage along with the accumulation of nutrients that are available in the soil under drought stress (Davies et al., 1986; Pavlu et al., 2018).

\section{Cytokinin Mediated Physiological Changes Under Drought Stress}

High CK concentrations (Figure 3) in plants tend to delay leaf senescence, increase proline levels, and survival of plants under water-stress conditions (Alvarez et al., 2008). The overexpression of the isopentenyl transferase gene (IPT) and related promoters such as PSAG12 (Gan and Amasino, 1995) in different plant species showed a substantial delay in plant senescence followed by delayed flowering and reduced yield ( $\mathrm{Ma}, 2008)$. This is inferred to be due to altered source/sink relationships.

Enhanced CK levels boosted the existence of plants under water deficit environments (Rivero et al., 2007). Use of promoter (SARK; a maturation- and stress-induced promoter) upstream to IPT for overexpression in both monocots and dicots induced drought tolerance (Rivero et al., 2007; Peleg et al., 2011; Qin et al., 2011). The transgenic $P_{S A R K}:: I P T$ rice showed altered hormone synthesis and hormone regulatory pathways, thereby modifying source/sink relationships, subsequently higher grain yield is obtained under the water stress environment (Peleg et al., 2011). Water deficit decreased photosynthetic activity and respiration resulting in lower internal $\mathrm{CO}_{2}$ in plants (Lawlor and Tezara, 2009). However, transgenic $P_{S A R K}:: I P T$ rice (Reguera et al., 2013) and transgenic tobacco plants expressing $P_{S A R K}: I P T$ (Rivero et al., 2009) increased internal $\mathrm{CO}_{2}$ level so that photosynthesis continues as that of normal plants because increased biosynthesis of CK safeguards the biochemical procedures related to photosynthesis under water-limited conditions. Reduced CK levels concomitantly induce ABA activity inducing stomatal conductance and hindering photosynthesis under drought stress (Rivero et al., 2010). Stress persuaded CK synthesis regulated by the stress-induced promoter, protecting harmful effects on the photosynthetic device, which allows better photosynthetic tariffs and higher yield under drought stress in tobacco (Rivero et al., 2009), peanut (Qin et al., 2011), and greenhouse-grown cotton (Kuppu et al., 2013).

\section{Cytokinin Mediated Physiological Changes Under Nutrient Deficiency}

Nutrients in growing media are detected by a complex system of signaling pathways generated by integrating PGRs (Krapp, 2015; Bellegarde et al., 2017; Gent and Forde, 2017; Guan et al., 2017; Awad et al., 2021). There are many genes such as isopentenyl transferase (IPT3, IPT5), P450 (CYP735A2), auxin response regulators $(A R R s)$, cytokinin response factors $(C R F s)$, and glutaredoxin genes (GRX) that regulate the CK biosynthesis and nitrate signaling (Pavlu et al., 2018). Long-distance shoot and root-derived $\mathrm{CK}$ mediates nitrate responses and control key characters, e.g., leaf size (Walch-Liu et al., 2000; Rahayu et al., 2005) and meristem activity-related traits (meristem size and organogenesis) (Müller et al., 2015). The cell cycling in shoot and root meristems regulates the magnitude of inorganic phosphate $(\mathrm{Pi})$ that, in turn, gets mediated by CK (Schaller et al., 2015). Potassium deficiency decreases CK level which induced root growth affecting potassium uptake (Nam et al., 2012). CK mediated GSH homeostasis and GSH breakdown play a physiologically significant role in nutrient utilization, especially during sulfur (S) deficiency (Bhargava et al., 2013). Boron (B) deficiency impairs root meristem development by impairing molecular machinery connecting the CK-mediated suppression of cyclin CYCD3 (Poza-Viejo et al., 2018).

\section{Cytokinin Mediated Physiological Changes Under Salinity Stress}

Increased CK levels enhance photosynthesis under salt stress by stimulating the expression of genes that promote the biosynthesis of chlorophyll (Ma et al., 2016). The overexpressed CK-degradation enzyme (CKX) in Arabidopsis plants showed enhanced $\mathrm{CK}$ biosynthesis followed by high $\mathrm{CO}_{2}$ assimilation (Cerný et al., 2013) whereas AtCKX1 mutants showed reductions in $\mathrm{CO}_{2}$ acclimatization rates, accompanied by lower stomata closure (Vojta et al., 2016). Further, CKs improve the potential of antioxidant defense systems that could protect their cells from stress-induced ROS gathering, protecting chloroplast integrity (Rivero et al., 2007; Zavaleta-Mancera et al., 2007), dropping electrolyte leakage and/or increasing malondialdehyde (MDA) levels (Liao et al., 2017; Xu et al., 2017). Cytokinin affects root and shoot development along with other agro-botanical traits under a water-limiting environment (White and Kirkegaard, 2010). Particularly, it decreases root to shoot hypocotyl relations, improves root growth, nutrient uptake, and enhances tolerance to water-limiting conditions (Pospíšilová et al., 2016). Further qualitative traits such as variation of vascular tissue and lignification of root tissues showed CK-regulated reactions to water-limiting environments (Pospíšilová et al., 2016).

\section{Abscisic Acid-Induced Physiological and Biochemical Mechanisms of Stress Tolerance}

Abscisic acid is one of the widely examined stress hormones which are well-correlated with the intensity of stress tolerance in crop plants. It coordinates an array of functions in plants, enabling them to withstand a variety of abiotic stresses 
(Finkelstein, 2013; Wani and Kumar, 2015; Raza et al., 2019b). It is well-reported that abscisic acid (ABA) accumulation increases in response to abiotic stresses such as drought, salt, and cold (Zhang et al., 2014; Vishwakarma et al., 2017; Malaga et al., 2020). The elevated level of ABA enables plants to cope with salt and drought by improving cellular dehydration and water balance. Besides, ABA regulates key processes like leaf abscission, inhibition of fruit ripening, and seed development (Zhang et al., 2014). Moreover, it also regulates multiple physiological processes by acting as signaling mediators to impart adaptation to abiotic stresses (Sah et al., 2016). ABA-induced gene expression is responsible for the quickest response to abiotic stress in plants (Yamaguchi-Shinozaki and Shinozaki, 2006). The rapid expression of short-term ABA stimulated genes facilitates plants to endure under unfavorable growing environments (Nemhauser et al., 2006).

The ABA-mediated stomatal closure under stress conditions suggests that cross talks with hormones such as JA, SA, BR, $\mathrm{CK}, \mathrm{NO}$, and ET also influence stomatal function (Acharya and Assmann, 2009). Exogenous application and/or cold stressinduced ABA synthesis enhances cold tolerance of plants, thus representing the role of $\mathrm{ABA}$ in plant adaptations to cold stress (Xue-Xuan et al., 2010). In addition, ABA works as a multipurpose mediator of numerous physiological processes. ABA plays a crucial role in stimulating seed dormancy, hindering seed germination and shoot growth while, on the other hand, promoting root growth, leaf senescence in plants switching from vegetative to reproductive phase to complete life cycle under low water potentials. Furthermore, ABA, in coordination with auxin, can enhance root hair formation in Arabidopsis (Shibata and Sugimoto, 2019). The gene expression analysis concluded that ABA could control plant expansion by reducing the signal transduction or biosynthesis of numerous growth-promoting PGRs such as CK, GA, and BRs at the transcriptional or posttranslational levels (Zhang et al., 2009a,b; O’Brien and Benkova, 2013; Fahad et al., 2015; Sah et al., 2016).

\section{ABA-Mediated Physiological Changes Under Drought Stress}

The moisture stress coupled with other environmental stresses, i.e., extreme temperature and salt, promote the synthesis of ABA in plants (Cutler et al., 2010; Kim et al., 2010). Classical physiological alterations in plants under water deficit stress include less root water absorption, low water potential, and turgor in the leaves, reduced leaf elongation, stomatal closure, modification in gene expression, and ABA-dependent adaptive physiological responses like modulation of root architecture (Clark et al., 2005; Harris, 2015). Plants have evolved an array of adaptive mechanisms to withstand water scarcity such as differential shoot and root growth. Early root growth promotion at the expense of shoot (hypocotyl) growth inhibition is probably mediated by ABA in Vigna radiata under mild water stress (Das and Kar, 2018). ABA is also considered as a prime signaling cue 1 for root-to-shoot stress (Schachtman and Goodger, 2008). It plays a role in drought stress tolerance in two ways: inducing cellular dehydration tolerance and maintaining water balance. Dehydration tolerance proteins within plant cells are encoded by gene expression, while guard cell regulation enables plants to achieve water balance. Excessive $\mathrm{ABA}$ is produced in response to osmotic stress resulting inactivation of ABA biosynthesis and inhibition of ABA degradation (Zhu, 2002). The biosynthesis of $\mathrm{ABA}$ in roots induced with soil drying and elated via the xylem to the shoot (Wang et al., 2000; Dodd, 2005). Different transgenic plants over-expressing ABA-biosynthesis genes had a greater ability to withstand water deficit stress. Genes, namely, AtNCED3 and NCED1 in Arabidopsis, play a critical function in ABA biosynthesis under drought. SgNCED1 overexpressed tobacco plants showed increased leaf $\mathrm{ABA}$ and tolerance to drought and salinity (Peleg and Blumwald, 2011). Overexpression of LeNCED1 showed increased ABA accumulation and ERA1 in transgenic canola (Brassica napus L.), which exhibited higher yield when grown under mild drought stress. Stomatal closure is a vital water conservation strategy in drought-tolerant plants, which is regulated through ABA-triggered complex series of events (Turner et al., 2001). Applied exogenous ABA and glycine betaine (GB) alone or in combination improved drought tolerance in all accessions of Axonopus compressus (Nawaz and Wang, 2020).

As ABA interacts with plant hormones under drought, it results in reducing $\mathrm{CK}$ levels, showing antagonistic effects between CK and ABA (Peleg et al., 2011). High ABA and low $\mathrm{CK}$ concentration facilitate the stomatal closure and decrease water loss via transpiration under water deficit stress (Morgan, 1990). Thus, indicating the role of ABA in inducing drought tolerance in crop plants. On the other hand, ABA and ET work together to hamper seedling growth (Cutler et al., 2010) but control seed growth antagonistically (Ghassemian et al., 2000). It inhibits BR-triggered responses in plants exposed to several abiotic stresses (Divi et al., 2010). The ABA signaling components ABI2 (abscisic acid insensitive 2) and GSK3s coregulate a network of stress-responsive genes to inhibit BR signaling in plants when exposed to abiotic stress (Wang et al., 2017). Several aspects of plant growth or development are controlled by $\mathrm{BR}$ and $\mathrm{ABA}$ antagonistically in a range of environmental stresses. The ABA-associated chemical signals that arise due to environmental stresses have a great influence on certain physiological processes such as the rate of grain-filling in wheat (Yang et al., 2006). On the other hand, CK and ABA are responsible for controlling carbon remobilization and plant senescence in wheat subjected to drought stress (Yang et al., 2003). Short-term ABA facilitates stimulus responses, regardless of the association of ABA to metabolic readjustments (Yang et al., 2014).

Among major abiotic stress factors, drought or moisture deficient conditions affect the root system of plants to a greater extent. Therefore, drought-induced ABA accumulation may be attributed to maintaining root development and shoot progress as a substitute for reduced growth (Farooq et al., 2009). Relative growth alters in response to ABA, like inhibition of leaf area development, higher root-shoot dry weight ratio, and production of deeper roots. Consequently, modulations in the root environment exhibit both systemic and local consequences on ABA-mediated responses (Farooq et al., 2009; Puertolas et al., 2015; Vishwakarma et al., 2017; Afzal et al., 2020). 


\section{ABA-Mediated Physiological Changes Under Salinity Stress}

Abcisic acid plays a critical role in plant adaptation responses to stress (Sharma et al., 2005). Plants experience osmotic stress and water deficit under salinity stress and respond by inducing $\mathrm{ABA}$ biosynthesis in roots and shoots (Cramer and Quarrie, 2002; Cabot et al., 2009). Accumulation of $\mathrm{Ca}^{2+}, \mathrm{K}^{+}$, and other compatible solutes such as sugars and proline are responsible for ABA-induced salinity tolerance (Gurmani et al., 2011). The ABA modulated salt responsive genes play a fundamental role in cellular signaling under salinity stress. ABA-induced expressions of HvVHA-A for subunit A (the catalytic subunit) of vacuolar $\mathrm{H}^{+}$-ATPase, HVP1, and HVP10 for vacuolar $\mathrm{H}^{+}$inorganic pyrophosphatase have been observed in Hordeum vulgare under saline conditions (Fukuda and Tanaka, 2006). Similarly, ABAmediated MAPK4-like, TIP 1, and GLP 1 gene expression have been reported under salinity in wheat crops (Keskin et al., 2010). In addition, ABA has been regarded as a key signaling molecule that stimulates the suppression of lateral root growth when plants are exposed to salt stress (Duan et al., 2013). ABA level elevates absolutely in lateral root cells under salinity stress, which provokes a dormant period in post-emergence lateral roots. A well-developed and thick casparian strip is formed in lateral roots during the dormant period acting as a barrier to minimize $\mathrm{Na}^{+}$ions diffusion via the endodermis. ABA signaling is activated within endodermal cells in the presence of $\mathrm{Na}^{+}$ions that seize growth, thereby restricting elongation of lateral roots under elevated salinity conditions (Fernando and Schroeder, 2016). PYL8/RCAR3 ABA receptor has been described to function in ABA-mediated restriction of primary root growth and improvement of lateral root growth when exposed to ABA (Zhao et al., 2014). Furthermore, it shows differential responses toward the plant antioxidant system under abiotic stresses. The up-regulation of antioxidant activity in callus cells of the cotton crop is attributed to the ABA-mediated signal transduction pathway (Bellaire et al., 2000). Higher activity of antioxidant enzymes in bermuda grass (Lu et al., 2009) and wheat (Agarwal et al., 2005) has been linked to ABA synthesis under salinity stress. ABA synthesis and accumulation of ROS occur under salinity stress. Thus, calcium and/or $\mathrm{H}_{2} \mathrm{O}_{2}$ act as second messengers of $\mathrm{ABA}$-induced stomatal closure and expression of genes in response to several abiotic stresses (Zhu, 2002; Asad et al., 2019). A comparative rise in ABA concentration is generally connected with soil water or leaf potential in plants exposed to salt stress (Zhang et al., 2006). The expression of salt-associated genes is usually controlled by ABA-mediated signaling, which enables plants to survive salinity stress (Keskin et al., 2010). Likewise, plant water status through guard cells and growth is regulated by ABA-induced expression of genes (Zhu, 2002).

Under a saline environment, $A B A$ triggers plant protective mechanisms that regulate the expression of genes persuaded by salt stress (Shakirova et al., 2003; Parida and Das, 2005; Sah et al., 2016). A significant concentration of ABA accumulates in the leaves of salt-tolerant maize hybrids under salt stress. As a growth pre-requisite, an increase in $\mathrm{ABA}$ is necessary for acidifying the apoplast (Zorb et al., 2014). Mediating leaf expansion and restricting $\mathrm{Na}$ and $\mathrm{Cl}$ in leaves is a wellreported facilitating role of salt-induced ABA (Cabot et al., 2009). The ABA synthesis improves stomatal conductance which gets disturbed under salt stress. The ABA regulates stomatal closure resulting in reduced water loss through transpiration (Wilkinson and Davies, 2010; Sah et al., 2016). The stomatal closure in plants growing under salinity might be attributed to ABA-induced higher $\mathrm{Ca}$ concentration in the cytoplasm. ABA-induced augmentation of $\mathrm{H}_{2} \mathrm{O}_{2}$ production activates ion channels present in plasma lemma and regulates turgor losses through guard cells (Kim and Wang, 2010). The ABA plays a vital role in the synthesis of osmoprotectants (Sah et al., 2016) like proline (Iqbal et al., 2014; Fahad et al., 2015) and dehydrins in response to ROS production under salt-stressinduced dehydration (Javed et al., 2020). Expression of the OsP5CS1 gene stimulated by salinity is associated with a rise in endogenous $\mathrm{ABA}$ concentration. The exogenous supply of $100 \mu \mathrm{M}$ ABA in rice seedlings had an ameliorated survival degree by $20 \%$ and elicit proline uptake by triggering the expression of OsP5CS1 gene in rice (Sripinyowanich et al., 2013). Thus, a positive correlation between $\mathrm{ABA}$ accumulation and salinity resistance was revealed in terms of synthesis and accumulation of compatible solutes, including proline and sugars, and $\mathrm{K}^{+}$ and $\mathrm{Ca}^{2+}$ in vacuoles of root cells, which counteract with $\mathrm{Na}^{+}$ and $\mathrm{Cl}^{-}$uptake (Gurmani et al., 2011). Moreover, mitogenactivated protein kinase (MAPK) is triggered due to NO generation because of ABA-mediated $\mathrm{H}_{2} \mathrm{O}_{2}$ accumulation. Thus, up-regulating genes for ROS scavenging antioxidant defense enzymes (Lu et al., 2009). ABA also plays a fundamental role in osmotic stress tolerance, as reported in ABA biosynthesis mutants of Arabidopsis (Koornneef et al., 1998) and other crops (Liotenberg et al., 1999) that wilt and die under prolonged exposure to drought and salt stress.

\section{ABA-Mediated Physiological Changes Under Flooding}

Flooding results in waterlogging or submergence conditions which inhibit plant growth and development. Under such unfavorable circumstances, plants always struggle to acclimatize by adapting several physiological mechanisms, including hormonal homeostasis. Change in leaf ABA concentrations in several species has been reported under waterlogged conditions (Bai et al., 2011; Salazar et al., 2015; Bashar, 2018; Cao et al., 2020). The response of ABA to waterlogging may vary among roots and leaves depending on the duration and plant species. For example, Malus sieversii showed more ABA concentration in the roots and leaves as compared to Malus hupehensis under hypoxic stress (Bai et al., 2011). According to Rodriguez-Gamir et al. (2011), the ABA level in citrus increased after 3 weeks of flooding. It was observed that the synthesis of $\mathrm{ABA}$ in older leaves increased and translocated to young leaves instead of $\mathrm{ABA}$ transportation from roots to shoots under flooding. The plant root system is severely damaged postwater logging normally in susceptible plants. Production of ROS in response to reoxygenation stress results in oxidative damage to functional tissues hampering normal physiological processes. However, a 
balance between $\mathrm{CK}$ and $\mathrm{ABA}$ is necessary for regulating both leaf senescence and stomatal closure under reoxygenation stages (Bashar, 2018). ABA plays a key role in modifying root hydraulic characteristics induced by asynchrony in root water uptake and leaf transpiration (Aroca et al., 2012).

The keypart of $\mathrm{ABA}$ is regulating the plant water balance both under flooding (Olivella et al., 2000) and drought stress (Nan et al., 2002), as detected in wheat plants. ABA concentration temporarily enhances with leaves and roots growth and then declines under water-logging conditions (Nan et al., 2002). Prolonged flooding also provokes shoot elongation, permitting the restoration of gas exchange among submerged marsh dock plant tissues and the atmosphere (Benschop et al., 2005, 2006). This adaptation procedure needs ABA-dependent biosynthesis of GA. Primarily, ethylene accumulation inhibits the expression of 9-cis-epoxycarotenoid dioxygenase, involved in downregulating ABA levels and/or activates ABA breakdown to phaseic acid (Salazar et al., 2015). The reduction in endogenous $\mathrm{ABA}$ is a prerequisite to stimulate gibberellin (GA) 3-oxidase expression, which is involved in translation to bioactive GA1. Downregulation of GA induced several genes encoding proteins involved in cell wall untying, during the cell cycle, interruption of starch, and other genes involved in internode development (Benschop et al., 2006). A similar response was also reported by Bailey-Serres and Voesenek (2008) in rice.

Photosynthetic capacity and carbohydrate synthesis reduced drastically due to stomatal closure resulting from enhanced ABA contents in rice leaves (Bai et al., 2013). Such kind of inhibition may also take place because of relatively greater cellular oxidative damage. Besides, ABA plays a significant role in rice adaptation to hypoxic conditions, suggesting that rice growth is tightly regulated through proline and ABA-mediated response in roots (Cao et al., 2020). Some authors also documented that the function and regulation of proline metabolism are dependent on ABA accumulation (Abraham et al., 2003). The expression of the genes involved in proline metabolism is tightly controlled by ABA-driven proline accumulation under hypoxic stress (Cao et al., 2020). Therefore, variations in gene expression linked with proline metabolism are regulated through ABA signaling, which is closely related to higher ABA-mediated antioxidant capacity in the rice roots. Under flooding stress, $\mathrm{ABA}$ accumulation is associated with an increase in ROS. Moreover, high ABA contents under flooding stress trigger stomatal closure and alter $\mathrm{H}_{2} \mathrm{O}_{2}$ concentration tracked by escalated antioxidant defense enzyme actions in Arabidopsis (Liu et al., 2012; Das and Kar, 2018). More importantly, ABA also acts as a connection between the oxidase injury of cellular structure and signal molecules under abiotic stresses through leaf senescence. However, the potential of ABA in boosting plant tolerance against waterlogging is not fully understood yet.

\section{Ethylene Induced Physiological and Biochemical Mechanisms of Stress Tolerance}

Ethylene which is a gaseous phytohormone plays a vital role in regulating numerous physiological processes including fruit ripening, flower and fruit senescence, leaf, and petal abscission (Abeles et al., 1992). Also, plants typically form increased levels of ET as a result of multiple abiotic stresses such as heat stress, waterlogging, drought, salinity, biotic stresses, organic and inorganic toxic compounds, and extreme $\mathrm{pH}$. The elevated ethylene concentrations are detrimental to the plants as it triggers senescence, chlorosis, and abscission. Moreover, it has a crucial role during cell signaling for stress tolerance in several plant species. The biosynthesis and sources of ET production, interaction with other signaling molecules, and its exogenous application under different abiotic stresses have been discussed (Hussain et al., 2020).

\section{Ethylene Mediated Physiological Changes Under Salinity}

Salt-induced effects in plants are moderately attributed to the production of ET hormone (Blumwald, 2000; Mayak et al., 2004a,b; Shibli et al., 2007). This enhanced ET was detected in several plant species, like tomato (Lycopersicon esculentum) and Arabidopsis (Richard and El-Abd, 1989; Hall and Smith, 1995). Similarly, elevated ethylene, ACC content, and action of the enzyme ACC oxidase in chickpea (Cicer arietinum) were monitored when plants were exposed to salinity stress (Kukreja et al., 2005). The ethylene accumulation under salt stress caused physiological and biochemical modifications in hybrid tomatoes such as increased leaf epinasty, reduced growth, increased cell sap osmolarity in leaves, diminished leaf tissue viability, macro and micronutrients reduced, and altered shoot soluble protein content. However, the electrolyte leakage, membrane damage, raffinose, and total sugars were concurrently augmented (Shibli et al., 2007). Though ET inhibitors reduced ethylene accumulation and prevented epinasty, such inhibitors were unable to eradicate the negative influences on growth and other physiological limitations caused by salt stress, inferring that ET is not the major factor contributing to detrimental consequences on tomato plant development and physiology (Shibli et al., 2007). Ethylene serves as a master regulator during salinity stress and stabilizes the cell redox homeostasis, alleviating nitrate and sulfate assimilations, defense against ROS, and crosstalk with other PGRs to maintain cell signaling integrity (Riyazuddin et al., 2020). Metabolic engineering found that ethylene is an important component of phytohormone signaling and can potentially impart salinity tolerance in plants (Atia et al., 2018). Moreover, miR319 crosstalk with ET positively regulates the ET synthesis in a dose-dependent manner in switchgrass and enhances salt tolerance by downregulation of key genes of the methionine cycle (Liu Q. et al., 2019; Liu Y. et al., 2019). Therefore, several earlier findings and research suggested the role of ET in salt tolerance in many crop species by crosstalk mechanism, altering the methionine cycle, regulating the enzymes, and gene expressions.

\section{Ethylene Mediated Physiological Changes Under Flooding}

Flooding is confined to gas exchange under stagnant water, which causes expeditious assemblage of the volatile ET in all flooded plant cells. Likewise, in water-logged plants, the root is a primary organ to respond to stress and further affects the 
normal physiological, biochemical, and molecular functioning at the whole-plant level. Ethylene biosynthesis, signaling, and its perception under flood conditions in plants represent a step forward to develop flood resilient crop plants (Khan et al., 2020). During ethylene accumulation, the previously stored reserves are commonly used as the aerobic metabolism partly or completely stopped under flooding. This impaired the membrane integrity and the reckoning of cytotoxic compounds from the flooded soil leading to the retardation of root growth and functions. The absorption and transport of water and nutrients impaired by malfunctioned roots affect the above soil organ function, which results in wilting, senescence, and, ultimately, death of the plant. Thus, plants use some adaptive measures and/or traits such as the formation of a suberin/lignin wall (primary barrier) in the roots that keep radially of oxygen to raise its efficiency to the root tip (Shiono et al., 2011; Afzal et al., 2021), developed aerenchyma that enhances tissue absorbance and aeration of roots (Takahashi et al., 2014), and establishment of aerenchyma-rich adventitious roots (Sauter, 2013) to improve the aeration, uphold root activity and whole-plant endurance under waterlogging.

Immediate accumulation of ET is an early flooding signal and a master regulator of various waterlogging-adaptive plant measures. ACC synthase (ACS) plays a substantial role in producing ET under flooding because of hypoxia in flooded roots (Drew, 1997). The cellular fluctuations of oxygen and ET are said to be the main signals activating plant-adaptive measures to excess water, thus, the progression of distinct temporal and spatial dynamics (Voesenek and Sasidharan, 2013). The ET biosynthesis pathway is stimulated by activation of key enzymes ACC oxidase and ACS under waterlogging (Van Der Straeten et al., 2001; Lee et al., 2011; Van Veen et al., 2013). The ET biosynthesis is directly or indirectly linked to the ROS, nitrous oxide (NO), and ET cross-talk signaling and many gene expressions such as ALCOHOL DEHYDROGENASE (ADH), HYPOXIA RESPONSIVE UNIVERSAL STRESS PROTEIN (HRU1), and ROP GUANOSINE TRIPHOSPHATASEACTIVATING PROTEIN4 (ROPGAP4), that regulates the hypoxia condition (Sasidharan et al., 2018). Additionally, a different subclass of ERF (ethylene response factor) is synthesized in response to multiple abiotic stress conditions. For instance, group ERF provides tolerance against flooding stress by activating hypoxia-inducible genes and regulated oxidative stress (Klay et al., 2018). Similarly, group V11 ERF ZmEREB180 regulates flooding stress in maize (Yu F. et al., 2019; Yu W. et al., 2019) and HRE2 in Arabidopsis (Eysholdt-Derzsó and Sauter, 2019) by promoting the emergence of adventitious roots under hypoxia conditions.

ET precursor, ACC is synthesized primarily in the roots under excess water and transported to the above-ground plant parts. There in the oxygen-mediated translation of ACC to ET occurs which results in the stimulation of the adaptive modifications via nastic activities and aerenchyma development in shoots (Jackson, 2002). Aerenchyma formation is species and environment-dependent and can be seen both in root and shoot organs (Colmer and Pedersen, 2008; Parlanti et al., 2011; Steffens et al., 2011), enabling plants to protrude the water surface and facilitating aeration to flooded parts.
Ethylene-mediated aerenchyma formation in wheat is controlled by ROS biosynthesis by NADPH oxidases (Yamauchi et al., 2014), whereas in rice and aerenchyma, develops during normal plant life cycle exposed to a stressful environment through ET dependent manner (Takahashi et al., 2014; Yukiyoshi and Karahara, 2014). ROS is an important intermediary in the ET-mediated signaling system. For example, ET-induced development of stem aerenchyma elaborated improved levels of superoxide radicals and $\mathrm{H}_{2} \mathrm{O}_{2}$ in pre-aerenchyma cells in submerged rice internodes (Steffens et al., 2011). ROSmediated apoptosis is the final lethal stage in the formation of aerenchyma, where the cell wall breaks down and includes ET-mediated upsurges in cellulases, pectinases, and xylanases enzymes (Bragina et al., 2003; Xu Q. T. et al., 2013). Ethyleneinduced aerenchyma improves the gas diffusion between shoot and root. Although, it can entirely substitute the water-loggedroots, signaling of ET can be conflict subjected to the type of species or genotype (McDonald and Visser, 2003; Steffens et al., 2006; Vidoz et al., 2010). Ethylene-mediated aerenchyma-rich (AR) formation triggers the mechanical incentives provided by the primary root primordia that also need ethylene-mediated ROS formation (Steffens et al., 2012).

The ET-mediated hyponasty is an adaptive measure to cope with water-logged conditions with a different growth frequency of the cells that occur on the lower and upper sides of the pretentious organ (Cox et al., 2004; Polko et al., 2012). For instance, ET governs hyponasty of shoots which has been detected in Rumex spp. and A. thaliana under water-logged conditions (Cox et al., 2003; Lee et al., 2011; Rauf et al., 2013). The cross-talks between ABA, auxin, and GA with ET have been reported in response to rapid hyponasty under submergence stress (Cox et al., 2004; Benschop et al., 2006). For instance, ET-dependent elongation of the shoot is altered by combining possessions of $\mathrm{ABA}$ and $\mathrm{GA}$ under submerged conditions (Fukao and Bailey-Serres, 2008). ET regulated shoot elongation characteristics to hydrological niches and displayed two separate growth responses like escape and dormancy (Voesenek and Bailey-Serres, 2015). Flood-induced ET production is crucial for inter-nodal elongation in deepwater rice (DWR), enabling the stem to keep above the water and facilitating aeration to the whole plant (Hattori et al., 2009). It may be inferred that ET regulates the water-logging tolerance in plants by alteration in physiological, biochemical, and molecular processes and as cross-talk with other signaling components.

\section{Ethylene Mediated Physiological Changes Under Drought}

Water deficit has been connected with extended distance signaling of ACC where the elevated amount of ACC produced high levels of endogenous ET in the plants (Mayak et al., 2004a; Sobeih et al., 2004), causing growth hindrance, early senescence, abscission, and ultimately, yield penalty in important crops (Dodd, 2005). Recent molecular investigations have exposed that ABA-dependent and independent drought-inducible gene expression (Shinozaki et al., 2007). The hormone signaling pathways cross-talk under drought conditions between ABA and ethylene act antagonistically among yield-attributing 
components (Wilkinson et al., 2012). Ethylene is responsible for leaf abscission in plants and subsequently, checks the water loss or enhanced water use efficiency under drought situations. Aside from these, ET production leads to a subsequent drop in ACC, suggesting the rate-dependent enzyme along the pathway of ET biosynthesis (feed-back inhibition) (Apelbaum and Yang, 1981). The transport of ACC from roots to shoots in the xylem vessels demonstrates the ET evolution in leaves (Liu H. Y. et al., 2006, 2007; Liu J. et al., 2006; Liu J. H. et al., 2006). However, in such leaves, ET changes do not affect the leaf elongation in maize under drought (Liu H. Y. et al., 2007). This implies that longdistance sink-source signals and leaf growth inhibition under drought are associated with ET and ACC activity (Schachtman and Goodger, 2008). The ethylene inhibitor (1-MCP) induced stomatal closure showed chemically driven stomatal closure instead of hydraulic signals dependency (Sharipova et al., 2012). Increasing levels of ABA and diminishing ET levels reveals in G. jamesonii under water deficit, and consequently, re-watering causes the reduction in transpiration rate $(\mathrm{Tr})$ and water probable of leaves (Olivella et al., 2000). Likewise, the ABA-mediated elongation of primary roots at low water potentials restricted ET production in maize (Spollen et al., 2000). Further, the ET production is antagonistically biased by endogenous $\mathrm{ABA}$ concentration during drought, controlling some drought responses in plants, e.g., root and leaf development (Tan and Thimann, 1989; Chaves et al., 2003). For instance, ABAinduced stomatal closure could antagonistically be potentially modulated by ET under drought (Wilkinson and Davies, 2009). Ethylene-induced leaf abscission in water-stressed Citrus plants is accompanied by $\mathrm{ABA}$ in roots. Thereby, providing new insights into the understanding of the mechanism of $\mathrm{ABA}$ and ET as primary signals under water deficit and regulation of leaf abscission (Wilkinson et al., 2012). A comprehensive understanding via a study of Arabidopsis mutant acs 7 with a lack of ET function showed the increased tolerance to multiple stresses linked to higher ABA accumulation (Dong et al., 2011). Thus, these findings suggest that the ratios of ET, ACC, and ABA regulate plant responses under water deficit conditions (Acharya and Assmann, 2009; Wilkinson and Davies, 2010; Wilkinson et al., 2012).

\section{Ethylene Mediated Physiological Changes Under Unfavorable Environmental Variables}

The ET mediates an array of physiological changes under salinity, drought, flooding, and other adverse environmental variables such as high temperature, heavy metal toxicity, etc. During heat stress, exogenous application of ethephon $\left(\mathrm{C}_{2} \mathrm{H}_{6} \mathrm{ClO}_{3} \mathrm{P}\right)$ regulates protein metabolism, antioxidant defense, enhances pollen thermos-tolerance in tomato (Jegadeesan et al., 2018), and heat shock factor expressions in rice (Wu and Yang, 2019). Moreover, it also provides thermo-tolerance in tomato seedlings under elevated $\mathrm{CO}_{2}$-induced heat stress via strengthening antioxidant defense and altering the expression of ERF1 and heat shock factors (Pan et al., 2019). Besides, ET plays a significant part under cold stress tolerance via stimulating proteins related to protein metabolism, lipid stability, and antioxidant defense (Hu et al., 2017). Moreover, the ERF057 in grapevine (Sun et al.,
2016), VaERF080, and VaERF087 in Arabidopsis (Sun et al., 2019) and SICBF1 in tomato (Yu F. et al., 2019) help in chilling stress tolerance. ET has a crucial role in improving the root architecture (Abozeid et al., 2017), root-shoot communications (Alves et al., 2017), regulating oxidative stress and biosynthesis, and transportation of antioxidants under oxidative stress in plants (Wang Y. et al., 2020). ET plays a key role under unfavorable environmental fluctuations and provides tolerance to plants via strengthening antioxidant defense, reducing oxidative stress, improved root-shoot communications, crosstalk with phytohormones, and signaling components, altering expressions of stress enzymes, genes, and proteins.

\section{Brassinosteroids, Salicylic Acid, Nitric Oxide, Jasmonic Acid, and Strigolactones Induced Physiological and Biochemical Mechanisms of Stress Tolerance \\ Brassinosteroids}

Brassinosteroids are a group of naturally occurring plant steroidal compounds with wide-ranging biological activity that have been given the stature of a phytohormone that offer the unique possibility of increasing crop yields through both changing plant metabolism and protecting plants from different environmental stresses (Figure 3). The brassinosteroids (BRs) regulate the growth and different developmental processes of plants (Yang et al., 2011; Iqbal et al., 2015). Initially, it was supposed that the BRs are physiologically related to the stimulation of stem elongation in plants (Mitchell et al., 1970; Fàbregas et al., 2018). Recently, numerous studies suggested BRs role as mediators of physiological, cellular, and molecular processes (i.e., development of anther, pollen production, stem elongation, vascular differentiation, root development, and cellulose biosynthesis) (Fàbregas et al., 2018; Javed et al., 2020). In addition, BR regulates cell division and promotes differentiation at the cellular level. Moreover, it regulates hypocotyl elongation and development of root, shoot, and leaf along with delaying senescence and reducing male sterility (Iqbal, 2015). Hence, mutants with BR impairment are observed to show short hypocotyl and petiole, delayed flowering, dark green colored leaves, reduced male fertility, dwarfism, etc. (Ye et al., 2010). There was impairment in the cell elongation with reduced parallel microtubule organization in Arabidopsis BR-deficient mutant, bull-I (Javed et al., 2020). Likewise, anomalous association and polar development of leaf and stem cells are observed in a rice mutant (BR-deficient dwarf1) that adversely affected the development of different organs (Hong et al., 2002). It was reported that BR effects largely depend on many factors including kinds of stress, plant species, growth stage, growth conditions (with or without stress), duration of stress, dose and its crosstalk with other hormones, growth regulators, and signaling molecules (Nolan et al., 2019; Yin et al., 2019).

The operation of the BR is regulated by BRASSINOSTEROIDINSENSITIVE1 (BRI1), a serine-threonine kinase plasma membrane receptor, and the inhibition of the BRI1 receptor is mediated by its C-terminal tail and inhibitor of the BRI1 kinase 1 (Wang et al., 2005; Wang and Chory, 2006). The BIN2 protein 
kinase is involved in the phosphorylation of the BES1/BZR1 transcription factor. It has also been found to be downstream of the BR signaling pathway (Wang et al., 2002; Yin et al., 2002). The 14-3-3 proteins are reported to hold the phosphorylated long-form of BES1 (i.e., BES1-L), BSU1, BIN2, and BES1/BZR1, and participate in the signaling of BR (Tang et al., 2008; Jiang et al., 2015). In plants, HXK1 (HEXOKINASE1) is the first known glucose sensor that induces hypocotyl elongation in darkness, mediated by BRs-dependent sugar. Thus, BR can potentially function downstream of HXK1 to regulate glucose-induced hypocotyl elongation (Zhang and He, 2015).

\section{Brassinosteroids Related to Tolerance to Abiotic Stress}

Brassinosteroid connects with other plant hormones related to stress tolerance conferring the ability of BR to play crucial roles in plant development and also advances tolerance in plants to a wide range of stresses (Ikekawa and Zhao, 1991; Ahammed et al., 2020), including heat, cold, drought, and salinity. This increase in stresses is generally correlated with higher expression of stress marker genes.

The increased expression of stress-responsive genes can be responsible for the higher stress tolerance in BR-treated plants. Several studies have confirmed the role of BRs in plant stress responses (Divi et al., 2010). The mechanisms by which BR controls plant stress responses and regulates the expression of stress response genes are not known. Fàbregas et al. (2018) showed that drought resistance is under the control of cell-typespecific BR signaling and that BRL3 overexpression activates an alternative pathway of BR signaling.

Salt Stress. The mitigation BRs of negative effects of salt stress have been shown to a wide range of plants (Ahammed et al., 2020). A study conducted by Anuradha and Rao (2001) reported that BR treated in rice seeds reduced the inhibitory effect of salt on germination. They reported the promotion of growth by BR under salt stress conditions was associated with enhanced levels of nucleic acids and soluble proteins. Although plants subjected to saline stress exhibited a reduction in all the morphophysiological and enzymatic attributes (NRA and NiRA), proline contents and enzymatic activities of antioxidants were enhanced in response to $\mathrm{NaCl}$ stress. However, deleterious effects induced by salinity were reduced if seeds were treated with epibrassinolide (EBL) before or after $\mathrm{NaCl}$ inhibitions (Shahid et al., 2011).

In eggplants, EBR treatment-induced enhanced tolerance to salt stress is manifested by the increased activity of antioxidant enzymes, decreased $\mathrm{Na}^{+}$and $\mathrm{Cl}^{-}$concentrations, and increased $\mathrm{K}^{+}$and $\mathrm{Ca}^{2+}$ concentrations. Similarly, EBR application can reduce the concentration of $\mathrm{NO}_{3}^{-}$and $\mathrm{NH}_{4}^{+}$in cucumber plants under salt stress (Yuan et al., 2012). Salt stress at level $150 \mathrm{mM}$ enhanced seeds germination of Eucalyptus camaldulensis but when seedling was grown hydroponically in salt, BR uptake through roots caused more damage (Sasse, 1999). Under salinity stress, exogenous EBR application in black locust reduced leaf $\mathrm{Na}^{+}$content and membrane leakage and improves the net photosynthetic rate, chlorophyll content, transpiration rate, stomatal conductance, and maximum quantum efficiency of PSII (Yue et al., 2018). When applied to a suitable concentration, brassinosteroid had a positive impact on secondary metabolite production in salt-treated peppermint (Çoban and Baydar, 2016). Ali et al. (2008) reported that EBR $(1 \mu \mathrm{M})$ can alleviate combined stress induced by $\mathrm{NaCl}$ and $\mathrm{NiCl}_{2}$ in Brassica juncea $\mathrm{BR}$ suggesting effective BRs in mitigating combined stress effects on plants. EBR applied in seed priming improves salt tolerance and induces total methylation, suggesting a role for $\mathrm{BR}$ in epigenetic modification under salt stress (Amraee et al., 2019).

Drought. Drought is an environmentally drastic stress that reduces crop productivity, especially in the semi-arid and arid region. In a study with cucumber plants, it was also demonstrated that BR treatment improves resistance to desiccation and high-temperature stress (Pustovoitova et al., 2001). Drought tolerance is closely associated with the accumulation of abscisic acid (ABA). Wang W. et al. (2019) showed that exogenous $\mathrm{BR}$ application can enhance the ABA level and mitigate the deleterious effects of drought on grapevine (Vitis vinifera L.) plants. In Chorispora bungeana, exogenous BR $(0.1 \mu \mathrm{M}$ EBR) application can enhance tolerance to drought caused by polyethene glycol (PEG) treatment (Li et al., 2011). Even Brassica juncea plants that experience weeklong drought stress at the early growth stage show reduced growth and photosynthetic rate even after 60 days. However, post-drought treatment with 28-homobrassinolide (HBL, $0.01 \mu \mathrm{M})$ at 30 days after sowing could remarkably improve both growth and photosynthesis after 60 days of sowing (Fariduddin et al., 2009). BR treatment can remarkably reduce the levels of ROS and lipid peroxidation under drought stress (Yuan et al., 2010). Although BR had a stimulatory growth effect under stress conditions when applied either as a seed treatment or foliar spray to drought-tolerant and drought-susceptible wheat varieties, overall, the drought-tolerant variety showed a higher response to $\mathrm{BR}$ application under water stress conditions. Increased water uptake and membrane stability and higher carbon dioxide and nitrogen assimilation rates in BR-treated plants under stress were correlated with BR-induced drought tolerance (Sairam, 1994).

Cold Stress. Low temperatures which induced chilling or freezing are considered as a handicap for plant production (Zhang et al., 2019). Cold stress-induced impairments in plants include decreased osmotic potential in the cells membrane, alterations in macromolecules activities, fluidity modifications, and also, mechanical constraints (Xiong and Zhu, 2002). In tomato (Solanum lycopersicum L.), mutants of BRs biosynthesis (dwf) show sensitivity to chilling stress, whereas overexpression of DWF results in an increased cold tolerance (Fang et al., 2019).

Cold stress also affects plant photosynthetic processes which are manifested by the reduction in the $\mathrm{CO}_{2}$ assimilation rate, photoinhibition at PSI and PSII, and decreased enzyme activity (Zhang et al., 2019). Similar to heat stress, ROS can also act as signal in mediating BR-regulated responses to cold stress tolerance (Cui et al., 2011).

Cross-Talk Between BRs and Different Hormones. Brassinosteroids can increase plant resistance to a range of stresses that lies in the complex interactions of BRs with 
other hormones. Since different plant hormones can regulate similar physiological processes, and cross-talk between different hormones can occur at the level of hormone biosynthesis, signal transduction or gene expression, it was proposed that $\mathrm{BR}$ regulates plant stress responses via cross-talk with other hormones (Wang Y. et al., 2020). BR and ABA signaling pathways emphasize the specific regulatory mechanisms between $\mathrm{ABA}$ and $\mathrm{BR}$ responses and harmonize plant growth and development under stress. BR signaling is essential for plant development, while ABA signaling is activated to ensure plants survive stress (Bulgakov and Avramenko, 2020). BRs regulates stress adaptation through the remodeling of cell wall, induce antioxidant defense, control adventitious, and lateral root developments in plants (Rao and Dixon, 2017; Kaya et al., 2019; Betti et al., 2021). Wang Y. et al. (2020) reported that in terms of modulating plant development and stress adaptation the crosstalk between BR and ABA, especially protein phosphorylation, protein stability control and downstream transcription control of key components of both pathways.

Cross-talk between BRs and auxins, GA, ABA, ethylene, and JA includes alteration in the expression of hormone biosynthetic genes and/or signaling intermediates (Finkelstein, 2013). The roles of ABA in cold, salt, and drought stresses (Zhu, 2002), and those of JA and ethylene in plant defense responses (Wang et al., 2002) are well-documented, the involvement of these hormones in BR-mediated stress tolerance with their crosstalk.

\section{Salicylic Acid}

Salicylic acid alleviates the adverse impacts of numerous abiotic stresses. For instance, the activities and levels of enzymes involved in the biosynthesis of SA are observed to be enhanced under salt stress in rice plants (Sawada et al., 2006; Hoque et al., 2020a,b). SA, itself, facilitated the restoration of membrane potential and averted the salinity stress persuaded $\mathrm{K}^{+}$loss via GORK channel in A. thaliana (Jayakannan et al., 2013). The SA enhanced salinity resistance in barley via an increase in the $\mathrm{Chl}$ and carotenoid contents and sustained membrane integrity by accumulating $\mathrm{K}^{+}$and soluble sugars (El-Tayeb, 2005). The $\mathrm{SA}$ regulated the photosynthetic process under salinity stress in mung bean cultivars by increasing the assimilation of nitrogen and sulfur, along with antioxidant metabolism (Nazar et al., 2011). Thus, both BRs and SA are well-avowed to advance stress tolerance by mitigating the harmful effects of abiotic stresses, especially salinity stress in plants (Ashraf et al., 2010; Bali et al., 2017).

\section{Nitric Oxide}

It is a volatile gasotransmitter having key functions as a regulator of vital plant growth processes viz., seed germination, root growth, floral transition, pollen tube growth, fruit ripening, photosynthesis, mitochondrial functionality, senescence, seed dormancy, gravitropism, stomatal movements, etc. (Siddiqui et al., 2011; Manai et al., 2014; Mostofa et al., 2015). Recently studies suggested that has crucial role during regulation of signaling network under normal and stress conditions, post-translational modifications, and regulation of oxidative stress through activation of antioxidant defense system (Sami et al., 2018; Sharma et al., 2020). NO cross-talk with other PGRs and regulate the fundamental processes under stress situations (Kumar and Pathak, 2018). Under drought stress, NO mediates the water status and associated enzymes to inhibit nutrient balance, oxidative defense, and primary and secondary metabolism, (Akram et al., 2017; Majeed et al., 2020; Wang X. et al., 2020). Under salinity stress, the endogenous supply of NO improved plant growth and increased osmotic pressure and cytoplasmic viscosity of plant cells (Dong et al., 2014). NO alleviates stress effects by mediating plant responses through upregulation of antioxidant defense system mediated by SA and $\mathrm{H}_{2} \mathrm{O}_{2}$ (Klessig et al., 2000; Mostofa et al., 2015; Singh et al., 2015).

\section{Jasmonic Acid}

Jasmonic acid and methyl jasmonates (MeJA) play a key part in improving plant stress tolerance via improving plant growth and physiological activities (i.e., reproductive processes, sex determination, fruit ripening, the formation of storage organ, senescence, interaction with other hormones, etc.) (Avanci et al., 2010; Cipollini, 2010; Nafie et al., 2011). Furthermore, being involved in chlorosis, antioxidant enzyme upregulation, senescence, seed and flower growth, and systemic resistance leads to protection against environmental stresses (Creelman and Mullet, 1997; Seltmann et al., 2010; Soares et al., 2010; Pieterse et al., 2012; Wasternack et al., 2012).

\section{Strigolactones}

Strigolactones are carotenoid-derived phytohormones that were first identified as germination stimulant in parasitic weeds and creating plant-microbe symbiotic relationship (Xie et al., 2010). Subsequently, strigolactone (SL) role in regulating the hyphal branching in the symbiotic association between plants and arbuscular mycorrhizal fungi (AMF) has also been reported (Akiyama et al., 2005). Furthermore, characterization of SLs have showed functional roles in root and shoot development, photomorphogenesis, leaf senescence, flower development, and suppression of shoot branching (Gomez-Roldan et al., 2008; Waters et al., 2017). The SLs have drawn special attention due to their physiological and molecular regulatory processes against various abiotic stresses. SL modulated stress responses through ABA was reported in Arabidopsis, where SL positively regulate stomatal closure (Ha et al., 2013). Contrary, cytokinin was found to negatively regulate the same process (Nishiyama et al., 2011). SL-loss of function mutants showed dense lateral root growth and inhibit adventitious root formation in many plant species (Arite et al., 2012; Rasmussen et al., 2013; Urquhart et al., 2015). Moreover, SL-deficient mutants are susceptible to water deficit and salt stresses inferring positive regulatory mechanisms in stress acclimatization (Cardinale et al., 2018). The SL modulated biological processes against environmental stresses are complex. This complexity is clearly reflected by the collective functions of abscisic acid, cytokinin, and SL in stomatal regulation and leaf senescence for plant adaptation to adverse environments (Lim et al., 2007; Czarnecki et al., 2013). Thus, these studies provide evidence to cross talks between SL and other phytohormones in response to adverse environments. 


\section{EXOGENOUS APPLICATION OF PLANT HORMONES TO SUPPORT STRESS RESISTANCE IN PLANTS}

Through exogenous supplementation of natural and synthetic PGRs, negative consequences of abiotic stress can be mitigated to a greater extent, although not completely. The PGRs like GA, $\mathrm{ABA}$, and $\mathrm{CK}$ are applied solely or in combination to improve plant stress tolerance. The application of these hormones $\left(\mathrm{GA}_{3}\right.$, $\mathrm{ABA}$, and $\mathrm{CK}$ ) showed a higher grain yield when applied by foliar spraying to dry seeded rice genotypes. They also increased the number of filled grains per panicle, thereby improved the harvest index. Moreover, $\mathrm{GA}_{3}, \mathrm{ABA}$, and $\mathrm{CK}$ also increased the activities of antioxidative enzymes (superoxide dismutase:SOD, and peroxide dismutase:POD) as a defense strategy against different altered soil moisture regimes (Rajinder et al., 2020). According to the report of Leshem et al. (1981), senescence can be delayed by the supplementation of $\mathrm{GA}_{3}$ at the grain filling stage. Whereas, the exogenous supply of $\mathrm{ABA}$ is observed to enhance the moisture stress resistance in plants (Wang et al., 2003; Li et al., 2004).

A reboot of drought-induced low plant growth could be achieved through the exogenous application of CK via improving photosynthesis, water use efficiency, and antioxidant metabolism of shoots (Kudoyarova et al., 2007; Ghanem et al., 2011; Merewitz et al., 2011; Nishiyama et al., 2011). CK protects plants under stressed environments from oxidative damage vis modulating the actions of antioxidants, particularly of CAT, SOD, and POD (Synkova et al., 2006; Zavaleta-Mancera et al., 2007; Zhang et al., 2008). An enhancement in the tiller production of cereals (barley, oat, and wheat) was observed in response to foliar application of SS-ethephon chlormequat chloride (CCC), a form of ethylene and trinexapac-ethyl and (TE) under stress. However, they remained ineffective in boosting shoot growth (Rajala and Peltonen-Sainio, 2001).

Exogenous SA application is reported to be positively connected with enhanced tolerance of plants to different abiotic stresses via stimulating the activity of antioxidant defense enzymes (Kaydan et al., 2007; Ashraf et al., 2010). Furthermore, SA plays numerous essential roles in photosynthetic rate, stomatal conductance, transpiration, switching antioxidative defense system and inhibiting $\mathrm{Na}^{+}$, and $\mathrm{Cl}^{-}$accumulation (Arfan et al., 2007; Gunes et al., 2007; Xu et al., 2008; Fayez and Bazaid, 2014). In the work of Jafar et al. (2012), the supply of SA improved the overall yield of two wheat cultivars grown under salinity stress. Foliar application of SA can decrease the contrary effects of salt stress by helping seedling growth, reinstating plant growth, and supporting the uptake of proline, $\mathrm{ABA}$, indole IAA, and CKs. Foliar application of phytohormones like auxin, IAA, CK, and BR showed stress alleviated stress by improving the antioxidant enzymes activities (SOD, POX, APX, and GPX) and accumulating the non-enzymatic antioxidants (tocopherol, ascorbate, and reduced GSH) (El-Mashad and Mohamed, 2012). The exogenous application of BRs and SA regulated different biochemical and physiological procedures to increase salt resistance in crop plants (Ashraf et al., 2010).
Exogenous applications of JA and MeJA created resilience in plants against stressful growth factors and adverse environments. For example, JA protected Zucchini against chilling stress, whereas in Mangifera indica, the treatment of MeJA enhanced fruit quality and improved chilling tolerance (Wang and Buta, 1994; Gonzalez-Aguilar et al., 2000). In other edible plants, the treatment of MeJA reduced the fungal development in grapefruit and upheld the post-harvest quality of papayas (Droby et al., 1999; Gonzalez-Aguilar et al., 2003). In addition, JA and MeJA, when supplemented exogenously to raspberry, have improved fruit quality via switching the antioxidant system (Ghasemnezhad and Javaherdashti, 2008; Wang K. et al., 2009). The process of germination was observed to be kindled in the dormant seeds with the exogenous applications of MeJA and JA (Ranjan and Lewak, 1992; Norastehnia et al., 2007; Dave et al., 2011). The application of MeJA and JA promoted essential oil biosynthesis in various oil crops (Rodriguez-Saona et al., 2001; Zhang et al., 2005). Thus, NO, ROS, calcium, ABA, ET, and SA together act as vital mediators of plant growth and development during JA signal transduction and synthesis.

\section{CONCLUSION}

Globally, the individual or combined effect of different abiotic stresses is seriously reducing the biological and economical yields of numerous crops which necessitates the development of biologically viable strategies to cope with these stresses. Endogenous biosynthesis of PGRs and their exogenous application as seed priming or foliar agents have the potential to mitigate the adverse impacts of abiotic stresses. The various types of PGRs interrelate with complex signaling systems to equilibrate the responses and thereby overcome damages caused by stress environmental conditions. Plants have developed complex mechanisms governed by multiple receptors to receive external signals and subsequently trigger an optimal response against stress conditions via PGRs that mainly control the defensive responses of plants by synergistic and antagonistic activities which has been referred to as signaling cross-talk. The interaction of phytohormones and stress is a well-known event in plant stress management. The list of these candidates involves both the classical and newly discovered phytohormones, and the list is continually growing with the advent of novel growth stimulatory phytochemicals. However, there is a dire need to investigate various factors which trigger the biosynthesis of PGRs in crop plants along their transportation receptors to increase our understanding of PGRs ameliorative role in stressed plants. Moreover, PGRs play a key role in association with crop growth stage, along with intensity and duration of abiotic stress, and need to be investigated in different crop species. PGRs signaling is very complex and at multilevel, affects the plant growth and developments. Therefore, the deep molecular understanding of plant hormone receptors, and ligands under multiple stresses can help to develop multiple stress tolerant crops. Likewise, the responses of plant hormone are modulated according to situations as singular stress or multiple stress. Therefore, the hormonal response under various stages and various stress 
factors are very crucial to understand the complex mechanism of abiotic stress tolerance. Moreover, the novel plant growth regulators such as salicylic acid, nitric oxide, strigolactones, and other signaling compounds have fundamental roles in regulating the stress and hormone response, which could be more focused in the near future to understand the crosstalk network of cell signaling. Consequently, in the recent years, various transcription factors such as MYB, MADS, WRKY, and

\section{REFERENCES}

Abadi, V. A. J. M., and Sepehri, M. (2016). Effect of Piriformospora indica and Azotobacter chroococcum on mitigation of zinc deficiency stress in wheat (Triticum aestivum L.). Symbiosis 69, 9-19. doi: 10.1007/s13199-015-0361-z

Abeles, F. B., Morgan, P. W., and Saltveit, M. E. Jr. (1992). Ethylene in Plant Biology, 2nd Edn. Academic Press.

Abozeid, A., Ying, Z., Lin, Y., Liu, J., Zhang, Z., and Tang, Z. (2017). Ethylene improves root system development under cadmium stress by modulating superoxide anion concentration in Arabidopsis thaliana. Front. Plant Sci. 8:253. doi: 10.3389/fpls.2017.00253

Abraham, E., Rigo, G., Szekely, G., Nagy, R., Koncz, C., and Szabados, L. (2003). Light dependent induction of proline biosynthesis by abscisic acid and salt stress is inhibited by brassinosteroid in Arabidopsis. Plant Mol. Biol. 51, 363-372. doi: 10.1023/A:1022043000516

Achard, P., Gong, F., Cheminant, S., Alioua, M., Hedden, P., and Genschik, P. (2008a). The cold inducible CBF1 factor-dependent signaling pathway modulates the accumulation of the growth-repressing DELLA proteins via its effect on gibberellin metabolism. Plant Cell 20, 2117-2129. doi: 10.1105/tpc.108.058941

Achard, P., Cheng, H., De Grauwe, L., Decat, J., Schoutteten, H., Moritz, T., et al. (2006). Integration of plant responses to environmentally activated phytohormonal signals. Science 311, 91-94. doi: 10.1126/science.1118642

Achard, P., Renou, J. P., Berthome, R., Harberd, N. P., and Genschik, P. (2008b). Plant DELLAs restrain growth and promote survival of adversity by reducing the levels of reactive oxygen species. Curr. Biol 18, 656-660. doi: 10.1016/j.cub.2008.04.034

Acharya, B. R., and Assmann, S. M. (2009). Hormone interactions in stomatal function. Plant Mol. Biol. 69, 451-462. doi: 10.1007/s11103-008-9427-0

Adesemoye, A. O., Obini, M., and Ugoji, E. O. (2008). Comparison of plant growth-promotion with Pseudomonas aeruginosa and Bacillus subtilis in three vegetables. Braz. J. Microbiol. 39, 423-426. doi: 10.1590/S1517-83822008000300003

Aerts, N., Pereira Mendes, M., and Van Wees, S. C. (2021). Multiple levels of crosstalk in hormone networks regulating plant defense. Plant J. 105, 489-504. doi: $10.1111 /$ tpj.15124

Afzal, I., Javed, T., Amirkhani, M., and Taylor, A. G. (2020). Modern seed technology: seed coating delivery systems for enhancing seed and crop performance. Agriculture 10:526. doi: 10.3390/agriculture10110526

Afzal, I., Saleem, S., Skalicky, M., Javed, T., Bakhtavar, M. A., Kamran, M., et al. (2021). Magnetic field treatments improves sunflower yield by inducing physiological and biochemical modulations in seeds. Molecules 26:2022. doi: 10.3390/molecules26072022

Agarwal, S., Sairam, R. K., Srivastava, G. C., and Meena, R. C. (2005). Changes in antioxidant enzymes activity and oxidative stress by abscisic acid and salicylic acid in wheat genotypes. Biol. Plantarum 49, 541-550. doi: 10.1007/s10535-005-0048-Z

Ahammed, G. J., Wang, Y., Mao, Q., Wu, M., Yan, Y., Ren, J., et al. (2020). Dopamine alleviates bisphenol A-induced phytotoxicity by enhancing antioxidant and detoxifcation potential in cucumber. Environ. Pollut. doi: 10.1016/j.envpol.2020.113957

Ahmad, Z., Waraich, E. A., Tariq, R. M. S., Iqbal, M. A., Ali, S., Soufan, W., et al. (2021). Foliar applied salicylic acid ameliorates water and salt stress by improving gas exchange and photosynthetic pigments in wheat. Pak. J. Bot. 53, 1553-1560. doi: 10.30848/PJB2021-5(17)
NAC had crucial roles in plant growth and development and also respond to multiple abiotic stresses regulated by PGRs, having future hopes to develop stress tolerant transgenics.

\section{AUTHOR CONTRIBUTIONS}

All authors listed have made a substantial, direct, and intellectual contribution to the work and approved it for publication.

Akiyama, K., Matsuzaki, K., and Hayashi, H. (2005). Plant sesquiterpenes induce hyphal branching in arbuscular mycorrhizal fungi. Nature 435, 824-827. doi: $10.1038 /$ nature 03608

Akram, N. A., Shafiq, F., and Ashraf, M. (2017). Ascorbic acid-a potential oxidant scavenger and its role in plant development and abiotic stress tolerance. Front. Plant Sci. 8:613. doi: 10.3389/fpls.2017.00613

Ali, B., Hayat, S., Fariduddin, Q., and Ahmad, A. (2008). 24-Epibrassinolide protects against the stress generated by salinity and nickel in Brassica juncea. Chemosphere 72, 1387-1392. doi: 10.1016/j.chemosphere.2008.04.012

Alvarez, S., Marsh, E. L., Schroeder, S. G., and Schachtman, D. P. (2008). Metabolomic and proteomic changes in the xylem sap of maize under drought. Plant Cell Environ. 31, 325-340. doi: 10.1111/j.1365-3040.2007.01770.x

Alves, L. R., Monteiro, C. C., Carvalho, R. F., Ribeiro, P. C., Tezotto, T., Azevedo, R. A., et al. (2017). Cadmium stress related to root-to-shoot communication depends on ethylene and auxin in tomato plants. Environ. Exp. Bot. 134, 102-115. doi: 10.1016/j.envexpbot.2016.11.008

Amraee, L., Rahmani, F., and Abdollahi Mandoulakani, B. (2019). 24Epibrassinolide alters DNA cytosine methylation of Linum usitatissimum L. under salinity stress. Plant Physiol. Biochem. 139, 478-484. doi: 10.1016/j.plaphy.2019.04.010

Anuradha, S., and Rao, S. S. R. (2001). Effect of brassinosteroids on salinity stress induced inhibition of seed germination and seedling growth of rice (Oryza sativa L.). Plant Growth Regul. 33, 151-153. doi: 10.1023/A:10175901 08484

Apelbaum, A., and Yang, S. F. (1981). Biosynthesis of stress ethylene induced by water deficit. Plant Physiol. 68, 594-596. doi: 10.1104/pp.68.3.594

Aquea, F., Federici, F., Moscoso, C., Vega, A., Jullian, P., Haseloff, J. I., et al. (2012). A molecular framework for the inhibition of Arabidopsis root growth in response to boron toxicity. Plant Cell Environ. 35, 719-734. doi: 10.1111/j.1365-3040.2011.02446.x

Arfan, M., Athar, H. R., and Ashraf, M. (2007). Does exogenous application of salicylic acid through the rooting medium modulate growth and photosynthetic capacity in two differently adapted spring wheat cultivars under salt stress? $\mathrm{J}$. Plant Physiol. 164, 685-694. doi: 10.1016/j.jplph.2006.05.010

Arite, T., Kameoka, H., and Kyozuka, J. (2012). Strigolactone positively controls crown root elongation in rice. J. Plant Growth Regul. 31, 165-172. doi: 10.1007/s00344-011-9228-6

Aroca, R., Porcel, R., and Ruiz-Lozano, J. M. (2012). Regulation of root water uptake under abiotic stress conditions. J. Exp. Bot. 63, 43-57. doi: $10.1093 /$ jxb/err266

Asad, M. A. U., Zakari, S. A., Zhao, Q., Zhou, L., Ye, Y., and Cheng, F. (2019). Abiotic stresses intervene with aba signaling to induce destructive metabolic pathways leading to death: premature leaf senescence in plants. Int. J. Mol. Sci. 20:E256. doi: 10.3390/ijms20020256

Ashraf, M., Akram, N. A., Arteca, R. N., and Foolad, M. R. (2010). The physiological, biochemical and molecular roles of brassinosteroids and salicylic acid in plant processes and salt tolerance. Crit. Rev. Plant Sci. 29, 162-190. doi: 10.1080/07352689.2010.483580

Atia, A., Barhoumi, Z., Debez, A., Hkiri, S., Abdelly, C., Smaoui, A., et al. (2018). Plant hormones: potent targets for engineering salinity tolerance in plants," in Salinity Responses and Tolerance in Plants, Vol. 1 (Cham: Springer), 159-184.

Avanci, N. C., Luche, D. D., Goldman, G. H., and Goldman, M. H. S. (2010). Jasmonates are phytohormones with multiple functions, including plant defense and reproduction. Genet. Mol. Res. 9, 484-505. doi: 10.4238/vol9-1gmr754 
Awad, M., El-Desoky, M. A., Ghallab, A., Kubes, J., Abdel-Mawly, S. E., Danish, S., et al. (2021). Ornamental plant efficiency for heavy metals phytoextraction from contaminated soils amended with organic materials. Molecules 26:3360. doi: 10.3390/molecules 26113360

Bai, T., Li, C., Li, C., Liang, D., and Ma, F. (2013). Contrasting hypoxia tolerance and adaptation in Malus species is linked to differences in stomatal behavior and photosynthesis. Physiol. Plant 147, 514-523. doi: 10.1111/j.1399-3054.2012.01683.x

Bai, T., Yin, R., Li, C., Ma, F., Yue, Z., and Shu, H. (2011). Comparative analysis of endogenous hormones in leaves and roots of two contrasting Malus species in response to hypoxia stress. J Plant Growth Regul. 30, 119-127. doi: 10.1007/s00344-010-9173-9

Bailey-Serres, J., and Voesenek, L. A. (2008). Flooding stress: acclimations and genetic diversity. Annu. Rev. Plant Biol. 59, 313-339. doi: 10.1146/annurev.arplant.59.032607.092752

Bailey-Serres, J., and Voesenek, L. A. C. J. (2010). Life in the balance: a signaling network controlling survival of flooding. Curr. Opin. Plant Biol. 13, 489-494. doi: $10.1016 /$ j.pbi.2010.08.002

Bali, S., Gautam, V., Kaur, P., Khanna, K., Kaur, R., Vig, A. P., et al. (2017). "Interaction of salicylic acid with plant hormones in plants under abiotic stress," in Salicylic Acid: A Multifaceted Hormone (Singapore: Springer), 201-219.

Bashandy, T., Guilleminot, J., Vernoux, T., Caparros-Ruiz, D., Ljung, K., Meyer, Y., et al. (2010). Interplay between the NADP-linked thioredoxin and glutathione systems in Arabidopsis auxin signaling. Plant Cell 22, 376-391. doi: 10.1105/tpc.109.071225

Bashar, K. K. (2018). Hormone dependent survival mechanisms of plants during post-waterlogging stress. Plant Signal. Behav. 13:e1529522. doi: $10.1080 / 15592324.2018 .1529522$

Basu, S., Clark, R. E., Bera, S., Casteel, C. L., and Crowder, D. W. (2021). Plant responses to multiple antagonists are mediated by order of attack and phytohormone crosstalk. bioRxiv. doi: 10.22541/au.161780423.34906884/v1

Bellaire, B. A., Carmody, J., Braud, J., Gossett, D. R., Banks, S. W., Cranlucas, M., et al. (2000). Involvement of abscisic acid-dependent and independent pathways in the upregulation of antioxidant enzyme activity during $\mathrm{NaCl}$ stress in cotton callus tissue. Free Radic Res. 33, 531-545. doi: 10.1080/10715760000301071

Bellegarde, F., Gojon, A., and Martin, A. (2017). Signals and players in the transcriptional regulation of root responses by local and systemic $\mathrm{N}$ signaling in Arabidopsis thaliana. J. Exp. Bot. 68, 2553-2565. doi: 10.1093/jxb/erx062

Benkova, E., Michniewicz, M., Sauer, M., Teichmann, T., Seifertova, D., Jürgens, G., et al. (2003). Local, efflux-dependent auxin gradients as a common module for plant organ formation. Cell 115, 591-602. doi: 10.1016/S0092-8674(03)00924-3

Benschop, J. J., Bou, J., Peeters, A. J., Wagemaker, N., Gühl, K., Ward, D., et al. (2006). Long-term submergence-induced elongation in Rumex palustrisrequires abscisic acid-dependent biosynthesis of Gibberellin1. Plant Physiol. 141, 1644-1652. doi: 10.1104/pp.106.082636

Benschop, J. J., Jackson, M. B., Gühl, K., Vreeburg, R. A., Croker, S. J., Peeters, A. J., et al. (2005). Contrasting interactions between ethylene and abscisic acid in Rumex species differing in submergence tolerance. Plant J. 44, 756-768. doi: 10.1111/j.1365-313X.2005.02563.x

Berens, M. L., Wolinska, K. W., Spaepen, S., Ziegler, J., Nobori, T., Nair, A., et al. (2019). Balancing trade-offs between biotic and abiotic stress responses through leaf age-dependent variation in stress hormone cross-talk. Proc. Nat. Acad. Sci. U.S.A. 116, 2364-2373. doi: 10.1073/pnas.1817233116

Betti, C., Della Rovere, F., Piacentini, D., Fattorini, L., Falasca, G., and Altamura, M. M. (2021). Jasmonates, ethylene and brassinosteroids control adventitious and lateral rooting as stress avoidance responses to heavy metals and metalloids. Biomolecules 11:77. doi: 10.3390/biom11010077

Bhargava, A., Clabaugh, I., To, J. P., Maxwell, B. B., Chiang, Y. H., Schaller, G. E., et al. (2013). Identification of cytokinin-responsive genes using microarray meta-analysis and RNA-Seq in Arabidopsis. Plant Physiol. 162, 272-294. doi: 10.1104/pp.113.217026

Bielach, A., Duclercq, J., Marhavý, P., and Benková, E. (2012). Genetic approach towards the identification of auxin-cytokinin crosstalk components involved in root development. Philos. T. R. Soc. B Biol. Sci. 367, 1469-1478. doi: 10.1098/rstb.2011.0233
Blancaflor, E. B., and Masson, P. H. (2003). Plant gravitropism. Unraveling the ups and downs of a complex process. Plant Physiol. 133, 1677-1690. doi: 10.1104/pp.103.032169

Blilou, I., Xu, J., Wildwater, M., Willemsen, V., Paponov, I., Friml, J., et al. (2005). The PIN auxin efflux facilitator network controls growth and patterning in Arabidopsis roots. Nature 433, 39-44. doi: 10.1038/nature 03184

Blumwald, E. (2000). Sodium transport and salt tolerance in plants. Curr. Opin. Cell Biol. 12, 431-434. doi: 10.1016/S0955-0674(00)00112-5

Bouguyon, E., Gojon, A., and Nacry, P. (2012). Nitrate sensing and signaling in plants. Semin. Cell. Dev. Biol. 23, 648-654. doi: 10.1016/j.semcdb.2012.01.004

Bouguyon, E., Perrine-Walker, F., Pervent, M., Rochette, J., Cuesta, C., Benkova, E., et al. (2016). Nitrate controls root development through posttranscriptional regulation of the NRT1. 1/NPF6. 3 transporter/sensor. Plant Physiol. 172, 1237-1248. doi: 10.1104/pp.16.01047

Bragina, T. V., Rodionova, N. A., and Grinieva, G. M. (2003). Ethylene production and activation of hydrolytic enzymes during acclimation of maize seedlings to partial flooding. Russ. J. Plant Physiol. 50, 794-798. doi: 10.1023/B:RUPP.0000003277.22914.6c

Bulgakov, V. P., and Avramenko, T. V. (2020). Linking brassinosteroid and ABA signaling in the context of stress acclimation. Int. J. Mol. Sci. 21:5108. doi: $10.3390 / \mathrm{ijms} 21145108$

Cabot, C., Sibole, J. V., Barcel'o, J., and Poschenrieder, C. (2009). Abscisic acid decreases leaf $\mathrm{Na}^{+}$exclusion in salt-treated Phaseolus vulgaris L. J. Plant Growth Regul. 28, 187-192. doi: 10.1007/s00344-009-9088-5

Cao, X., Wu, L., Wu, M., Zhu, C., Jin, Q., and Zhang, J. (2020). Abscisic acid mediated proline biosynthesis and antioxidant ability in roots of two different rice genotypes under hypoxic stress. BMC Plant Biol. 20:198. doi: 10.1186/s12870-020-02414-3

Cao, X., Yang, H., Shang, C., Ma, S., Liu, L., and Cheng, J. (2019). The roles of auxin biosynthesis YUCCA gene family in plants. Int. J. Mol. Sci. 20:6343. doi: $10.3390 /$ ijms 20246343

Cardinale, F., Korwin Krukowski, P., Schubert, A., and Visentin, I. (2018). Strigolactones: mediators of osmotic stress responses with a potential for agrochemical manipulation of crop resilience. J. Exp. Bot. doi: $10.1093 / \mathrm{jxb} / \mathrm{erx} 494$

Casanova-Sáez, R., Mateo-Bonmatí, E., and Ljung, K. (2021). Auxin metabolism in plants. Cold Spring Harbor Perspect. Biol. 13:a039867. doi: 10.1101/cshperspect.a039867

Casanova-Sáez, R., and Voß, U. (2019). Auxin metabolism controls developmental decisions in land plants. Trends Plant Sci. 24, 741-754. doi: 10.1016/j.tplants.2019.05.006

Cassab, G. I., Eapen, D., and Campos, M. E. (2013). Root hydrotropism: an update. Am. J. Bot. 100, 14-24. doi: 10.3732/ajb.1200306

Cerný, M., Kuklová, A., Hoehenwarter, W., Fragner, L., Novák, O., Rotková, G., et al. (2013). Proteome and metabolome profiling of cytokinin action in Arabidopsis identifying both distinct and similar responses to cytokinin downand up-regulation. J. Exp. Bot. 64, 4193-4206. doi: 10.1093/jxb/ert227

Chakraborty, S., Nguyen, B., Wasti, S. D., and Xu, G. (2019). Plant leucine-rich repeat receptor kinase (LRR-RK): structure, ligand perception, and activation mechanism. Molecules 24:3081. doi: 10.3390/molecules24173081

Chaves, M., Maroco, J., and Pereira, J. (2003). Understanding plant responses to drought from genes to the whole plant. Funct. Plant Biol. 30, 239-264. doi: 10.1071/FP02076

Chen, D., Shao, Q., Yin, L., Younis, A., and Zheng, B. (2019). Polyamine function in plants: development, and roles in abiotic stress responses. Front. Plant Sci. 9:1945. doi: 10.3389/fpls.2018.01945

Chen, Z., Liu, Y., Yin, Y., Liu, Q., Li, N., Li, X., et al. (2019). Expression of AtGA2ox1 enhances drought tolerance in maize. Plant Growth Regul. 89, 203-215. doi: 10.1007/s10725-019-00526-x

Cipollini, D. (2010). Constitutive expression of methyl jasmonates inducible responses delays reproduction and constrains fitness responses to nutrients in Arabidopsis thaliana. Evol. Ecol. 24, 59-68. doi: 10.1007/s10682-0089290-0

Claeys, H., De Bodt, S., and Inzé, D. (2014). Gibberellins and DELLAs: central nodes in growth regulatory networks. Trends Plant Sci. 19, 231-239. doi: $10.1016 /$ j.tplants.2013.10.001 
Claeys, H., Skirycz, A., Maleux, K., and Inze, D. (2012). DELLA signaling mediates stress-induced cell differentiation in Arabidopsis leaves through modulation of anaphase-promoting complex/cyclosome activity. Plant Physiol. 159, 739-747. doi: 10.1104/pp.112.195032

Clark, L. J. G., Gowing, D. J., Lark, R. M., Leeds-Harrison, P. B., Miller, A. J., Wells, D. M., et al. (2005). Sensing the physical and nutritional status of the root environment in the field: a review of progress and opportunities. J. Agric. Sci. 143, 347-358. doi: 10.1017/S0021859605005253

Çoban, Ö., and Baydar, N. G. (2016). Brassinosteroid effects on some physical and biochemical properties and secondary metabolite accumulation in peppermint (Mentha piperita L.) under salt stress. Industrial Crops Products 86, 251-258. doi: $10.1016 /$ j.indcrop.2016.03.049

Coelho Filho, M. A., Colebrook, E. H., Lloyd, D. P. A., Webster, C. P., Mooney, S. J., Phillips, A. L., et al. (2013). The involvement of gibberellin signalling in the effect of soil resistance to root penetration on leaf elongation and tiller number in wheat. Plant Soil 371, 81-94. doi: 10.1007/s11104-013-1662-8

Colebrook, E. H., Thomas, S. G., Phillips, A. L., and Hedden, P. (2014). The role of gibberellin signalling in plant responses to abiotic stress. J. Exp. Biol. 217, 67-75. doi: 10.1242/jeb.089938

Colmer, T. D., and Pedersen, O. (2008). Oxygen dynamics in submerged rice (Oryza sativa). New Phytol. 178, 326-334. doi: 10.1111/j.1469-8137.2007.02364.x

Cox, M. C., Benschop, J. J., Vreeburg, R. A., Wagemaker, C. A., Moritz, T., Peeters, A. J., et al. (2004). The roles of ethylene, auxin, abscisic acid, and gibberellin in the hyponastic growth of submerged Rumex palustris petioles. Plant Physiol. 136, 2948-2960. doi: 10.1104/pp.104.049197

Cox, M. C. H., Millenaar, F. F., de Jong van Berkel, Y. E. M., Peeters, A. J. M., and Voesenek, L. A. C. J. (2003). Plant movement. Submergence-induced petiole elongation in Rumex palustris depends on hyponastic growth. Plant Physiol. 132, 282-291. doi: 10.1104/pp.102.014548

Cramer, G. R., and Quarrie, S. A. (2002). Abscisic acid is correlated with the leaf growth inhibition of four genotypes of maize differing in their response to salinity. Funct. Plant Biol. 29, 111-115. doi: 10.1071/PP01131

Creelman, R. A., and Mullet, J. E. (1997). Biosynthesis and action of jasmonates in plants. Annu. Rev. Plant Physiol. Plant Mol. Biol. 48, 355-381. doi: 10.1146/annurev.arplant.48.1.355

Cui, J. X., Zhou, Y. H., Ding, J. G., Xia, X. J., Shi, K. A. I., Chen, S. C., et al. (2011). Role of nitric oxide in hydrogen peroxide-dependent induction of abiotic stress tolerance by brassinosteroids in cucumber. Plant Cell Environ. 34, 347-358. doi: $10.1111 / j .1365-3040.2010 .02248 . x$

Cutler, S. R., Rodriguez, P. L., Finkelstein, R. R., and Abrams, S. R. (2010). Abscisic acid: emergence of a core signaling network. Annu. Rev. Plant Biol. 61, 651-679. doi: 10.1146/annurev-arplant-042809-112122

Czarnecki, O., Yang, J., Weston, D. J., Tuskan, G. A., and Chen, J. G. (2013). A dual role of strigolactones inphosphate acquisition and utilization in plants. Int. J. Mol. Sci. 14, 7681-7701. doi: 10.3390/ijms14047681

Dan, H., Yang, G., and Zheng, Z. L. (2007). A negative regulatory role for auxin in sulphate deficiency response in Arabidopsis thaliana. Plant Mol. Biol. 63, 221-235. doi: 10.1007/s11103-006-9084-0

Das, S., and Kar, R. K. (2018). Abscisic acid mediated differential growth responses of root and shoot of Vigna radiata (L.) Wilczek seedlings under water stress. Plant Physiol. Biochem. 123, 213-221. doi: 10.1016/j.plaphy.2017.12.016

Dave, A., Hernández, M. L., He, Z., riotis, V. M., Vaistij, F. E., Larson, T. R., et al. (2011). 12-Oxo-phytodienoic acid accumulation during seed development represses seed germination in Arabidopsis. Plant Cell 23, 583-599. doi: $10.1105 /$ tpc. 110.081489

Davies, P. J. (2013). Plant Hormones: Physiology, Biochemistry and Molecular Biology. Heidelberg: Springer Science \& Business Media.

Davies, W. J., Metcalfe, J., Lodge, T. A., and da Costa, A. R. (1986). Plant growth substances and the regulation of growth under drought. Aust. J. Plant Physiol. 13, 105-125. doi: 10.1071/PP9860105

Di Mambro, R., De Ruvo, M., Pacifici, E., Salvi, E., Sozzani, R., Benfey, P. N., et al. (2017). Auxin minimum triggers the developmental switch from cell division to cell differentiation in the Arabidopsis root. Proc. Natl. Acad. Sci. U.S.A. 114, E7641-E7649. doi: 10.1073/pnas.1705833114

Divi, U. K., Rahman, T., and Krishna, P. (2010). Brassinosteroid-mediated stress tolerance in Arabidopsis shows interactions with abscisic acid, ethylene and salicylic acid pathways. BMC Plant Biol. 10:151. doi: 10.1186/1471-2229-10-151
Dodd, I. C. (2005). Root-to-shoot signaling: assessing the roles of 'up' in the up and down world of long-distance signaling in planta. Plant Soil 274, 251-270. doi: 10.1007/s11104-004-0966-0

Dong, H., Zhen, Z., Peng, J., Chang, L., Gong, Q., and Wang, N. N. (2011). Loss of ACS7 confers abiotic stress tolerance by modulating ABA sensitivity and accumulation in Arabidopsis. J. Exp. Bot. 62, 4875-4887. doi: $10.1093 / \mathrm{jxb} / \mathrm{err} 143$

Dong, Y. J., Jinc, S. S., Liu, S., Xu, L. L., and Kong, J. (2014). Effects of exogenous nitric oxide on growth of cotton seedlings under $\mathrm{NaCl}$ stress. J. Soil Sci. Plant. Nutr. 14, 1-13. doi: 10.4067/S0718-95162014005000001

Drew, M. C. (1997). Oxygen deficiency and root metabolism: injury and acclimation under hypoxia and anoxia. Annu. Rev. Plant Physiol. Plant Mol. Biol. 48, 223-250. doi: 10.1146/annurev.arplant.48.1.223

Droby, S., Porat, R., Cohen, L., Weiss, B., Shapiro, B., Philosoph-Hasas, S., et al. (1999). Suppressing green mold decay in grapefruit with postharvest jasmonates application. J. Am. Soc. Hortic. Sci. 124, 184-188. doi: 10.21273/JASHS.124.2.184

Duan, L., Dietrich, D., Ng, C. H., Chan, P. M., Bhalerao, R., Bennett, M. J., et al. (2013). Endodermal ABA signaling promotes lateral root quiescence during salt stress in Arabidopsis seedlings. Plant Cell 25, 324-341. doi: $10.1105 /$ tpc. 112.107227

EL Sabagh, A., Hossain, A., Barutçular, C., Iqbal, M. A., Islam, M. S., Fahad, S., et al. (2020a). "Consequences of salinity stress on the quality of crops and its mitigation strategies for sustainable crop production: an outlook of arid and semi-arid regions," in Environment, Climate, Plant and Vegetation Growth (Cham: Springer), 503-533.

EL Sabagh, A., Hossain, A., Barutçular, C., Islam, M. S., Ratnasekera, D., Kumar, N., et al. (2019b). Drought and salinity stress management for higher and sustainable canola (Brassica napus L.) production: a critical review. Aust. J. Crop Sci. 13, 88-96.

EL Sabagh, A., Hossain, A., Islam, M. S, Fahad, S., Ratnasekera, D., Meena, R. S., Wasaya, A., et al. (2020b). "Nitrogen fixation of legumes under the family fabaceae: adverse effect of abiotic stresses and mitigation strategies," in The Plant Family Fabaceae, eds M. Hasanuzzaman, S. Araújo, and S. Gill (Singapore: Springer), 75-111.

EL Sabagh, A., Hossain, A., Islam, M. S., Barutçular, C., Ratnasekera, D., Kumar, N., et al. (2019a). Sustainable soybean production and abiotic stress management in saline environments: a critical review. Aust. J. Crop Sci. 13, 228-236.

EL Sabagh, A., Hossain, A., Islam, M. S., Dinajpur, B., Iqbal, M. A., Aftab, T., et al. (2021a). "Prospective role of plant growth regulators for tolerance to abiotic stresses," in Plant Growth Regulators: Signalling Under Stress Conditions, eds T. Aftab, and K. R. Hakeem (Springer Nature Switzerland AG), 1-38. doi: 10.1007/978-3-030-61153-8_1

EL Sabagh, A., Çig, F., Seydoşoglu, S., Battaglia, M. L., Javed, T., Iqbal, M. A., et al. (2021b). "Salinity stress in maize: effects of stress and recent developments of tolerance for improvement," in Cereal Grains (London: IntechOpen), 1-20. doi: 10.5772/intechopen. 98745

El-Mashad, A. A. A., and Mohamed, H. I. (2012). Brassinolide alleviates salt stress and increases antioxidant activity of cowpea plants (Vigna sinensis). Protoplasma 249, 625-635. doi: 10.1007/s00709-0110300-7

El-Tayeb, M. A. (2005). Response of barley grains to the interactive effect of salinity and salicylic acid. Plant Growth Regul. 45, 215-224. doi: 10.1007/s10725-005-4928-1

Enders, T. A., and Strader, L. C. (2015). Auxin activity: past, present, and future. Am. J. Bot. 102, 180-196. doi: 10.3732/ajb.1400285

Eysholdt-Derzsó, E., and Sauter, M. (2019). Hypoxia and the group VII ethylene response transcription factor HRE2 promote adventitious root elongation in Arabidopsis. Plant Biol. 21, 103-108. doi: 10.1111/plb. 12873

Fàbregas, N., Lozano-Elena, F., Blasco-Escámez, D., Tohge, T., Martínez-Andújar, C., Albacete, A., et al. (2018). Overexpression of the vascular brassinosteroid receptor BRL3 confers drought resistance without penalizing plant growth. Nat. Commun. 9:4680. doi: 10.1038/s41467-018-06861-3

Faget, M., Nagel, K. A., Walter, A., Herrera, J. M., Jahnke, S., Schurr, U., et al. (2013). Root-root interactions -extending our perspective to be more inclusive of the range of theories in ecology and agriculture using in-vivo analyses. Ann. Bot. 112, 253-266. doi: 10.1093/aob/mcs296 
Fahad, S., Hussain, S., Matloob, A., Khan, F. A., Khaliq, A., Saud, S., et al. (2015). Phytohormones and plant responses to salinity stress: a review. Plant Growth Regul. 75, 391-404. doi: 10.1007/s10725-014-0013-y

Fahad, S., Ullah, A., Ali, U., Ali, E., Saud, S., Hakeem, K. R., et al. (2019). “Drought tolerance in plants role of phytohormones and scavenging system of ROS," in Plant Tolerance to Environmental Stress Role of Phytoprotectants, eds M. Hasanuzzaman, M. Fujita, H. Oku, and M. Tofazzal Islam (Boca Raton, FL: CRC Press), 103-113.

Falik, O., Mordoch, Y., Ben-Natan, D., Vanunu, M., Goldstein, O., and Novoplansky, A. (2013). Plant responsiveness to root-root communication of stress cues. Ann. Bot. 110, 271-280. doi: 10.1093/aob/mcs045

Fang, S., Clark, R. T., Zheng, Y., Iyer-Pascuzzi, A. S., Weitz, J. S., Kochian, L. V., et al. (2013). Genotypic recognition and spatial responses by rice roots. Proc. Natl. Acad Sci. U.S.A. 110, 2670-2675. doi: 10.1073/pnas.1222821110

Fang, P., Yan, M., Chi, C., Wang, M., Zhou, Y. H., Zhou, J., et al. (2019). Brassinosteroids act as a positive regulator of photoprotection in response to chilling stress. Plant Physiol. doi: 10.1104/pp.19.00088

Fariduddin, Q., Khanam, S., Hasan, S. A., Ali, B., Hayat, S., and Ahmad, A. (2009). Efect of 28-homobrassinolide on the drought stress-induced changes in photosynthesis and antioxidant system of Brassica juncea L. Acta Physiol. Plant 31, 889-897. doi: 10.1007/s11738-009-0302-7

Farooq, M., Wahid, A., Kobayashi, N., Fujita, D. B., and Basra, S. M. (2009). "Plant drought stress: effects, mechanisms and management," in Sustainable Agriculture (Dordrecht: Springer), 185-212.

Fayez, K. A., and Bazaid, S. A. (2014). Improving drought and salinity tolerance in barley by application of salicylic acid and potassium nitrate. J. Saudi Soc. Agric. Sci. 13, 45-55. doi: 10.1016/j.jssas.2013.01.001

Fernando, V. C. D., and Schroeder, D. F. (2016). "Role of ABA in Arabidopsis salt, drought and desiccation tolerance," in Abiotic and Biotic Stress in Plants - Recent Advances And Future Perspectives, eds A. K. Shanker and C. Shanker (London: IntechOpen), 507-524.

Finkelstein, R. (2013). Abscisic acid synthesis and response. Am. Soc. Plant Biol. 11:e0166. doi: 10.1199/tab.0166

Fu, Y., Yang, Y., Chen, S., Ning, N., and Hu, H. (2019). Arabidopsis IAR4 modulates primary root growth under salt stress through ROSmediated modulation of auxin distribution. Front. Plant Sci. 10:522. doi: $10.3389 /$ fpls.2019.00522

Fukao, T., and Bailey-Serres, J. (2008). Ethylene - a key regulator of submergence responses in rice. Plant Sci. 175, 43-51. doi: 10.1016/j.plantsci.2007. 12.002

Fukao, T., Xu, K., Ronald, P. C., and Bailey-Serres, J. (2006). A variable cluster of ethylene response factor-like genes regulates metabolic and developmental acclimation responses to submergence in rice. Plant Cell 18, 2021-2034. doi: $10.1105 /$ tpc. 106.043000

Fukuda, A., and Tanaka, Y. (2006). Effects of ABA, auxin, and gibberellin on the expression of genes for vacuolar $\mathrm{H}^{+}$- inorganic pyrophosphatase, $\mathrm{H}^{+}$ATPase subunitA, and $\mathrm{Na}^{+} / \mathrm{H}^{+}$antiporter in barley. Plant Physiol. Biochem. 44, 351-358. doi: 10.1016/j.plaphy.2006.06.012

Galvan-Ampudia, C. S., and Testerink, C. (2011). Salt stress signals shape the plant root. Curr. Opin. Plant Biol. 14, 296-302. doi: 10.1016/j.pbi.2011.03.019

Gan, S., and Amasino, R. M. (1995). Inhibition of leaf senescence by autoregulated production of cytokinin. Science 270, 1986-1988. doi: $10.1126 /$ science.270.5244.1986

Gent, L., and Forde, B. G. (2017). How do plants sense their nitrogen status? J. Exp. Bot. 68, 2531-2539. doi: 10.1093/jxb/erx013

Ghanem, M. E., Albacete, A., Smigocki, A. C., Frebort, I., Pospisilova, H., Marti'nez-Andujar, C., et al. (2011). Root-synthesized cytokinins improve shoot growth and fruit yield in salinized tomato (Solanum lycopersicum L.) plants. J. Exp. Bot. 62, 125-140. doi: 10.1093/jxb/erq266

Ghasemnezhad, M., and Javaherdashti, M. (2008). Effect of methyl jasmonate treatment on antioxidant capacity, internal quality and postharvest life of raspberry fruit. Caspian J. Environ. Sci. 6, 73-78.

Ghassemian, M., Nambara, E., Cutler, S., Kawaide, H., Kamiya, Y., and McCourt, P. (2000). Regulation of abscisic acid signaling by the ethylene response pathway in Arabidopsis. Plant Cell 12, 1117-1126. doi: 10.1105/tpc.12.7.1117

Giehl, R. F., Lima, J. E., and von Wirén, N. (2012). Localized iron supply triggers lateral root elongation in arabidopsis by altering the AUX1-mediated auxin distribution. Plant Cell 24, 33-49. doi: 10.1105/tpc.111.092973
Gojon, A., Krouk, G., Perrine-Walker, F., and Laugier, E. (2011). Nitrate transceptor(s) in plants. J. Exp. Bot. 62, 2299-2308. doi: 10.1093/jxb/erq419

Gomez-Roldan, V., Fermas, S., Brewer, P. B., Puech-Pagès, V., Dun, E. A., Pillot, J. P., et al. (2008). Strigolactone inhibition of shoot branching. Nature 455, 189-194. doi: 10.1038/nature07271

Gonzalez-Aguilar, G. A., Buta, J. G., and Wang, C. Y. (2003). Methyl jasmonate and modified atmosphere packaging (MAP) reduce decay and maintain postharvest quality of papaya "sunrise". Postharvest Biol. Technol. 28, 361-370. doi: 10.1016/S0925-5214(02)00200-4

Gonzalez-Aguilar, G. A., Fortiz, J., Cruz, R., Báez, R., and Wang, C. Y. (2000). Methyl jasmonate reduces chilling injury and maintains postharvest quality of mango fruit. J. Agric. Food Chem. 48, 515-519. doi: 10.1021/jf9902806

Gou, J., Strauss, S. H., Tsai, C. J., Fang, K., Chen, Y., Jiang, X., et al. (2010). Gibberellins regulate lateral root formation in Populus through interactions with auxin and other hormones. Plant Cell 22, 623-639. doi: 10.1105/tpc.109.073239

Guan, P., Ripoll, J. J., Wang, R., Vuong, L., Bailey-Steinitz, L. J., Ye, D., et al. (2017). Interacting TCP and NLP transcription factors control plant responses to nitrate availability. Proc. Natl. Acad. Sci. U.S.A. 114, 2419-2424. doi: 10.1073/pnas.1615676114

Gunes, A., Inal, A., Alpaslan, M., Eraslan, F., Bagci, E. G., and Cicek, N. (2007). Salicylic acid induced changes on some physiological parameters symptomatic for oxidative stress and mineral nutrition in maize (Zea mays L.) grown under salinity. J. Plant Physiol. 164, 728-736. doi: 10.1016/j.jplph.2005.12.009

Gurmani, A. R., Bano, A., Khan, S. U., Din, J., and Zhang, J. L. (2011). Alleviation of salt stress by seed treatment with abscisic acid (ABA), 6-benzylaminopurine (BA) and chlormequat chloride (CCC) optimizes ion and organic matter accumulation and increases yield of rice (Oryza sativa L.). Aust. J. Crop Sci. $5,1278-1285$.

Ha, C. V., Leyva-Gonzálezc, M. A., Osakabe, Y., Tran, U. T., Nishiyama, R., Watanabe, Y., et al. (2013). Positive regulatory role of strigolactone in plant responses to drought and salt stress. PNAS 111, 851-856. doi: 10.1073/pnas.1322135111

Hall, M. A., and Smith, A. R. (1995). Ethylene and the responses of plants to stress. Bulg. J. Plant Physiol. 21, 71-79.

Harris, J. (2015). Abscisic acid: hidden architect of root system structure. Plants 4, 548-572. doi: 10.3390/plants4030548

Hasanuzzaman, M., Bhuyan, M. H. M., Zulfiqar, F., Raza, A., Mohsin, S. M., Mahmud, J. A., et al. (2020). Reactive oxygen species and antioxidant defense in plants under abiotic stress:Revisiting the crucial role of a universal defense regulator. Antioxid. 9:681. doi: 10.3390/antiox9080681

Hattori, Y., Nagai, K., Furukawa, S., Song, X-J., Kawano, R., Sakakibara, H., et al. (2009). The ethylene response factors SNORKEL1 and SNORKEL2 allow rice to adapt to deep water. Nat. 460, 1026-1030. doi: 10.1038/nature08258

He, Y., Liu, Y., Li, M., Lamin-Samu, A. T., Yang, D., Yu, X., et al. (2021). The arabidopsis SMALL AUXIN UP RNA32 protein regulates ABA-mediated responses to drought stress. Front. Plant Sci. 12:259. doi: 10.3389/fpls.2021.625493

Hedden, P., and Thomas, S. G. (2012). Gibberellin biosynthesis and its regulation. Biochem. J. 444, 11-25. doi: 10.1042/BJ20120245

Holland, J. J., Roberts, D., and Liscum, E. (2009). Understanding phototropism: from Darwin to today. J. Exp. Bot. 60, 1969-1978. doi: 10.1093/jxb/erp113

Hong, D. K., Talha, J., Yao, Y., Zou, Z. Y., Fu, H. Y., Gao, S. J., et al. (2021). Silicon enhancement for endorsement of Xanthomonas albilineans infection in sugarcane. Ecotoxicol. Environ. Safety 220:112380. doi: 10.1016/j.ecoenv.2021.112380

Hong, Z., Ueguchi-Tanaka, M., Shimizu-Sato, S., Inukai, Y., Fujioka, S., Shimada, Y., et al. (2002). Loss-of-function of a rice brassinosteroid biosynthetic enzyme, C-6 oxidase, prevents the organized arrangement and polar elongation of cells in the leaves and stem. Plant J. 32, 495-508. doi: 10.1046/j.1365-313X.2002.01438.x

Hoque, T. S., Sohag, A. A. M., Burritt, D. J., and Hossain, M. A. (2020a). "Salicylic acid-mediated salt stress tolerance in plants," in Plant Phenolics, Vol. 1, Sustainable Agriculture, eds R. Lone, R. Shuab, A. N. Kamili, and Z. A. Reshi (Singapore: Springer), 1-38.

Hoque, T. S., Sohag, A. A. M., Kordrostami, M., Hossain, M. A., Islam, M. S., Burritt, D. J., et al. (2020b). "The effect of exposure to a combination of stressors on rice productivity and grain yields," in Rice Research for Quality Improvement: 
Genomics and Genetic Engineering, Vol. 1, Breeding Techniques and Abiotic Stress Tolerance, ed A. Roychoudhury (Singapore: Springer), 675-727.

Hossain, A., Farooq, M., EL Sabagh, A., Hasanuzzaman, M., Erman, M., and Islam, T. (2020). "Morphological, physiobiochemical and molecular adaptability of legumes of fabaceae to drought stress, with special reference to Medicago sativa L.” in The Plant Family Fabaceae, eds M. Hasanuzzaman, S. Araújo, and S. Gill (Singapore: Springer), 289-317.

Hu, L. Y., Li, D., Sun, K., Cao, W., Fu, W. Q., Zhang, W., et al. (2018). Mutualistic fungus Phomopsis liquidambari increases root aerenchyma formation through auxin-mediated ethylene accumulation in rice (Oryza sativa L.). Plant Physiol. Biochem. 130, 367-376. doi: 10.1016/j.plaphy.2018.07.018

Hu, Y. F., Zhou, G., Na, X. F., Yang, L., Nan, W. B., Liu, X., et al. (2013). Cadmium interferes with maintenance of auxin homeostasis in Arabidopsis seedlings. J. Plant Physiol. 170, 965-975. doi: 10.1016/j.jplph.2013.02.008

Hu, Z., Liu, A., Bi, A., Amombo, E., Gitau, M. M., Huang, X., et al. (2017). Identification of differentially expressed proteins in bermudagrass response to cold stress in the presence of ethylene. Environ. Exp. Bot. 139, 67-78. doi: 10.1016/j.envexpbot.2017.04.001

Hussain, T., Fatima, A., Suhel, M., Singh, S., Sharma, A., Prasad, S. M., et al. (2020). A brief appraisal of ethylene signaling under abiotic stress in plants. Plant Signal. Behav. 15:1782051. doi: 10.1080/15592324.2020.1782051

Iglesias, M. J., Terrile, M. C., Bartoli, C. G., D’Ippólito, S., and Casalongué, C. A. (2010). Auxin signaling participates in the adaptative response against oxidative stress and salinity by interacting with redox metabolism in Arabidopsis. Plant Mol. Biol. 74, 215-222. doi: 10.1007/s11103-010-9667-7

Ikekawa, N., and Zhao, Y. L. (1991). "Application of 24-epibrassinolide in agriculture," in Brassinosteroids -Chemistry, Bioactivity and Applications, ACS, Symp. Ser., eds H. G. Cutler, T. Yokota, and G. Adam (Washington, DC: American Chemical Society), 280-291.

Indu Lal, D., Dadrwal, B. K., Saha, D., Chand, S., Chauhan, J., Dey, P., et al. (2021). "Molecular advances in plant root system architecture response and redesigning for improved performance under unfavorable environments," in Frontiers in Plant-Soil Interaction (Academic Press), 49-82.

Iqbal, M. A. (2015). Improving the growth and yield of canola (Brassica napus L.) with seed treatment and foliar sprays of brassica (Brassica naups L.) and moringa (Moringaoleifera L.) leaf extracts. Am. Eur. J. Agric. Environ. Sci. 14, 1067-1073.

Iqbal, M. A., Abdul, H., Siddiqui, M. H., Imtiaz, H., Tanveer, A., Saira, I., et al. (2019). A meta-analysis of the impact of foliar feeding of micronutrients on productivity and revenue generation of forage crops. Planta Daninha 37:e019189237. doi: 10.1590/s0100-83582019370100046

Iqbal, M. A., and Iqbal, A. (2015). A study on dwindling agricultural water availability in irrigated plains of Pakistan and drip irrigation as a future life line. Am. Eur. J. Agric. Environ. Sci. 15, 184-190.

Iqbal, M. A., Tanveer, A., Zahoor, A., Abdul Manan, M. S., and Bilal, A. (2015). Overviewing comparative efficacy of different germination enhancement techniques for cereal crops. Am. Eur. J. Agric. Environ. Sci. 15, 1790-1802.

Iqbal, M. A., Asif, I., Nadeem, A., Rana, N. A., Haroon, Z. K., and Qaiser, M. (2014). Response of canola to foliar application of moringa (Moringa oleifera L.) and brassica (Brassica napus L.) water extracts. Int. J. Agric. Crop Sci. 7, 1431-1433.

Islam, M. S., Hasan, M. K., Islam, B., Renu, N. A., Hakim, M. A., Islam, M. R., et al. (2021). Responses of water and pigments status, dry matter partitioning, seed production, and traits of yield and quality to foliar application of GA3 in Mungbean (Vigna radiata L.). Front. Agron. 2:596850. doi: 10.3389/fagro.2020.596850

Islam, M. S., Akhter, M. M., El Sabagh, A., Liu, L. Y., Nguyen, N. T., Ueda, A., et al. (2011). Comparative studies on growth and physiological responses to saline and alkaline stresses of Foxtail millet (Setaria italica L.) and Proso millet (Panicum miliaceum L.). Aust. J. Crop Sci. 5, 1269-1277.

Jackson, M. B. (2002). Long-distance signaling from roots to shoots assessed: the flooding story. J. Exp. Bot. 53, 175-181. doi: 10.1093/jexbot/53.367.175

Jafar, M. Z., Farooq, M., Cheema, M. A., Afzal, I., Basra, S. M., Wahid, M. A., et al. (2012). Improving the performance of wheat by seed priming under saline conditions. J. Agron. Crop Sci. 198, 38-45. doi: 10.1111/j.1439-037X.2011.00485.X

Javed, T., Shabbir, R., Ali, A., Afzal, I., Zaheer, U., and Gao, S. J. (2020). Transcription factors in plant stress responses: challenges and potential for sugarcane improvement. Plants 9:491. doi: 10.3390/plants9040491
Javeed, H. M R., Ali, M., Skalicky, M., Nawaz, F., Qamar, R., Rehman, A. U., et al. (2021). Lipoic acid combined with melatonin mitigates oxidative stress and promotes root formation and growth in salt-stressed canola seedlings (Brassica napus L.). Molecules. 26:3147. doi: 10.3390/molecules 26113147

Jayakannan, M., Bose, J., Babourina, O., Rengel, Z., and Shabala, S. (2013). Salicylic acid improves salinity tolerance in Arabidopsis by restoring membrane potential and preventing salt-induced $\mathrm{K}^{+}$loss via a GORK channel. J. Exp. Bot. 64, 2255-2268. doi: 10.1093/jxb/ert085

Jegadeesan, S., Chaturvedi, P., Ghatak, A., Pressman, E., Meir, S., Faigenboim, A., et al. (2018). Proteomics of heat-stress and ethylene-mediated thermotolerance mechanisms in tomato pollen grains. Front. Plant Sci. 9:1558. doi: 10.3389/fpls.2018.01558

Ji, H., Pardo, J. M., Batelli, G., Van Oosten, M. J., Bressan, R. A., and Li, X. (2013). The salt overly sensitive (SOS) pathway: established and emerging roles. Mol. Plant 6, 275-286. doi: 10.1093/mp/sst017

Jiang, J., Zhang, C., and Wang, X. (2015). A recently evolved isoform of the transcription factor BES1 promotes brassinosteroid signaling and development in Arabidopsis thaliana. Plant Cell 27, 361-374. doi: 10.1105/tpc.114. 133678

Kabouw, P., Van Dam, N. M., van der Putten, W. H., and Biere, A. (2012). How genetic modification of roots affects rhizosphere processes and plant performance? J. Exp. Bot. 63, 3475-3483. doi: 10.1093/jxb/err399

Kaneko, M., Itoh, H., Inukai, Y., Sakamoto, T., Ueguchi-Tanaka, M., Ashikari, M., et al. (2003). Where do gibberellin biosynthesis and gibberellin signaling occur in rice plants? Plant J. 35, 104-115. doi: 10.1046/j.1365-313X.2003.01780.x

Kaneyasu, T., Kobayashi, A., Nakayama, M., Fujii, N., Takahashi, H., and Miyazawa, Y. (2007). Auxin response, but not its polar transport, plays a role in hydrotropism of Arabidopsis roots. J. Exp. Bot. 58, 1143-1150. doi: 10.1093/jxb/erl274

Kaya, C., Ashraf, M., Wijaya, L., and Ahmad, P. (2019). The putative role of endogenous nitric oxide in brassinosteroid-induced antioxidant defence system in pepper (Capsicum annuum L.) plants under water stress. Plant Physiol. Biochem. 143, 119-128. doi: 10.1016/j.plaphy.2019.08.024

Kaydan, D., Yagmur, M., and Okut, N. (2007). Effects of salicylic acid on the growth and some physiological characters in salt stressed wheat (Triticum aestivum L.). Tarim Bilim. Derg. 13, 114-119. doi: 10.1501/Tarimbil_00000 00444

Kazan, K. (2013). Auxin and the integration of environmental signals into plant root development. Ann. Bot. 112, 1655-1665. doi: 10.1093/aob/mct229

Keskin, B. C., Sarikaya, A. T., Yüksel, B., and Memon, A. R. (2010). Abscisic acid regulated gene expression in bread wheat (Triticum aestivum L.). Aust. J. Crop Sci. 4, 617-625.

Khan, M. I. R., Trivellini, A., Chhillar, H., Chopra, P., Ferrante, A., Khan, N. A., et al. (2020). The significance and functions of ethylene in flooding stress tolerance in plants. Environ. Exp. Bot. 179:104188. doi: 10.1016/j.envexpbot.2020.104188

Kiba, T., Kudo, T., Kojima, M., and Sakakibara, H. (2011). Hormonal control of nitrogen acquisition: roles of auxin, abscisic acid, and cytokinin. J. Exp. Bot. 62, 1399-1409. doi: 10.1093/jxb/erq410

Kim, J. I., Baek, D., Park, H. C., Chun, H. J., Oh, D. H., Lee, M. K., et al. (2013). Overexpression of Arabidopsis YUCCA6 in potato results in high-auxin developmental phenotypes and enhanced resistance to water deficit. Mol. Plant. 6, 337-349. doi: 10.1093/mp/sss100

Kim, T. H., Böhmer, M., Hu, H., Nishimura, N., and Schroeder, J. I. (2010). Guard cell signal transduction network: advances in understanding abscisic acid, $\mathrm{CO}_{2}$, and $\mathrm{Ca}^{2+}$ signaling. Annu. Rev. Plant Biol. 61, 561-591. doi: 10.1146/annurev-arplant-042809-112226

Kim, T. W., and Wang, Z. Y. (2010). Brassinosteroid signal transduction from receptor kinases to transcription factors. Annu. Rev. Plant Biol. 61, 681-704. doi: 10.1146/annurev.arplant.043008.092057

Kinoshita, N., Wang, H., Kasahara, H., Liu, J., MacPherson, C., Machida, Y., et al. (2012). IAA-Ala Resistant3, an evolutionarily conserved target of miR167, mediates Arabidopsis root architecture changes during high osmotic stress. Plant Cell 24, 3590-3602. doi: 10.1105/tpc.112.097006

Klay, I., Gouia, S., Liu, M., Mila, I., Khoudi, H., Bernadac, A., et al. (2018). Ethylene Response Factors (ERF) are differentially regulated by different abiotic stress types in tomato plants. Plant Sci. 274, 137-145. doi: $10.1016 /$ j.plantsci.2018.05.023 
Klessig, D. F., Durner, J., Noad, R., Navarre, D. A., Wendehenne, D., Kumar, D., et al. (2000). Nitric oxide and salicylic acid signaling in plant defense. Proc. Nat. Acad. Sci. USA. 97, 8849-8855. doi: 10.1073/pnas.97.16.8849

Kolbert, Z., Feigl, G., Freschi, L., and Poór, P. (2019). Gasotransmitters in action: nitric oxide-ethylene crosstalk during plant growth and abiotic stress responses. Antioxidants 8:167. doi: 10.3390/antiox8060167

Koornneef, M., Leon-Kloosterziel, K. M., Schwartz, S. H., and Zeevaart, J. A. D. (1998). The genetic and molecular dissection of abscisic acid biosynthesis and signal transduction in Arabidopsis. Plant Physiol. Biochem. 36, 83-89. doi: 10.1016/S0981-9428(98)80093-4

Krapp, A. (2015). Plant nitrogen assimilation and its regulation: a complex puzzle with missing pieces. Curr. Opin. Plant Biol. 25, 115-122. doi: 10.1016/j.pbi.2015.05.010

Kreps, J. A., Wu, Y., Chang, H.-S., Zhu, T., Wang, X., and Harper, J. F. (2002). Transcriptome changes for Arabidopsis in response to salt, osmotic, and cold stress. Plant Physiol. 130, 2129-2141. doi: 10.1104/pp.008532

Krouk, G., Lacombe, B., Bielach, A., Perrine-Walker, F., Malinska, K., Mounier, E., et al. (2010). Nitrate-regulated auxin transport by NRT1.1 defines a mechanism for nutrient sensing in plants. Dev. Cell. 18, 927-937. doi: 10.1016/j.devcel.2010.05.008

Krugman, T., Peleg, Z., Quansah, L., Chagué, V., Korol, A. B., Nevo, E., et al. (2011). Alteration in expression of hormone-related genes in wild emmer wheat roots associated with drought adaptation mechanisms. Funct. Integr. Genomic 11, 565-583. doi: 10.1007/s10142-0110231-6

Ku, Y. S., Sintaha, M., Cheung, M. Y., and Lam, H. M. (2018). Plant hormone signaling crosstalks between biotic and abiotic stress responses. Int. J. Mol. Sci. 19:3206. doi: 10.3390/ijms19103206

Kudoyarova, G. R., Vysotskaya, L. B., Cherkozyanova, A., and Dodd, I. C. (2007). Effect of partial root zone drying on the concentration of zeatin-type cytokinins in tomato (Solanum lycopersicum L.) xylem sap and leaves. J. Exp. Bot. 58, 161-168. doi: 10.1093/jxb/erl116

Kuiper, D. (1993). Sink strength: established and regulated by plant growth regulators. Plant Cell Environ. 16, 1025-1026. doi: 10.1111/j.1365-3040.1996.tb02052.x

Kukreja, S., Nandwal, A. S., Kumar, N., Sharma, S. K., Sharma, S. K., Unvi, V., et al. (2005). Plant water status, $\mathrm{H}_{2} \mathrm{O}_{2}$ scavenging enzymes, ethylene evolution and membrane integrity of Cicer arietinum as affected by salinity. Biol. Plant 49, 305-308. doi: 10.1007/s10535-005-5308-4

Kumar, P., and Pathak, S. (2018). Nitric oxide: a key driver of signaling in plants. MOJ Eco. Environ. Sci. 3, 145-148. doi: 10.15406/mojes.2018.03.00079

Kuppu, S., Mishra, N., Hu, R., Sun, L., Zhu, X., Shen, G., et al. (2013). Water-deficit inducible expression of a cytokinin biosynthetic gene IPT improves drought tolerance in cotton. PLoS ONE 8:e64190. doi: 10.1371/journal.pone.0064190

Lager, I. D. A., and réasson, O., Dunbar, T. L., and reasson, E., Escobar, M. A., and Rasmusson, A. G. (2010). Changes in external pH rapidly alter plant gene expression and modulate auxin and elicitor responses. Plant Cell Environ. 33, 1513-1528. doi: 10.1111/j.1365-3040.2010.02161.x

Lawlor, D. W., and Tezara, W. (2009). Causes of decreased photosynthetic rate and metabolic capacity in water-deficient leaf cells: a critical evaluation of mechanisms and integration of processes. Ann. Bot. 103, 561-579. doi: $10.1093 / \mathrm{aob} / \mathrm{mcn} 244$

Lay-Pruitt, K. S., and Takahashi, H. (2020). Integrating $\mathrm{N}$ signals and root growth: the role of nitrate transceptor NRT1. 1 in auxin-mediated lateral root development. J. Exp. Bot. 71:4365. doi: 10.1093/jxb/eraa243

Lee, M., Jung, J. H., Han, D. Y., Seo, P. J., Park, W. J., and Park, C. M. (2012). Activation of a flavin monooxygenase gene YUCCA7 enhances drought resistance in Arabidopsis. Planta 235, 923-938. doi: 10.1007/s00425-011-1552-3

Lee, S. C., Mustroph, A., Sasidharan, R., Vashisht, D., Pedersen, O., Oosumi, T., et al. (2011). Molecular characterization of the submergence response of the Arabidopsis thaliana ecotype Columbia. New Phytol. 190, 457-471. doi: 10.1111/j.1469-8137.2010.03590.x

Lequeux, H., Hermans, C., Lutts, S., and Verbruggen, N. (2010). Response to copper excess in Arabidopsis thaliana: impact on the root system architecture, hormone distribution, lignin accumulation and mineral profile. Plant Physiol. Biochem. 48, 673-682. doi: 10.1016/j.plaphy.2010.05.005

Leshem, Y. Y., Wurzburger, J., and Grossman, S. (1981). Cytokinin interaction with free radical metabolism and senescence effects on endogenous lipoxygenase and purine oxidation. Physiol. Planta 53, 9-12. doi: 10.1111/j.1399-3054.1981.tb05037.x

Li, C., Xu, H., Xu, J., Chun, X., and Ni, D. (2011). Effects of aluminum on ultrastructure and antioxidant activity in leaves of tea plant. Acta Physiol. Plant. 33, 973-978. doi: 10.1007/s11738-010-0629-0

Li, C., Yin, C., and Liu, S. (2004). Different responses of two contrasting Populus davidiana populations to exogenousabscisic acid application. Environ. Exp. Bot. 5, 237-246. doi: 10.1016/j.envexpbot.2003.11.001

Liao, X., Guo, X., Wang, Q., Wang, Y., Zhao, D., Yao, L., et al. (2017). Overexpression of MsDREB6.2 results in cytokinin-deficient developmental phenotypes and enhances drought tolerance in transgenic apple plants. Plant J. 89, 510-526. doi: 10.1111/tpj.13401

Lim, P. O., Kim, H. J., and Nam, H. G. (2007). Leaf senescence. Annu. Rev. Plant Biol. 58, 115-136. doi: 10.1146/annurev.arplant.57.032905.105316

Lin, I. S., Wu, Y. S., Chen, C. T., Chen, G. H., Hwang, S. G., Jauh, G. Y., et al. (2017). AtRBOH I confers submergence tolerance and is involved in auxinmediated signaling pathways under hypoxic stress. Plant Growth Regul. 83, 277-285. doi: 10.1007/s10725-017-0292-1

Liotenberg, S., North, H., and Marion-Poll, A. (1999). Molecular biology and regulation of abscisic acid biosynthesis in plants. Plant Physiol. Biochem. 37, 341-350. doi: 10.1016/S0981-9428(99)80040-0

Liu, B., Zhao, S., Li, P., Yin, Y., Niu, Q., Yan, J., et al. (2021). Plant buffering against the high-light stress-induced accumulation of CsGA2ox8 transcripts via alternative splicing to finely tune gibberellin levels and maintain hypocotyl elongation. Hort. Res. 8, 1-10. doi: 10.1038/s41438-020-00430-w

Liu, H. Y., Sun, W. N., Su, W. A., and Tang, Z. C. (2006). Co-regulation of water channels and potassium channels in rice. Physiol. Planta 128, 58-69. doi: 10.1111/j.1399-3054.2006.00709.x

Liu, H. Y., Yu, X., Cui, D. Y., Sun, M. H., Sun, W. N., et al. (2007). The role of water channel proteins and nitric oxide signalling in rice seed germination. Cell Res. 17, 638-649. doi: 10.1038/cr.2007.34

Liu, J., Yu, B. J., and Liu, Y. L. (2006). Effects of spermidine and spermine levels on salt tolerance associated with tonoplast H-ATPase and H-PPase activities in barley roots. Plant Growth Regul. 49, 119-126. doi: 10.1007/s10725-006-9001-1

Liu, J. H., Nada, K., Honda, C., Kitashiba, H., Wen, X. P., Pang, X. M., et al. (2006). Polyamine biosynthesis of apple callus under salt stress: importance of the arginine decarboxylase pathway in stress response. J. Exp. Bot. 57, 2589-2599. doi: $10.1093 /$ jxb/erl018

Liu, L., Nakamura, Y., Taliman, N. A., EL Sabagh, A., Moghaieb, R. E., and Saneoka, H. (2020). Differences in the growth and physiological responses of the leaves of Peucedanum japonicum and Hordeum vulgare exposed to salinity. Agriculture 10:317. doi: 10.3390/agriculture 10080317

Liu, P., Sun, F., Gao, R., and Dong, H. (2012). RAP2.6L overexpression delays waterlogging induced premature senescence by increasing stomatal closure more than antioxidant enzyme activity. Plant Mol. Biol. 79, 609-622. doi: 10.1007/s11103-012-9936-8

Liu, Q., Arnold, R. J., Yang, S. Z., Wu, J. Y., Li, Z. H., Li, Y., et al. (2019). Foliar application of exogenous polyamines to ameliorate drought-induced oxidative damage and physiological inhibition in Toona ciliata seedlings. Aust. For. 82, 139-150. doi: 10.1080/00049158.2019.1636349

Liu, Y., Li, D., Yan, J., Wang, K., Luo, H., and Zhang, W. (2019). MiR319 mediated salt tolerance by ethylene. Plant Biotechnol. J. 17, 2370-2383. doi: 10.1111/pbi.13154

Lo, S. F., Yang, S. Y., Chen, K. T., Hsing, Y. I., Zeevaart, J. A., Chen, L. J., et al. (2008). A novel class of gibberellin 2-oxidases control semidwarfism, tillering, and root development in rice. Plant Cell 20, 2603-2618. doi: 10.1105/tpc.108.060913

Lu, S., Su, W., Li, H., and Guo, Z. (2009). Abscisic acid improves drought tolerance of triploid bermudagrass and involves $\mathrm{H}_{2} \mathrm{O}_{2}^{-}$and NO induced antioxidant enzyme activities. Plant Physiol. Biochem. 47, 132-138. doi: 10.1016/j.plaphy.2008.10.006

Ma, N., Hu, C., Wan, L., Hu, Q., Xiong, J., and Zhang, C. (2017). Strigolactones improve plant growth, photosynthesis, and alleviate oxidative stress under salinity in rapeseed (Brassica napus L.) by regulating gene expression. Front. Plant Sci. 8:1671. doi: 10.3389/fpls.2017.01671

$\mathrm{Ma}$, Q. H. (2008). Genetic engineering of cytokinins and their application to agriculture. Crit. Rev. Biotechnol. 28, 213-232. doi: 10.1080/07388550802262205 
Ma, X., Zhang, J., and Huang, B. (2016). Cytokinin-mitigation of saltinduced leaf senescence in perennial ryegrass involving the activation of antioxidant systems and ionic balance. Environ. Exp. Bot. 125, 1-11. doi: 10.1016/j.envexpbot.2016.01.002

Majeed, S., Nawaz, F., Naeem, M., Ashraf, M. Y., Ejaz, S., Ahmad, K. S., et al. (2020). Nitric oxide regulates water status and associated enzymatic pathways to inhibit nutrients imbalance in maize (Zea mays L.) under drought stress. Plant Physiol Biochem.155, 147-160. doi: 10.1016/j.plaphy.2020.07.005

Malaga, S., Janeczko, A., Janowiak, F., Waligórski, P., Oklestkova, J., Dubas, E., et al. (2020). Involvement of homocastasterone, salicylic and abscisic acids in the regulation of drought and freezing tolerance in doubled haploid lines of winter barley. Plant Growth Regul. 90, 173-188. doi: 10.1007/s10725-019-00544-9

Manai, J., Kalai, T., Gouia, H., and Corpas, F. J. (2014). Exogenous nitric oxide (NO) ameliorates salinity-induced oxidative stress in tomato (Solanum lycopersicum) plants. J. Soil Sci. Plant Nutr. 14, 433-446. doi: $10.4067 /$ S0718-95162014005000034

Mao, C., He, J., Liu, L., Deng, Q., Yao, X., Liu, C., et al. (2020). OsNAC2 integrates auxin and cytokinin pathways to modulate rice root development. Plant Biotech. J. 18, 429-442. doi: 10.1111/pbi.13209

Martín-Rejano, E. M., Camacho-Cristóbal, J. J., Herrera-Rodríguez, M. B., Rexach, J., Navarro-Gochicoa, M. T., and González-Fontes, A. (2011). Auxin and ethylene are involved in the responses of root system architecture to low boron supply in Arabidopsis seedlings. Physiol. Planta 142, 170-178. doi: 10.1111/j.1399-3054.2011.01459.x

Mattiello, L., Kirst, M., da Silva, F. R., Jorge, R. A., and Menossi, M. (2010). Transcriptional profile of maize roots under acid soil growth. BMC Plant Biol. 10:196. doi: 10.1186/1471-2229-10-196

Mayak, S., Tirosh, T., and Glick, B. R. (2004a). Plant growth promoting bacteria that confer resistance to water stress in tomato and pepper. Plant Sci. 166, 525-530. doi: 10.1016/j.plantsci.2003.10.025

Mayak, S., Tirosh, T., and Glick, B. R. (2004b). Plant growth promoting bacteria that confer resistance in tomato to salt stress. Plant Physiol. Biochem. 42, 565-572. doi: 10.1016/j.plaphy.2004.05.009

McDonald, M. P., and Visser, E. J. W. (2003). A study of the interaction between auxin and ethylene in wild type and transgenic ethylene insensitive tobacco during adventitious root formation induced by stagnant root zone conditions. Plant Biol. 5, 550-556. doi: 10.1055/s-2003-44790

Merewitz, E. B., Gianfagna, T., and Huang, B. (2011). Protein accumulation in leaves and roots associated with improve drought tolerance in creeping bentgrass expressing an ipt gene for cytokinin synthesis. J. Exp. Bot. 62, 5311-5333. doi: 10.1093/jxb/err166

Mitchell, J. W., Mandava, N., Worley, J. F., Plimmer, J. R., and Smith, M. V. (1970). Brassins: a new family of plant hormones from rape pollen. Nature 225, 1065-1066. doi: 10.1038/2251065a0

Miyazawa, Y., Moriwaki, T., Uchida, M., Kobayashi, A., Fujii, N., and Takahashi, H. (2012). Overexpression of MIZU-KUSSEI1 enhances root hydrotropic response by retaining cell viability under hydrostimulated condition in Arabidopsis thaliana. Plant Cell Physiol. 53, 1926-1933. doi: $10.1093 / \mathrm{pcp} / \mathrm{pcs} 129$

Morgan, P. W. (1990). "Effects of abiotic stresses on plant hormone systems," in Stress Responses in Plants: Adaptation and Acclimation Mechanisms (Hoboken, NJ: Wiley-Liss Inc), 113-146.

Mostofa, M. G., Fujita, M., and Tran, L. S. P. (2015). Nitric oxide mediates hydrogen peroxide- and salicylic acid-induced salt tolerance in rice (Oryza sativa L.) seedlings. Plant Growth Regul. 77, 265-277. doi: 10.1007/s10725-015-0061-y

Muday, G. K., Rahman, A., and Binder, B. M. (2012). Auxin and ethylene: collaborators or competitors? Trends Plant Sci. 17, 181-195. doi: 10.1016/j.tplants.2012.02.001

Müller, D., Waldie, T., Miyawaki, K., To, J. P., Melnyk, C. W., Kieber, J. J., et al. (2015). Cytokinin is required for escape but not release from auxin mediated apical dominance. Plant J. 82, 874-886. doi: 10.1111/tpj. 12862

Nafie, E., Hathout, T., Al, S., and $\mathrm{Al}$, M. (2011). Jasmonic acid elicits oxidative defense and detoxification systems in Cucumis melo L. cells. Braz. J. Plant Physiol. 23, 161-174. doi: 10.1590/S1677-04202011000 200008

Nam, Y. J., Tran, L. S. P., Kojima, M., Sakakibara, H., Nishiyama, R., and Shin, R. (2012). Regulatory roles of cytokinins and cytokinin signaling in response to potassium deficiency in Arabidopsis. PLoS ONE 7:e47797. doi: 10.1371/journal.pone.0047797

Nan, R., Carman, J. G., and Salisbury, F. B. (2002). Water stress, $\mathrm{CO}_{2}$ and photoperiod influence hormone levels in wheat. J. Plant Physiol. 159, 307-312. doi: 10.1078/0176-1617-00703

Nawaz, M., and Wang, Z. (2020). Abscisic acid and glycine betaine mediated tolerance mechanisms under drought stress and recovery in Axonopus compressus: a new insight. Sci. Rep. 10, 1-10. doi: 10.1038/s41598-020-6 $3447-0$

Nazar, R., Iqbal, N., Syeed, S., and Khan, N. A. (2011). Salicylic acid alleviates decreases in photosynthesis under salt stress by enhancing nitrogen and sulfur assimilation and antioxidant metabolism differentially in two mungbean cultivars. J. Plant Physiol. 168, 807-815. doi: 10.1016/j.jplph.2010.11.001

Nazir, F., Fariduddin, Q., and Khan, T. A. (2020). Hydrogen peroxide as a signalling molecule in plants and its crosstalk with other plant growth regulators under heavy metal stress. Chemosphere 252:126486. doi: $10.1016 /$ j.chemosphere.2020.126486

Nemhauser, J. L., Hong, F., and Chory, J. (2006). Different plant hormones regulate similar processes through largely nonoverlapping transcriptional responses. Cell 126, 467-475. doi: 10.1016/j.cell.2006.05.050

Nishiyama, R., Watanabe, Y., Fujita, Y., Le, D. T., Kojima, M., Werner, T., et al. (2011). Analysis of cytokinin mutants and regulation of cytokinin metabolic genes reveals important regulatory roles of cytokinins in drought, salt and abscisic acid responses, and abscisic acid biosynthesis. Plant Cell 23, 2169-2183. doi: $10.1105 /$ tpc. 111.087395

Nolan, T., Vukasinovic, N., Liu, D., Russinova, E., and Yin, Y. (2019). Brassinosteroids: multi-dimensional regulators of plant growth, development, and stress responses. Plant Cell. doi: 10.1105/tpc.19.00335

Norastehnia, A., Sajedi, R. H., and Nojavan-Asghari, M. (2007). Inhibitory effects of methyl jasmonate on seed germination in maize (Zea mays): effect on $\alpha$-amylase activity and ethylene production. Gen. Appl. Plant Physiol. 33, 13-23.

O'Brien, J. A., and Benkova, E. (2013). Cytokinin cross-talking during biotic and abiotic stress responses. Front. Plant Sci. 4:451. doi: 10.3389/fpls.2013.00451

Olivella, C., Biel, C., Savé, R., and Vendrell, M. (2000). Hormonal and physiological responses of Gerbera jamesonii to flooding stress. Hort. Sci. 35, 222-225. doi: 10.21273/HORTSCI.35.2.222

Olszewski, N., Sun, T. P., and Gubler, F. (2002). Gibberellin signaling: biosynthesis, catabolism, and response pathways. Plant Cell 14, S61-S80. doi: $10.1105 /$ tpc. 010476

Pan, C., Zhang, H., Ma, Q., Fan, F., Fu, R., Ahammed, G. J., et al. (2019). Role of ethylene biosynthesis and signaling in elevated $\mathrm{CO}_{2}$ induced heat stress response in tomato. Planta 250, 563-572. doi: 10.1007/s00425-019-03192-5

Parida, A. K., and Das, A. B. (2005). Salt tolerance and salinity effects on plants: a review. Ecotoxicol. Environ. Saf. 60, 324-349. doi: 10.1016/j.ecoenv.2004. 06.010

Parlanti, S., Kudahettige, N. P., Lombardi, L., Mensuali-Sodi, A., Alpi, A., Perata, P., et al. (2011). Distinct mechanisms for aerenchyma formation in leaf sheaths of rice genotypes displaying a quiescence or escape strategy for flooding tolerance. Ann. Bot. 107, 1335-1343. doi: 10.1093/aob/mcr086

Pasternak, T., Palme, K., and Paponov, I. A. (2020). Glutathione enhances auxin sensitivity in arabidopsis roots. Biomolecules 10:1550. doi: $10.3390 /$ biom 10111550

Pavlu, J., Novák, J., Koukalová, V., Luklová, M., Brzobohatý, B., and Cerny, M. (2018). Cytokinin at the crossroads of abiotic stress signalling pathways. Int. J. Mol. Sci. 19:2450. doi: 10.3390/ijms190 82450

Peleg, Z., and Blumwald, E. (2011). Hormone balance and abiotic stress tolerance in crop plants. Curr. Opin. Plant Biol. 14, 290-295. doi: 10.1016/j.pbi.2011.02.001

Peleg, Z., Reguera, M., Tumimbang, E., Walia, H., and Blumwald, E. (2011). Cytokinin-mediated source/sink modifications improve drought tolerance and increase grain yield in rice under water-stress. Plant Biotechnol. J. 9, 747-758. doi: 10.1111/j.1467-7652.2010.00584.x

Pérez-Torres, C. A., López-Bucio, J., Cruz-Ramírez, A., Ibarra-Laclette, E., Dharmasiri, S., Estelle, M., et al. (2008). Phosphate availability alters lateral root development in Arabidopsis by modulating auxin sensitivity via a mechanism involving the TIR1 auxin receptor. Plant Cell 20, 3258-3272. doi: $10.1105 /$ tpc. 108.058719 
Peto, A., Lehotai, N., Lozano-Juste, J., León, J., Tari, I., Erdei, L., et al. (2011). Involvement of nitric oxide and auxin in signal transduction of copper-induced morphological responses in Arabidopsis seedlings. Ann. Bot. 108, 449-457. doi: $10.1093 / \mathrm{aob} / \mathrm{mcr} 176$

Pieterse, C. M. J., Van Der Does, D., Zamioudis, C., Leon-Reyes, A., and Van Wees, S. C. (2012). Hormonal modulation of plant immunity. Annu. Rev. Cell. Dev. Biol. 28, 489-521. doi: 10.1146/annurev-cellbio-092910-154055

Polko, J. K., van Zanten, M., van Rooij, J. A., Marée, A. F. M., Voesenek, L. A. C. J, Peeters, A. J. M., and Pierik, R. (2012). Ethylene-induced differential petiole growth in Arabidopsis thaliana involves local microtubule reorientation and cell expansion. New Phytol. 193, 339-348. doi: 10.1111/j.1469-8137.2011.03920.x

Polko, J. K., Voesenek, L. A. C. J., Peeters, A. J. M., and Pierik, R. (2011). Petiole hyponasty: an ethylene-driven, adaptive response to changes in the environment. AoB Plants. 2011:plr031. doi: 10.1093/aobpla/plr031

Pospíšilová, H., Jiskrová, E., Vojta, P., Mrízová, K., Kokáš, F., Cudejková, M. M., et al. (2016). Transgenic barley overexpressing a cytokinin dehydrogenase gene shows greater tolerance to drought stress. New Biotechnol. 33, 692-705. doi: 10.1016/j.nbt.2015.12.005

Potters, G., Pasternak, T. P., Guisez, Y., Palme, K. J., and Jansen, M. A. K. (2007). Stress-induced morphogenic responses: growing out of trouble? Trends Plant Sci. 12, 98-105. doi: 10.1016/j.tplants.2007.01.004

Poza-Viejo, L., Abreu, I., González-García, M. P., Allauca, P., Bonilla, I., Bolaños, L., et al. (2018). Boron deficiency inhibits root growth by controlling meristem activity under cytokinin regulation. Plant Sci. 270, 176-189. doi: 10.1016/j.plantsci.2018.02.005

Prigge, M. J., Platre, M., Kadakia, N., Zhang, Y., Greenham, K., Whitnie Szutu, W., et al. (2020). Genetic analysis of the Arabidopsis TIR1/AFB auxin receptors reveals both overlapping and specialized functions. Elife 9:e54740. doi: 10.7554/eLife.54740.sa2

Puertolas, J., Conesa, M. R., Ballester, C., and Dodd, I. C. (2015). Local root abscisic acid (ABA) accumulation depends on the spatial distribution of soil moisture in potato: implications for ABA signaling under heterogeneous soil drying. J. Exp. Bot. 66, 2325-2334. doi: 10.1093/jxb/eru501

Pustovoitova, T. N., Zhdanova, N. E., and Zholkevich, V. N. (2001). "Epibrassinolide increases plant drought resistance," in Doklady Biochemistry and Biophysics, Vol. 376 (Kluwer Academic Publishers-Plenum Publishers), 36-38.

Qin, H., Gu, Q., Zhang, J., Sun, L., Kuppu, S., Zhang, Y., et al. (2011). Regulated expression of an isopentenyl transferase gene (IPT) in peanut significantly improves drought tolerance and increases yield under field conditions. Plant Cell Physiol. 52, 1904-1914. doi: 10.1093/pcp/pcr125

Rademacher, W. (2000). Growth retardants: effects on gibberellin biosynthesis and other metabolic pathways. Annu. Rev. Plant Physiol. Plant Mol. Biol. 51, 501-531. doi: 10.1146/annurev.arplant.51.1.501

Rahayu, Y. S., Walch-Liu, P., Neumann, G., Römheld, V., Von Wirén, N., and Bangerth, F. (2005). Root-derived cytokinins as long-distance signals for $\mathrm{NO}_{3}$-induced stimulation of leaf growth. J. Exp. Bot. 56, 1143-1152. doi: $10.1093 / j x b /$ eri107

Rahman, A. (2013). Auxin: a regulator of cold stress response. Physiol. Planta 147, 28-35. doi: 10.1111/j.1399-3054.2012.01617.x

Rajala, A., and Peltonen-Sainio, P. (2001). Plant growth regulator effects on spring cereal root and shoot growth. Agron. J. 93, 936-943. doi: 10.2134/agronj2001.934936x

Rajinder, P., Gulshan, M., Sardana, V., Asthir, B., and Chauhan, B. S. (2020). Performance of dry-seeded rice genotypes under varied soil moisture regimes and foliar-applied hormones. Plants 9:539. doi: 10.3390/plants9040539

Rampey, R. A., LeClere, S., Kowalczyk, M., Ljung, K., Sandberg, G., and Bartel, B. (2004). A family of auxin-conjugate hydrolases that contributes to free indole-3-acetic acid levels during Arabidopsis germination. Plant Physiol. 135, 978-988. doi: 10.1104/pp.104.039677

Ranjan, R., and Lewak, S. (1992). Jasmonic acid promotes germination and lipase activity in non-stratified apple embryos. Physiol Plant. 86, 335-339. doi: 10.1034/j.1399-3054.1992.860222.x

Rao, X., and Dixon, R. A. (2017). Brassinosteroid mediated cell wall remodeling in grasses under abiotic stress. Front Plant Sci. 8:806. doi: 10.3389/fpls.2017.00806

Rasmussen, A., Depuydt, S., Goormachtig, S., and Geelen, D. (2013). Strigolactones fine-tune the root system. Planta 238, 615-626. doi: $10.1007 / \mathrm{s} 00425-013-1911-3$
Rauf, M., Arif, M., Fisahn, J., Xue, G. P., Balazadeh, S., and Mueller-Roeber, B. (2013). NAC transcription factor speedy hyponastic growth regulates flooding-induced leaf movement in Arabidopsis. Plant Cell 25, 4941-4955. doi: 10.1105/tpc.113.117861

Raza, A., Ashraf, F., Zou, X., Zhang, X., and Tosif, H. (2020). "Plant adaptation and tolerance to environmental stresses: mechanisms and perspectives," in Plant Ecophysiology and Adaptation Under Climate Change: Mechanisms and Perspectives I. (Singapore: Springer), 117-145.

Raza, A., Mehmood, S. S., Tabassum, J., and Batool, R. (2019b). “Targeting plant hormones to develop abiotic stress resistance in wheat," in Wheat Production in Changing Environments (Singapore: Springer), 557-577.

Raza, A., Razzaq, A., Mehmood, S. S., Zou, X., Zhang, X., Lv, Y., et al. (2019a). Impact of climate change on crops adaptation and strategies to tackle its outcome: a review. Plants 8:34. doi: 10.3390/plants8020034

Reguera, M., Peleg, Z., Abdel-Tawab, Y. M., Tumimbang, E. B., Delatorre, C. A., and Blumwald, E. (2013). Stress-induced cytokinin synthesis increases drought tolerance through the coordinated regulation of carbon and nitrogen assimilation in rice. Plant Physiol. 163, 1609-1622. doi: 10.1104/pp.113.227702

Remy, E., Cabrito, T. R., Baster, P., Batista, R. A., Teixeira, M. C., Friml, J., et al. (2013). A major facilitator superfamily transporter plays a dual role in polar auxin transport and drought stress tolerance in Arabidopsis. Plant Cell 25, 901-926. doi: 10.1105/tpc.113.110353

Ribba, T., Garrido, F., and O'Brien, J. A. (2020). Auxin-mediated responses under salt stress: from developmental regulation to biotechnological applications. J. Exp. Bot. 71, 3843-3853. doi: 10.1093/jxb/eraa241

Richard, A. J., and El-Abd, S. O. (1989). Prevention of salt-induced epinasty by a-aminooxyacetic acid and cobalt. Plant Growth Regul. 8, 315-323. doi: 10.1007/BF00024662

Rieu, I., Eriksson, S., Powers, S. J., Gong, F., Griffiths, J., Woolley, L., et al. (2008). Genetic analysis reveals that C19-GA 2-oxidation is a major gibberellin inactivation pathway in Arabidopsis. Plant Cell 20, 2420-2436. doi: $10.1105 /$ tpc. 108.058818

Rigas, S., Debrosses, G., Haralampidis, K., Vicente-Agullo, F., Feldmann, K. A., Grabov, A., et al. (2001). TRH1 encodes a potassium transporter required for tip growth in Arabidopsis root hairs. Plant Cell 13, 139-151. doi: $10.1105 /$ tpc.13.1.139

Rivero, R. M., Gimeno, J., Van Deynze, A., Walia, H., and Blumwald, E. (2010). Enhanced cytokinin synthesis in tobacco plants expressing $P_{S A R K}$ : IPT prevents the degradation of photosynthetic protein complexes during drought. Plant Cell Physiol. 51, 1929-1941. doi: 10.1093/pcp/pcq143

Rivero, R. M., Kojima, M., Gepstein, A., Sakakibara, H., Mittler, R., Gepstein, S., et al. (2007). Delayed leaf senescence induces extreme drought tolerance in a flowering plant. Proc. Natl. Acad. Sci. U.S.A. 104, 19631-19636. doi: 10.1073/pnas.0709453104

Rivero, R. M., Shulaev, V., and Blumwald, E. (2009). Cytokinin-dependent photorespiration and the protection of photosynthesis during water deficit. Plant Physiol. 150, 1530-1540. doi: 10.1104/pp.109.139378

Riyazuddin, R., Verma, R., Singh, K., Nisha, N., Keisham, M., Bhati, K. K., et al. (2020). Ethylene: a master regulator of salinity stress tolerance in plants. Biomol. 10:959. doi: 10.3390/biom10060959

Rodriguez-Gamir, J., Ancillo, G., Gonzalez-Mas, M. C., Primo-Millo, E., Iglesias, D. J., and Forner-Giner, M. A. (2011). Root signalling and modulation of stomatal closure in flooded citrus seedlings. Plant Physiol. Biochem. 49, 636-645. doi: 10.1016/j.plaphy.2011.03.003

Rodriguez-Saona, C., Crafts-Brandner, S. J., Paré, P. W., and Henneberry, T. J. (2001). Exogenous methyl jasmonate induces volate emissions in cotton plants. J. Chem. Ecol. 27, 679-695. doi: 10.1023/A:1010393700918

Ronzhina, E. S., and Mokronosov, A. T. (1994). Source-sink relations and the role of cytokinins in the regulation of transport and partitioning of organicsubstances in plants. Russ. J. Plant Physiol. 41, 396-406.

Sah, S. K., Reddy, K. R., and Li, J. (2016). Abscisic acid and abiotic stress tolerance in crop plants. Front. Plant Sci. 7:571. doi: 10.3389/fpls.2016.00571

Sairam, R. K. (1994). Effects of homobrassinolide application on plant metabolism and grain yield under irrigated and moisture-stress conditions of two wheat varieties. Plant Growth Regul. 14, 173-181. doi: 10.1007/BF00025220

Sakakibara, H., Takei, K., and Hirose, N. (2006). Interactions between nitrogen and cytokinin in the regulation of metabolism and development. Trends Plant Sci. 11, 440-448. doi: 10.1016/j.tplants.2006.07.004 
Salazar, C., Hernández, C., and Teresa, P. M. (2015). Plant water stress: associations between ethylene and abscisic acid response. Chil. J. Agric. Res. 75, 71-79. doi: 10.4067/S0718-58392015000300008

Sami, F., Faizan, M., Faraz, A., Siddiqui, H., Yusuf, M., and Hayat, S. (2018). Nitric oxide-mediated integrative alterations in plant metabolism to confer abiotic stress tolerance, NO crosstalk with phytohormones and NO-mediated post translational modifications in modulating diverse plant stress. Nitric Oxide 73, 22-38. doi: 10.1016/j.niox.2017.12.005

Sasidharan, R., Hartman, S., Liu, Z., Martopawiro, S., Sajeev, N., Van Veen, H., et al. (2018). Signal dynamics and interactions during flooding stress. Plant Physiol. 176, 1106-1117. doi: 10.1104/pp.17.01232

Sasse, J. (1999). "Physiological actions of brassinosteroids," in Brassinosteroids Steroidal Plant Hormones, eds A. Sakurai, T. Yokota, and S. D. Clouse (Tokyo: Springer-Verlag), 137-161.

Sauter, M. (2013). Root responses to flooding. Curr. Opin. Plant. Biol. 16, 282-286. doi: 10.1016/j.pbi.2013.03.013

Sawada, H., Shim, I. S., and Usui, K. (2006). Induction of benzoic acid 2-hydroxylase and salicylic acid biosynthesis-modulation by salt stress in rice seedlings. Plant Sci. 171, 263-270. doi: 10.1016/j.plantsci.2006. 03.020

Schachtman, D. P., and Goodger, J. Q. D. (2008). Chemical root to shoot signaling under drought. Trends Plant Sci. 13, 281-287. doi: 10.1016/j.tplants.2008.04.003

Schaller, G. E., Bishopp, A., and Kieber, J. J. (2015). The Yin-Yang of hormones: cytokinin and auxin interactions in plant development. Plant Cell 27, 44-63. doi: $10.1105 /$ tpc.114.133595

Seki, M., Ishida, J., Narusaka, M., Fujita, M., Nanjo, T., Umezawa, T., et al. (2002). Monitoring the expression pattern of around 7,000 Arabidopsis genes under ABA treatments using a full-length cDNA microarray. Funct. Integr. Genom. 2, 282-291. doi: 10.1007/s10142-002-0070-6

Seltmann, M. A., Stingl, N. E., Lautenschlaeger, J. K., Krischke, M., Mueller, M. J., and Berger, S. (2010). Differential impact of lipoxygenase and jasmonates on natural and stress-induced senescence in Arabidopsis. Plant Physiol. 152, 1940-1950. doi: 10.1104/pp.110.153114

Sereflioglu, S., Dinler, B. S., and Tasci, E. (2017). Alpha-tocopherol-dependent salt tolerance is more related with auxin synthesis rather than enhancement antioxidant defense in soybean roots. Acta Biol. Hungarica 68, 115-125. doi: 10.1556/018.68.2017.1.10

Seto, Y., Yasui, R., Kameoka, H., Tamiru, M., Cao, M., Terauchi, R., et al. (2019). Strigolactone perception and deactivation by a hydrolase receptor DWARF14. Nat. Commun. 10, 1-10. doi: 10.1038/s41467-018-08124-7

Shabbir, R., Javed, T., Afzal, I., Sabagh, A. E., Ali, A., Vicente, O., et al. (2021). Modern biotechnologies: innovative and sustainable approaches for the improvement of sugarcane tolerance to environmental stresses. Agronomy 11:1042. doi: 10.3390/agronomy11061042

Shahid, M. A., Pervez, M. A., Balal, R. M., Mattson, N. S., Rashid, A., Ahmad, R., et al. (2011). Brassinosteroid (24-epibrassinolide) enhances growth and alleviates the deleterious effects induced by salt stress in pea (Pisum sativum L.). Austral. J. Crop Sci. 5, 500-510.

Shakirova, F. M., Sakhabutdinova A. R., Bezrukova M. V., Fatkhutdinova R. A., and Fatkhutdinova D. R. (2003). Changes in the hormonal status of wheat seedlings induced by salicylic acid and salinity. Plant Sci. 164 317-322. doi: 10.1016/S0168-9452(02)00415-6

Shani, E., Weinstain, R., and Zhanga, Y. (2013). Gibberellins accumulate in the elongating endodermal cells of Arabidopsis root. Proc. Natl. Acad. Sci. U.S.A. 110, 4834-4839. doi: 10.1073/pnas.1300436110

Sharipova, G. V., Veselov, D. S., Kudoyarova, G. R., Timergalin, M. D., and Wilkinson, S. (2012). Effect of ethylene perception inhibitor on growth, water relations, and abscisic acid content in wheat plants under water deficit. Russ. J. Plant Physiol. 59, 573-580. doi: 10.1134/S1021443712040127

Sharma, L., Priya, M., Kaushal, N., Bhandhari, K., Chaudhary, S., Dhankher, O. P., et al. (2020). Plant growth-regulating molecules as thermoprotectants: functional relevance and prospects for improving heat tolerance in food crops. J. Exp. Bot. 71, 569-594. doi: 10.1093/jxb/erz333

Sharma, N., Abrams, S. R., and Waterer, D. R. (2005). Uptake, movement, activity, and persistence of an abscisic acid analog ( 80 acetylene ABA methyl ester) in marigold and tomato. J. Plant Growth Regul. 24, 28-35. doi: $10.1007 / \mathrm{s} 00344-004-0438-\mathrm{Z}$
Shen, C., Bai, Y., Wang, S., Zhang, S., Wu, Y., Chen, M., et al. (2010). Expression profile of PIN, AUX/LAX and PGP auxin transporter gene families in Sorghum bicolor under phytohormone and abiotic stress. FEBS J. 277, 2954-2969. doi: 10.1111/j.1742-4658.2010.07706.x

Shibata, M., and Sugimoto, K. (2019). A gene regulatory network for root hair development. J. Plant Res. 132, 301-309. doi: 10.1007/s10265-019-01100-2

Shibli, R. A., Kushad, M., Yousef, G. G., and Lila, M. A. (2007). Physiological and biochemical responses of tomato microshoots to induced salinity stress with associated ethylene accumulation. Plant Growth Regul. 51, 159-169. doi: 10.1007/s10725-006-9158-7

Shinozaki, K., and Yamaguchi-Shinozaki, K. (2007). Gene networks involved in drought stress response and tolerance. J. Exp. Bot. 58, 221-227. doi: 10.1093/jxb/erl164

Shiono, K., Ogawa, S., Yamazaki, S., Isoda, H., Fujimura, T., Nakazono, M., et al. (2011). Contrasting dynamics of radial $\mathrm{O}_{2}$-loss barrier induction and aerenchyma formation in rice roots of two lengths. Ann. Bot. 107, 89-99. doi: $10.1093 / \mathrm{aob} / \mathrm{mcq} 221$

Siddiqui, M. H., Al-Whaibi, M. H., and Basalah, M. O. (2011). Role of nitric oxide in tolerance of plants to abiotic stress. Protoplas. 248, 447-455. doi: 10.1007/s00709-010-0206-9

Siddiqui, M. H., Muhammad, A. I., Wajid, N., Imtiaz, H., and Abdul, K. (2019). Bio-economic viability of rainfed wheat (Triticum aestivum L.) cultivars under integrated fertilization regimes in Pakistan. Custos e Agronegocio 15, 81-96.

Singh, A. P., Dixit, G., Mishra, S., Dwivedi, S., Tiwari, M., Mallick, S., et al. (2015). Salicylic acid modulates arsenic toxicity by reducing its root to shoot translocation in rice (Oryza sativa L.). Front. Plant Sci. 6:340. doi: $10.3389 /$ fpls. 2015.00340

Skirycz, A., Claeys, H., Debod, S., Oikawa, A., Shinoda, S., Andriankaja, M., et al. (2011). Pause-and-stop: the effects of osmotic stress on cell proliferation during early leaf development in Arabidopsis and a role for ethylene signaling in cell cycle arrest. Plant Cell 23, 1876-1888. doi: 10.1105/tpc.111.084160

Skirycz, A., De Bodt, S., Obata, T., De Clercq, I., Claeys, H., De Rycke, R., et al. (2010). Developmental stage specificity and the role of mitochondrial metabolism in the response of Arabidopsis leaves to prolonged mild osmotic stress. Plant Physiol. 152, 226-244. doi: 10.1104/pp.109.148965

Soares, A. M., Souza, T. F., Jacinto, T., and Machado, O. L. T. (2010). Effect of methyl jasmonate on antioxidative enzyme activities and on the contents of ROS and $\mathrm{H}_{2} \mathrm{O}_{2}$ in Ricinus communis leaves. Braz. J. Plant Physiol. 22, 151-158. doi: 10.1590/S1677-04202010000300001

Sobeih, W. Y., Dodd, I. C., Bacon, M. A., Grierson, D., and Davies, W. J. (2004). Long-distance signals regulating stomatal conductance and leaf growth in tomato (Lycopersicon esculentum) plants subjected to partial root zone drying. J. Exp. Bot. 55, 2353-2363. doi: 10.1093/jxb/erh204

Spollen, W. G., LeNoble, M. E., Samuel, T., Bernstein, N., and Sharp, R. E. (2000). Abscisic acid accumulation maintains maize primary root elongation at low water potentials by restricting ethylene production. Plant Physiol. 122, 967-976. doi: $10.1104 / p p .122 .3 .967$

Sripinyowanich, S., Klomsakul, P., Boonburapong, B., Bangyeekhun, T., Asami, T., Gu, H., et al. (2013). Exogenous ABA induces salt tolerance in indica rice (Oryza sativa L.): the role of OsP5CS1 and OsP5CR gene expression during salt stress. Environ. Exp. Bot. 86, 94-105. doi: 10.1016/j.envexpbot.2010.01.009

Steffens, B., Geske, T., and Sauter, M. (2011). Aerenchyma formation in the rice stem and its promotion by $\mathrm{H}_{2} \mathrm{O}_{2}$. New Phytol. 190, 369-378. doi: 10.1111/j.1469-8137.2010.03496.x

Steffens, B., Kovalev, A., Gorb, S. N., and Sauter, M. (2012). Emerging roots alter epidermal cell fate through mechanical and reactive oxygen species signaling. Plant Cell 24, 3296-3306. doi: 10.1105/tpc.112.101790

Steffens, B., Wang, J., and Sauter, M. (2006). Interactions between ethylene, gibberellin and abscisic acid regulate emergence and growth rate of adventitious roots in deep water rice. Planta 223, 604-612. doi: 10.1007/s00425-005-0111-1

Sun, X., Qiu, Y., Peng, Y., Ning, J., Song, G., Yang, Y., et al. (2020). Close temporal relationship between oscillating cytosolic $\mathrm{K}+$ and growth in root hairs of Arabidopsis. Int. J. Mol. Sci. 21:6184. doi: 10.3390/ijms21176184

Sun, X., Zhao, T., Gan, S., Ren, X., Fang, L., Karungo, S. K., et al. (2016). Ethylene positively regulates cold tolerance in grapevine by modulating the expression of ethylene response factor 057. Sci. Rep. 6, 1-14. doi: 10.1038/srep24066

Sun, X., Zhu, Z., Zhang, L., Fang, L., Zhang, J., Wang, Q., et al. (2019). Overexpression of ethylene response factors VaERF080 and VaERF087 from 
Vitis amurensis enhances cold tolerance in Arabidopsis. Sci. Hortic. 243, 320-326. doi: 10.1016/j.scienta.2018.08.055

Sustr, M., Soukup, A., and Tylova, E. (2019). Potassium in root growth and development. Plants 8:435. doi: 10.3390/plants8100435

Suzuki, N. (2016). Hormone signaling pathways under stress combinations. Plant Signal. Behav. 11:e1247139. doi: 10.1080/15592324.2016.1247139

Synkova, H., Semoradova, S., Schnablova, R., Witters, E., Husak, M., and Valcke, R. (2006). Cytokinin-induced activity of antioxidant enzymes in transgenic Pssuipt tobacco during plant ontogeny. Biol. Planta 50, 31-41. doi: 10.1007/s10535-005-0071-0

Takahashi, F., Hanada, K., Kondo, T., and Shinozaki, K. (2019). Hormone-like peptides and small coding genes in plant stress signaling and development. Curr. Opin. Plant Biol. 51, 88-95. doi: 10.1016/j.pbi.2019.05.011

Takahashi, H., Yamauchi, T., Colmer, T., and Nakazono, M. (2014). Low-Oxygen Stress in Plants. In: Arenchyma formation in plants, eds J. T. Van Dongen and F. Licausi (Vienna: Springer), 21, 247-265.

Tal, L., Gil, M. X A., Guercio, A. M., and Shabek, N. (2020). Structural aspects of plant hormone signal perception and regulation by ubiquitin ligases. Plant Physiol. 182, 1537-1544. doi: 10.1104/pp.19.01282

Tan, Z. Y., and Thimann, K. V. (1989). The roles of carbon dioxide and abscisic acid in the production of ethylene. Physiol. Planta 75, 13-19. doi: 10.1111/j.1399-3054.1989.tb02056.x

Tang, W., Kim, T. W., Oses-Prieto, J. A., Sun, Y., Deng, Z., Zhu, S., et al. (2008). BSKs mediate signal transduction from the receptor kinase BRI1 in Arabidopsis. Science 321, 557-560. doi: 10.1126/science.1156973

Taniguchi, Y. Y., Taniguchi, M., Tsuge, T., Oka, A., and Aoyama, T. (2010). Involvement of Arabidopsis thaliana phospholipase Dzeta2 in root hydrotropism through the suppression of root gravitropism. Planta 231, 491-497. doi: 10.1007/s00425-009-1052-x

Tanimoto, E. (2012). Tall or short? Slender or thick? A plant strategy for regulating elongation growth of roots by low concentrations of gibberellin. Ann. Bot. 110, 373-381. doi: 10.1093/aob/mcs049

Teale, W. D., Paponov, I. A., and Palme, K. (2006). Auxin in action: signalling, transport and the control of plant growth and development. Nat. Rev. Mol. Cell Biol. 7, 847-859. doi: 10.1038/nrm2020

Terrile, M. C., París, R., Calderón-Villalobos, L. I. A., Iglesias, M. J., Lamattina, L., Estelle, M., et al. (2012). Nitric oxide influences auxin signaling through S-nitrosylation of the Arabidopsis TRANSPORT INHIBITOR RESPONSE 1 auxin receptor. Plant J. 70, 492-500. doi: 10.1111/j.1365-313X.2011.04885.x

Tognetti, V. B., Bielach, A., and Hrtyan, M. (2017). Redox regulation at the site of primary growth: auxin, cytokinin and ROS crosstalk. Plant Cell Environ. 40, 2586-2605. doi: 10.1111/pce.13021

Turner, N. C., Wright, G. C., and Siddique, K. H. M. (2001). Adaptation of grain legumes (pulses) to water-limited environments. Adv. Agron. 71, 123-231. doi: 10.1016/S0065-2113(01)71015-2

Tuteja, N., and Sopory, S. K. (2008). Chemical signaling under abiotic stress environment in plants. Plant Signal. Behav. 3, 525-536. doi: $10.4161 /$ psb.3.8.6186

Urquhart, S., Foo, E., and Reid, J. B. (2015). The role of strigolactones in photomorphogenesis of pea is limited to adventitious rooting. Physiol Plant. 153, 392-402. doi: 10.1111/ppl.12246

Van Der Straeten, D., Zhou, Z., Prinsen, E., Van Onckelen, H. A., and Van Montagu, M. C. (2001). A comparative molecular-physiological study of submergence response in lowland and deep water rice. Plant Physiol. 125, 955-968. doi: 10.1104/pp.125.2.955

Van Veen, H., Mustroph, A., Barding, G. A., Vergeer-Van, Eijk, M., WelschenEvertman, R. A. M., Pedersen, O., et al. (2013). Two Rumex species from contrasting hydrological niches regulate flooding tolerance through distinct mechanisms. Plant Cell 25, 4691-4707. doi: 10.1105/tpc.113. 119016

Vanneste, S., and Friml, J. (2009). Auxin: a trigger for change in plant development. Cell 136, 1005-1016. doi: 10.1016/j.cell.2009.03.001

Vega, A., O’Brien, J. A., and Gutiérrez, R. A. (2019). Nitrate and hormonal signaling crosstalk for plant growth and development. Curr. Opin. Plant Biol. 52, 155-163. doi: 10.1016/j.pbi.2019.10.001

Verma, V., Ravindran, P., and Kumar, P. P. (2016). Plant hormonemediated regulation of stress responses. BMC Plant Biol. 16, 1-10. doi: 10.1186/s12870-016-0771-y
Vicente-Agullo, F., Rigas, S., Desbrosses, G., Dolan, L., Hatzopoulos, P., and Grabov, A. (2004). Potassium carrier TRH1 is required for auxin transport in Arabidopsis roots. Plant J. 40, 523-535. doi: 10.1111/j.1365-313X.2004.02230.X

Vidoz, M. L., Loreti, E., Mensuali, A., Alpi, A., and Perata, P. (2010). Hormonal interplay during adventitious root formation in flooded tomato plants. Plant J. 63, 551-562. doi: 10.1111/j.1365-313X.2010.04262.x

Vishal, B., and Kumar, P. P. (2018). Regulation of seed germination and abiotic stresses by gibberellins and abscisic acid. Front. Plant Sci. 9:838. doi: 10.3389/fpls.2018.00838

Vishwakarma, K., Upadhyay, N., Kumar, N., Yadav, G., Singh, J., Mishra, R. K., et al. (2017). Abscisic acid signaling and abiotic stress tolerance in plants: a review on current knowledge and future prospects. Front. Plant Sci. 8:161. doi: 10.3389/fpls.2017.00161

Visser, E. J. W., and Voesenek, L. A. C. J. (2004). Acclimation to soil flooding - sensing and signal-transduction. Plant Soil 254, 197-214. doi: 10.1007/1-4020-4099-7_10

Voesenek, L. A. C. J., and Bailey-Serres, J. (2015). Flood adaptive traits and processes: an overview. New Phytol. 206, 57-73. doi: 10.1111/nph.13209

Voesenek, L. A. C. J., Colmer, T. D., Pierik, R., Millenaar, F. F., and Peeters, J. M. (2006). How plants cope with complete submergence? New Phytol. 170, 213-226. doi: 10.1111/j.1469-8137.2006.01692.x

Voesenek, L. A. C. J., and Sasidharan, R. (2013). Ethylene-and oxygen signalling-drive plant survival during flooding. Plant Biol. 15, 426-435. doi: $10.1111 /$ plb.12014

Vojta, P., Kokáš, F., Husičková, A., Grúz, J., Bergougnoux, V., Marchetti, C. F., et al. (2016). Whole transcriptome analysis of transgenic barley with altered cytokinin homeostasis and increased tolerance to drought stress. New Biotechnol. 33, 676-691. doi: 10.1016/j.nbt.2016.01.010

Walch-Liu, P., Neumann, G., Bangerth, F., and Engels, C. (2000). Rapid effects of nitrogen form on leaf morphogenesis in tobacco. J. Exp. Bot. 51, 227-237. doi: 10.1093/jexbot/51.343.227

Wang, C., Yang, A., Yin, H., and Zhang, J. (2008). Influence of water stress on endogenous hormone contents and cell damage of maize seedlings. J. Integr. Plant Biol. 50, 427-434. doi: 10.1111/j.1774-7909.2008.00638.x

Wang, C. Y., and Buta, J. G. (1994). Methyl jasmonate reduces chilling injury in Cucurbita pepo through its regulation of abscisic acid and polyamine levels. Environ. Exp. Bot. 34, 427-432. doi: 10.1016/0098-8472(94)90025-6

Wang, H., Tang, J., Liu, J., Hu, J., Liu, J., Chen, Y., et al. (2017). Abscisic acid signaling inhibits brassinosteroid signaling through dampening the dephosphorylation of BIN2 by ABI1 and ABI2. Mol. Plant 11, 315-325. doi: 10.1016/j.molp.2017.12.013

Wang, K., Jin, P., Cao, S., Shang, H., Yang, Z., and Zheng, Y. (2009). Methyl jasmonate reduces decay and enhances antioxidant capacity in Chinese bayberries. J. Agric. Food Chem. 57, 5809-5815. doi: 10.1021/jf900914a

Wang, W., Paschalidis, K., Feng, J. C., Song, J., and Liu, J. H. (2019). Polyamine catabolism in plants: a universal process with diverse functions. Front. Plant Sci. 10:561. doi: 10.3389/fpls.2019.00561

Wang, W., Withers, J., Li, H., Zwack, P. J., Rusnac, D. V., Shi, H., et al. (2020). Structural basis of salicylic acid perception by Arabidopsis NPR proteins. Nature 586, 311-316. doi: 10.1038/s41586-020-2596-y

Wang, X., and Chory, J. (2006). Brassinosteroids regulate dissociation of of BKI1, a negative regulator of BRI1 signaling, from the plasma membrane. Science 313, 1118-1122. doi: 10.1126/science. 1127593

Wang, X., Li, X., Meisenhelder, J., Hunter, T., Yoshida, S., Asami, T., et al. (2005). Autoregulation and homodimerization are involved in the activation of the plant steroid receptor BRI1. Dev. Cell 8, 855-865. doi: 10.1016/j.devcel.2005.05.001

Wang, X., Ruan, M., Wan, Q., He, W., Yang, L., Liu, X., et al. (2020). Nitric oxide and hydrogen peroxide increase glucose-6-phosphate dehydrogenase activities and expression upon drought stress in soybean roots. Plant Cell Rep. 39, 63-73. doi: 10.1007/s00299-019-02473-3

Wang, Y., Li, K., and Li, X. (2009). Auxin redistribution modulates plastic development of root system architecture under salt stress in Arabidopsis thaliana. J. Plant Physiol. 166, 1637-1645. doi: 10.1016/j.jplph.2009.04.009

Wang, Y., Yuan, M., Li, Z., Niu, Y., Jin, Q., Zhu, B., et al. (2020). Effects of ethylene biosynthesis and signaling on oxidative stress and antioxidant defense system in Nelumbo nucifera G. under cadmium exposure. Environ. Sci. Pollut. Res. 1-15. doi: $10.1007 / \mathrm{s} 11356-020-09918-3$ 
Wang, Z., Huang, B., and Xu, V. Q. (2003). Effects of abscisic acid on drought responses of kentucky bluegrass. J. Amer. Soc. Hort. Sci. 128, 36-41. doi: 10.21273/JASHS.128.1.0036

Wang, Z., Xiong, Y., and Wang, M. (2000). Study on Expert System of Irrigation Forecast and Decision Making for Water Saving. Yangling: Institute of Agricultural Soil Water Engineering of North West Science and Technology University of Agriculture Forestry.

Wang, Z. Y., Nakano, T., Gendron, J., He, J., Chen, M., Vafeados, D., et al. (2002). Nuclear-localized BZR1 mediates brassinosteroid-induced growth and feedback suppression of brassinosteroid biosynthesis. Dev. Cell 2, 505-513. doi: 10.1016/S1534-5807(02)00153-3

Wani, S. H., and Kumar, V. (2015). Plantstresstolerance: engineering ABA: a Potentphytohormone. Transcriptomics 3:1000113.

Wasternack, C., Goetz, S., Hellwege, A., Forner, S., Strnad, M., and Hause, B. (2012). Another JA/COI1-independent role of OPDA detected in tomato embryo development. Plant Signal. Behav. 7, 1349-1353. doi: $10.4161 /$ psb.21551

Waters, M. T., Gutjahr, C., Bennett, T., and Nelson, D. C. (2017). Strigolactone signaling and evolution. Annu. Rev. Plant Biol. 68, 291-322. doi: 10.1146/annurev-arplant-042916-040925

Werner, T., Holst, K., Pörs, Y., Guivarc'h, A., Mustroph, A., Chriqui, D., et al. (2008). Cytokinin deficiency causes distinct changes of sink and source parameters in tobacco shoots and roots. J. Exp. Bot. 59, 2659-2672. doi: $10.1093 /$ jxb/ern134

White, R. G., and Kirkegaard, J. A. (2010). The distribution and abundance of wheat roots in a dense, structured subsoil-implications for water uptake. Plant Cell Environ. 33, 133-148. doi: 10.1111/j.1365-3040.2009.02059.x

Wilkinson, S., and Davies, W. J. (2009). Ozone suppresses soil drying- and abscisic acid (ABA)-induced stomatal closure via an ethylene-dependent mechanism. Plant Cell Environ. 32, 949-959. doi: 10.1111/j.1365-3040.2009.01970.x

Wilkinson, S., and Davies, W. J. (2010). Drought, ozone, ABA and ethylene: new insights from cell to plant to community. Plant Cell Environ. 33, 510-525. doi: 10.1111/j.1365-3040.2009.02052.x

Wilkinson, S., Kudoyarova, G. R., Veselov, D. S., Arkhipova, T. N., and Davies, W. J. (2012). Plant hormone interactions: innovative targets for crop breeding and management. J. Exp. Bot. 63, 3499-509. doi: 10.1093/jxb/ers148

Woo, Y. M., Park, H. J., Su'udi, M., Yang, J. I., Park, J. J., Back, K., et al. (2007). Constitutively wilted 1 , a member of the rice YUCCA gene family, is required for maintaining water homeostasis and an appropriate root to shoot ratio. Plant Mol. Biol. 65, 125-136. doi: 10.1007/s11103-007-9203-6

Wu, Y. S., and Yang, C. Y. (2019). Ethylene-mediated signaling confers thermo tolerance and regulates transcript levels of heat shock factors in rice seedlings under heat stress. Bot. Stud. 60, 1-12. doi: 10.1186/s40529-019-0272-z

Xie, X., Yoneyama, K., and Yoneyama, K. (2010). The strigolactone story. Annu. Rev. Phytopathol. 48, 93-117. doi: 10.1146/annurev-phyto-073009-114453

Xiong, L., and Zhu, J. K. (2002). Molecular and genetic aspects of plant responses to osmotic stress. Plant Cell Environ. 25, 131-139. doi: 10.1046/j.1365-3040.2002.00782.x

Xu, K., Xu, X., Fukao, T., Canlas, P., Maghirang-Rodriguez, R., Heuer, S., et al. (2006). Sub1A is an ethylene response-factor-like gene that confers submergence tolerance to rice. Nature 442, 705-708. doi: 10.1038/nature04920

Xu, M., Zhu, L., Shou, H., and Wu, P. (2005). A PIN1 family gene, OsPIN1, involved in auxin-dependent adventitious root emergence and tillering in rice. Plant Cell Physiol. 46, 1674-1681. doi: 10.1093/pcp/pci183

Xu, P., Zhao, P. X., Cai, X. T., Mao, J. L., Miao, Z. Q., and Xiang, C. B. (2020). Integration of jasmonic acid and ethylene into auxin signaling in root development. Front. Plant Sci. 11:271. doi: 10.3389/fpls.2020.00271

Xu, Q., Xu, X., Zhao, Y., Jiao. K., Herbert, J. S., and Hao, L. (2008). Salicylic acid, hydrogen peroxide and calcium-induced salinity tolerance associated with endogenous hydrogen peroxide homeostasis in naked oat seedlings. Plant Growth Regul. 54, 249-259. doi: 10.1007/s10725-007-9247-2

Xu, Q. T., Fan, H. Y., Jiang, Z., Zhou, Z. Q., Yang, L., Mei, F. Z., et al. (2013). Cell wall degradation and the dynamic changes of $\mathrm{Ca}^{2+}$ and related enzymes in the developing aerenchyma of wheat (Triticum aestivum L.) under waterlogging. Acta. Biol. Hung. 64, 328-340. doi: 10.1556/ABiol.64.2013.3.6

Xu, S., Brockmöller, T., Navarro-Quezada, A., Kuhl, H., Gase, K., Ling, Z., et al. (2017). Wild tobacco genomes reveal the evolution of nicotine biosynthesis. Proc. Natl. Acad. Sci. U.S.A. 114, 6133-6138. doi: 10.1073/pnas.1700073114
Xu, W., Jia, L., Shi, W., Liang, J., Zhou, F., Li, Q., et al. (2013). Abscisic acid accumulation modulates auxin transport in the root tip to enhance proton secretion for maintaining root growth under moderate water stress. New Phytol. 197, 139-150. doi: 10.1111/nph.12004

Xuan, L., Li, J., Wang, X., and Wang, C. (2020). Crosstalk between hydrogen sulfide and other signal molecules regulates plant growth and development. Int. J. Mol. Sci. 21:4593. doi: 10.3390/ijms21134593

Xue-Xuan, X., Hong-Bo, S., Yuan-Yuan, M., Gang, X., Jun-Na, S., Dong-Gang, G., et al. (2010). Biotechnological implications from abscisic acid (ABA) roles in cold stress and leaf senescence as an important signal for improving plant sustainable survival under abiotic-stressed conditions. Crit. Rev. Biotechnol. 30, 222-230. doi: 10.3109/07388551.2010.487186

Yamaguchi-Shinozaki, K., and Shinozaki, K. (2006). Transcriptional regulatory networks in cellular responses and tolerance to dehydration and cold stresses. Annu. Rev. Plant Biol. 57, 781-803. doi: 10.1146/annurev.arplant.57.032905.105444

Yamauchi, T., Tanaka, A., Inahashi, H., Nishizawa, N. K., Tsutsumi, N., Inukai, Y., et al. (2019). Fine control of aerenchyma and lateral root development through AUX/IAA-and ARF-dependent auxin signaling. Proc. Nat. Acad. Sci. U.S.A. 116, 20770-20775. doi: 10.1073/pnas.1907181116

Yamauchi, T., Watanabe, K., Fukazawa, A., Mori, H., Abe, F., Kawaguchi, K., et al. (2014). Ethylene and reactive oxygen species are involved in root aerenchyma formation and adaptation of wheat seedlings to oxygen-deficient conditions. J. Exp. Bot. 65, 261-273. doi: 10.1093/jxb/ert371

Yang, C., Liu, J., Dong, X., Cai, Z., Tian, W., and Wang, X. (2014). Short-term and continuing stresses differentially interplay with multiple hormones to regulate plant survival and growth. Mol. Plant 7, 841-855. doi: 10.1093/mp/ssu013

Yang, C. J., Zhang, C., Lu, Y. N., Jin, J. Q., and Wang, X. L. (2011). The mechanisms of brassinosteroids action: from signal transduction to plant development. Mol. Plant 4, 588-600. doi: 10.1093/mp/ssr020

Yang, J., Zhang, J., Wang, Z., Liu, K., and Wang, P. (2006). Abscisic acid and ethylene interact in wheat grains in response to soil-drying during grain filling. New Phytol. 171, 293-303. doi: 10.1111/j.1469-8137.2006. 01753.x

Yang, J. C., Zhang, J. H., Wag, Z. Q., Zhu, Q. S., and Liu, L. J. (2003). Involvement of abscisic acid and cytokinins in the senescence and remobilization of carbon reserves in wheat subjected to water stress during grain filling. Plant Cell Environ. 26, 1621-1631. doi: 10.1046/j.1365-3040.2003.01081.x

Yang, Q., Chen, Z. Z., Zhou, X. F., Yin, H. B., Li, X., Xin, X. F., et al. (2008). Overexpression of SOS (salt overly sensitive) genes increases salt tolerance in transgenic Arabidopsis. Mol. Plant 2, 22-31. doi: 10.1093/mp/ $\operatorname{ssn} 058$

Ye, Q., Zhu, W., Li, L., Zhang, S., Yin, Y., Ma, H., et al. (2010). Brassinosteroids control male fertility by regulating the expression of key genes involved in Arabidopsis anther and pollen development. Proc. Natl. Acad. Sci. U.S.A. 107, 6100-6105. doi: 10.1073/pnas.0912333107

Yin, W., Dong, N., Niu, M., Zhang, X., Li, L., Liu, J., et al. (2019). Brassinosteroidregulated plant growth and development and gene expression in soybean. Crop J. 7, 411-418. doi: 10.1016/j.cj.2018.10.003

Yin, Y., Wang, Z. Y., Mora-Garcia, S., Li, J., Yoshida, S., Asami, T., et al. (2002). BES1 accumulates in the nucleus in response to brassinosteroids to regulate gene expression and promote stem elongation. Cell 109, 181-191. doi: 10.1016/S0092-8674(02)00721-3

Yu, F., Liang, K., Fang, T., Zhao, H., Han, X., Cai, M., et al. (2019). A group VII ethylene response factor gene, ZmEREB180, coordinates waterlogging tolerance in maize seedlings. Plant Biotechnol. J. 17, 2286-2298. doi: $10.1111 /$ pbi.13140

Yu, W., Sheng, J., Zhao, R., Wang, Q., Ma, P., and Shen, L. (2019). Ethylene biosynthesis is involved in regulating chilling tolerance and SICBF1 gene expression in tomato fruit. Postharvest Biol. Technol. 149, 139-147. doi: 10.1016/j.postharvbio.2018.11.012

Yuan, G.-F., Jia, C.-G., Li, Z., Sun, B., Zhang, L.-P., Liu, N., et al. (2010). Efect of brassinosteroids on drought resistance and abscisic acid concentration in tomato under water stress. Sci. Hortic. 126, 103-108. doi: 10.1016/j.scienta.2010.06.014

Yuan, H. M., Xu, H. H., Liu, W. C., and Ying-Tang, L. (2013). Copper regulates primary root elongation through PIN1-mediated auxin redistribution. Plant Cell Physiol. 54, 766-778. doi: 10.1093/pcp/pct030 
Yuan, L., Yuan, Y., Du, J., Sun, J., and Guo, S. (2012). Efects of 24-epibrassinolide on nitrogen metabolism in cucumber seedlings under $\mathrm{Ca}\left(\mathrm{NO}_{3}\right)_{2}$ stress. Plant Physiol. Biochem. 61, 29-35. doi: 10.1016/j.plaphy.2012.09.004

Yue, J., You, Y., Zhang, L., Fu, Z., Wang, J., Zhang, J., et al. (2018). Exogenous 24epibrassinolide alleviates efects of salt stress on chloroplasts and photosynthesis in Robinia pseudoacacia L. seedlings. J. Plant Growth Regul. 38, 669-682. doi: 10.1007/s00344-018-9881-0

Yukiyoshi, K., and Karahara, I. (2014). Role of ethylene signalling in the formation of constitutive aerenchyma in primary roots of rice. AoB Plants 6:plu043. doi: 10.1093/aobpla/plu043

Zavaleta-Mancera, H. A., López-Delgado, H., Loza-Tavera, H., Mora, H. M., Trevilla-García, C., Vargas-Suárez, M., et al. (2007). Cytokinin promotes catalase and ascorbate peroxidase activities and preserves the chloroplast integrity during dark-senescence. J. Plant Physiol. 164, 1572-1582. doi: 10.1016/j.jplph.2007.02.003

Zawaski, C., and Busov, V. B. (2014). Roles of gibberellin catabolism and signaling in growth and physiological response to drought and short-day photoperiods in Populus trees. PLoS ONE 9:e86217. doi: 10.1371/journal.pone.008 6217

Zentella, R., Zhang, Z. L., Park, M., Thomas, S. G., Endo, A., Murase, K., et al. (2007). Global analysis of della direct targets in early gibberellin signaling in Arabidopsis. Plant Cell 19, 3037-3057. doi: 10.1105/tpc.107.054999

Zhang, F. L., Niu, B., and Wang, Y. C. (2008). A novel betaine aldehyde dehydrogenase gene from Jatropha curcas, encoding an enzyme implicated in adaptation to environmental stress. Plant Sci. 174:510-8.

Zhang, H., Zhu, H., Pan, Y., Yu, Y., Luan, S., and Li, L. (2014). ADTX/MATEtype transporter facilitates abscisic acid efflux and modulates ABA sensitivity and drought tolerance in Arabidopsis. Mol. Plant 7, 1522-1532. doi: $10.1093 / \mathrm{mp} / \mathrm{ssu} 063$

Zhang, J., Jia, W., Yang, J., and Ismail, A. M. (2006). Role of ABA in integrating plant responses to drought and salt stresses. Field Crop Res. 97, 111-119. doi: 10.1016/j.fcr.2005.08.018

Zhang, Q., Li, J., Zhang, W., Yan, S., Wang, R., Zhao, J., et al. (2012). The putative auxin efflux carrier OsPIN3t is involved in the drought stress response and drought tolerance. Plant J. 72, 805-816. doi: 10.1111/j.1365-313X.2012.05121.x

Zhang, S., Cai, Z., and Wang, X. (2009a). The primary signaling outputs of brassinosteroids are regulated by abscisic acid signaling. Proc. Natl. Acad. Sci. U.S.A. 106, 4543-4548. doi: 10.1073/pnas.0900349106

Zhang, S., Tajima, H., Nambara, E., Blumwald, E., and Bassil, E. (2020). Auxin homeostasis and distribution of the auxin efflux carrier PIN2 Require vacuolar NHX-Type Cation/H+ antiporter activity. Plants 9:1311. doi: 10.3390/plants9101311

Zhang, S., Wei, Y., Lu, Y., and Wang, X. (2009b). Mechanisms of brassinosteroids interacting with multiple hormones. Plant Signal. Behav. 4, 1117-1120. doi: $10.4161 /$ psb.4.12.9903

Zhang, Y., and He, J. (2015). Sugar-induced plant growth is dependent on brassinosteroids. Plant Signal. Behav. 10:e1082700. doi: 10.1080/15592324.2015.1082700

Zhang, Y. S., Ye, H. C., Liu, B. Y., Wang, H., and Li, G. F. (2005). Exogenous $\mathrm{GA}_{3}$ an flowering induce the conversion of artemisinic acid to artemisinin in Artemisia annua plants. Russian J. Plant Physiol. 52, 68-73. doi: 10.1007/s11183-005-0009-6
Zhang, Z., Wu, P., Zhang, W., Yang, Z., Liu, H., Ahammed, G. J., et al. (2019). Calcium is involved in exogenous NO-induced enhancement of photosynthesis in cucumber (Cucumis sativus L.) seedlings under low temperature. Sci. Hortic. doi: 10.1016/j.scienta.2019.108953

Zhao, F. Y., Han, M. M., Zhang, S. Y., Wang, K., Zhang, C. R., Liu, T., et al. (2012). Hydrogen peroxide-mediated growth of the root system occurs via auxin signaling modification and variations in the expression of cell-cycle genes in rice seedlings exposed to cadmium stress. J. Integr. Plant Biol. 54, 991-1006. doi: 10.1111/j.1744-7909.2012.01170.x

Zhao, Y., Wu, L., Fu, Q., Wang, D., Li, J., Yao, B., et al. (2021). INDITTO2 transposon conveys auxin-mediated DRO1 transcription for rice drought avoidance. Plant Cell Environ. 44, 1846-1857. doi: 10.1111/pce.14029

Zhao, Y., Xing, L., Wang, X., Hou, Y. J., Gao, J., Wang, P., et al. (2014). The ABA receptor PYL8 promotes lateral root growth by enhancing MYB77-dependent transcription of auxin-responsive genes. Sci. Signal. 7:ra53. doi: $10.1126 /$ scisignal.2005051

Zhou, Y., and Underhill, S. J. (2017). Breadfruit (Artocarpus altilis) DELLA genes: gibberellin-regulated stem elongation and response to high salinity and drought. Plant Growth Regul. 83, 375-383. doi: 10.1007/s10725-017-0302-3

Zhu, J. K. (2002). Salt and drought stress signal transduction in plants. Annu. Rev. Plant. Biol. 53, 247-273. doi: 10.1146/annurev.arplant.53.091401.143329

Zolla, G., Heimer, Y. M., and Barak, S. (2010). Mild salinity stimulates a stressinduced morphogenic response in Arabidopsis thaliana roots. J. Exp. Bot. 61, 211-224. doi: 10.1093/jxb/erp290

Zorb, C., Senbayram, M., and Peiter, E. (2014). Potassium in agriculture-status and perspectives. J. Plant Physiol. 171, 656-669. doi: 10.1016/j.jplph.2013.08.008

Zwiewka, M., Bielach, A., Tamizhselvan, P., Madhavan, S., Ryad, E. E., Tan, S., et al. (2019). Root adaptation to H2O2-induced oxidative stress by ARF-GEF BEN1and cytoskeleton-mediated PIN2 trafficking. Plant Cell Physiol. 60, 255-273. doi: $10.1093 / \mathrm{pcp} / \mathrm{pcz} 001$

Conflict of Interest: The authors declare that the research was conducted in the absence of any commercial or financial relationships that could be construed as a potential conflict of interest.

Publisher's Note: All claims expressed in this article are solely those of the authors and do not necessarily represent those of their affiliated organizations, or those of the publisher, the editors and the reviewers. Any product that may be evaluated in this article, or claim that may be made by its manufacturer, is not guaranteed or endorsed by the publisher.

Copyright (C) 2021 Sabagh, Mbarki, Hossain, Iqbal, Islam, Raza, Llanes, Reginato, Rahman, Mahboob, Singhal, Kumari, Rajendran, Wasaya, Javed, Shabbir, Rahim, Barutçular, Habib Ur Rahman, Raza, Ratnasekera, Konuskan, Hossain, Meena, Ahmed, Ahmad, Mubeen, Singh, Skalicky, Brestic, Sytar, Karademir, Karademir, Erman and Farooq. This is an open-access article distributed under the terms of the Creative Commons Attribution License (CC BY). The use, distribution or reproduction in other forums is permitted, provided the original author(s) and the copyright owner(s) are credited and that the original publication in this journal is cited, in accordance with accepted academic practice. No use, distribution or reproduction is permitted which does not comply with these terms. 